\title{
Evaluation of Ultra Fine Cigarette Smoke Particles Penetration on 3M 6200 Half Mask Respirators with P-100 Filters
}

\author{
Selcuk Elhan \\ se0012@mix.wvu.edu
}

Follow this and additional works at: https://researchrepository.wvu.edu/etd

Part of the Other Engineering Commons

\section{Recommended Citation \\ Elhan, Selcuk, "Evaluation of Ultra Fine Cigarette Smoke Particles Penetration on 3M 6200 Half Mask Respirators with P-100 Filters" (2019). Graduate Theses, Dissertations, and Problem Reports. 4045. https://researchrepository.wvu.edu/etd/4045}

This Thesis is protected by copyright and/or related rights. It has been brought to you by the The Research Repository @ WVU with permission from the rights-holder(s). You are free to use this Thesis in any way that is permitted by the copyright and related rights legislation that applies to your use. For other uses you must obtain permission from the rights-holder(s) directly, unless additional rights are indicated by a Creative Commons license in the record and/ or on the work itself. This Thesis has been accepted for inclusion in WVU Graduate Theses, Dissertations, and Problem Reports collection by an authorized administrator of The Research Repository @ WVU. For more information, please contact researchrepository@mail.wvu.edu. 
2019

Evaluation of Ultra Fine Cigarette Smoke Particles Penetration on 3M 6200 Half Mask Respirators with P-100 Filters

Selcuk Elhan

Follow this and additional works at: https://researchrepository.wvu.edu/etd 


\title{
Evaluation of Ultra Fine Cigarette Smoke Particles Penetration on 3M 6200 Half Mask Respirators with P-100 Filters
}

\author{
Selcuk Elhan
}

Thesis submitted to the Statler College of Engineering and Mineral Resources at West Virginia University

in partial fulfillment of the requirements for the degree of

\author{
Master of Science \\ in \\ Safety Management \\ Xinjian He, Ph.D., Chair \\ Ziqing Zhuang, Ph.D. \\ Eun Gyung (Emily) Lee, Ph.D.
}

Department of Industrial and Management Systems Engineering Morgantown, WV

2019

Keywords: Ultrafine Particles, Particle Penetration, Half Mask Respirators, P-100 filters, P- Trak, Number of Cigarette Smoke Concentration.

Copyright 2019: Selcuk Elhan 


\section{Abstract \\ Evaluation of Ultra Fine Cigarette Smoke Particles Penetration on 3M 6200 Half Mask Respirators with P-100 Filters}

\section{Selcuk Elhan}

This study was aimed to investigate the effectiveness of half mask respirator with double P-100 filters by determining the penetration of cigarette smoke particles. In this study, faceseal leakage of a breathing manikin donned a 3M 6200 half mask elastomeric respirator with double P-100 filters was determined at various test conditions. A full factorial test conditions of 4 sealing conditions (Non-sealed, only nose sealed, nose and chin sealed, and fully sealed), 2 inspiratory breathing types (Constant, cyclic), 4 flowing rates $(15,30,50,85 \mathrm{~L} / \mathrm{min}$ for cyclic; 15, 30, 50, 80 $\mathrm{L} / \mathrm{min}$ for constant) were employed and each test condition was repeated three times. Ultra fine smoke particles were generated by burning a cigarette in an exposure chamber. For each test condition, particle number concentrations using a P-Trak condensation particle counter were measured, inside and outside of the elastomeric half mask respirator and penetration was calculated as a ratio of two concentrations $\left(\mathrm{P}=\mathrm{C}_{\mathrm{in}} / \mathrm{C}_{\text {out }}\right)$.

Our hypothesis claimed that variables of sealing type, breathing flow type, and flowing rate were all significant features which have an effect on penetration percentage of ultrafine cigarette smoke aerosol through 3M 6200 half mask respirator with P-100 filters. Non-sealed and partially sealed conditions showed that the penetration percentage $\left(\mathrm{P}=\mathrm{C}_{\mathrm{in}} / \mathrm{C}_{\text {out }}\right)$ of cigarette smoke was more than $0.03 \%$ (i.e., penetration $\geq 0.03 \%$, which is an acceptable criterion, and showed statistically significant result (p-value: $7.58 \mathrm{E}-20<\alpha$, which was assigned as 0.05 ). However, fully- 
sealed test results were measured the smoke penetration percentage equal or lower than $0.03 \%$ (penetration $\leq 0.03 \%$ ). Our findings showed that 3M 6200 half mask respirator with P-100 filters served proper protection against ultrafine cigarette smoke aerosol.

This report consists of 5 chapters. In Chapter 1, introduction part was described in detail, 3M 6200 half mask respirator and P-100 filters were explained. Chapter 2 starts with a brief literature review of similar researches. In Chapter 3, experimental set-up was demonstrated. In Chapter 4, the collected data were presented along with the statistical test results analyzed with ANOVA one-way analysis of variance in order to find out which variables are significant in this study. 


\section{Acknowledgements}

The author wishes to acknowledge Dr. Xinjian (Kevin) He, Dr. Gary Winn, Dr. Eun Gyung

(Emily) Lee, Dr. Ziqing Zhuang, and Tavus Kulyyeva for their help in creating and writing this thesis. 


\section{Table of Contents}

\section{Contents}

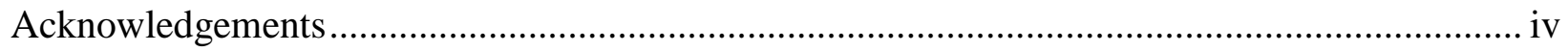

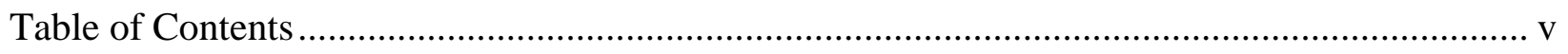

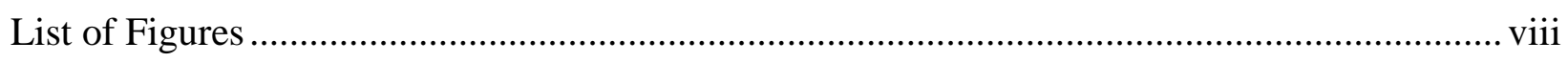

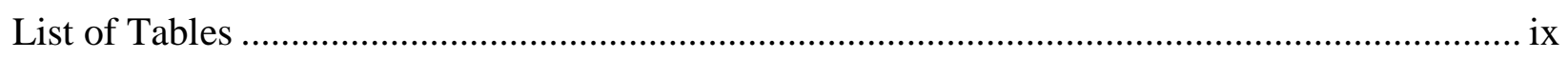

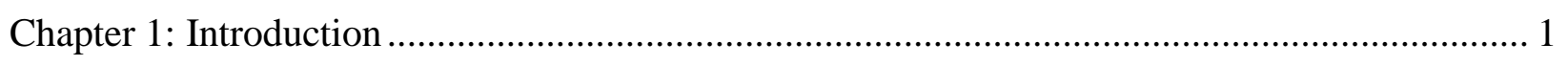

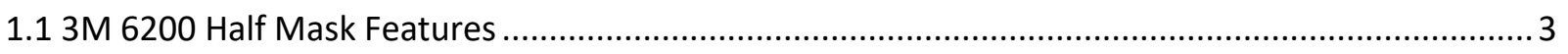

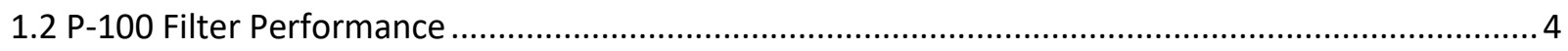

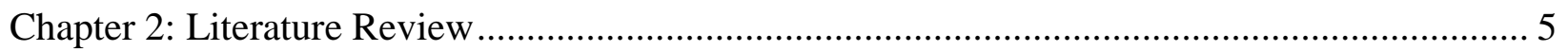

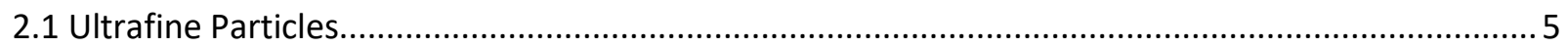

2.2 Ultrafine Particles in Cigarette Smoke ……………………………………………………....

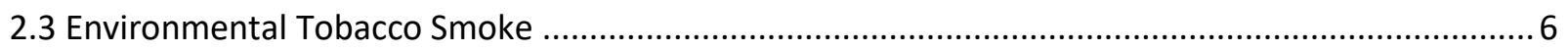

2.4 Health Effects of Ultrafine Smoke Particles .........................................................................

2.5 P-100 Filter Efficiency Against Nanoparticles ............................................................................

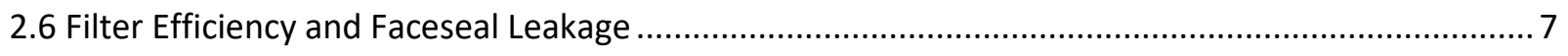

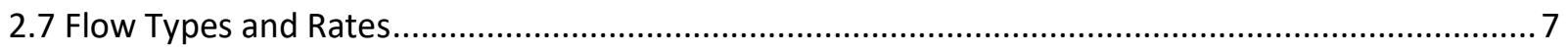

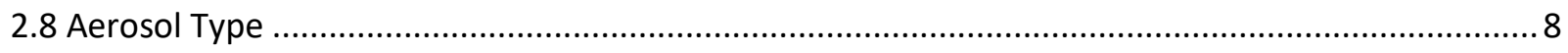

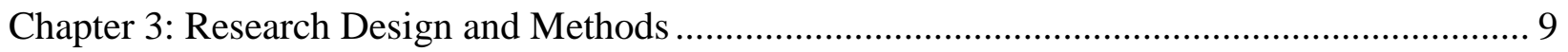

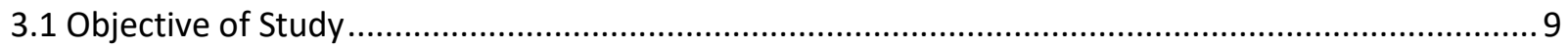

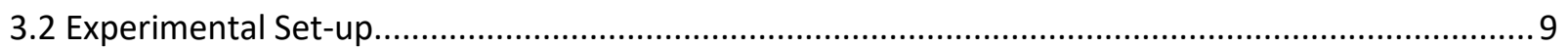

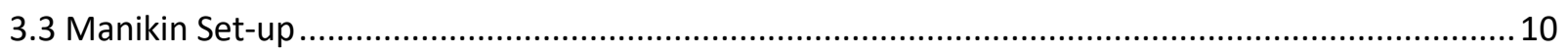

3.3.1 Non-Sealed Test Set-up.............................................................................................11

3.3.2 Only Nose Area Sealed Test Set-up..................................................................................11

3.3.3 Nose and Chin Areas Sealed Test Set-up ..............................................................................12

3.3.4 Fully-Sealed Test Set-up .................................................................................................13

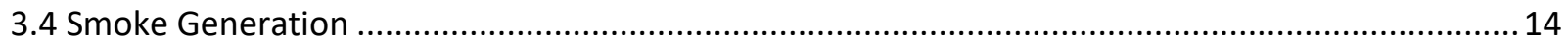

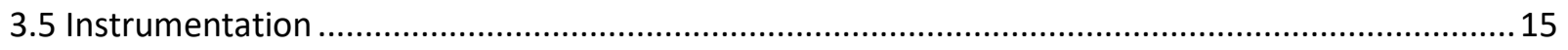

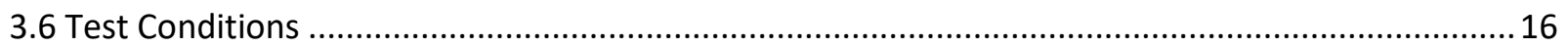

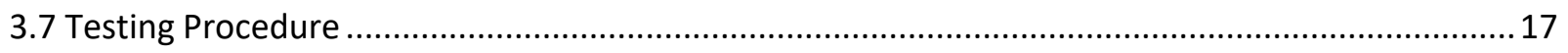

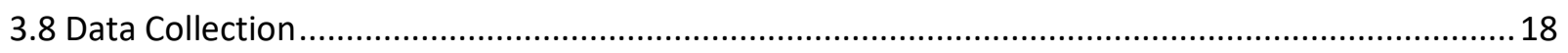

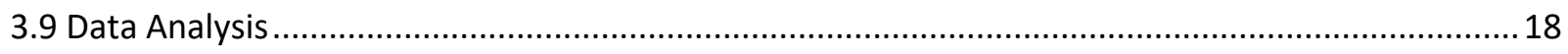




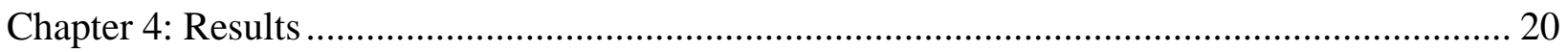

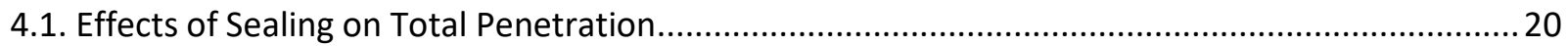

4.1.1 Analyzing the Effects of Sealing Types on Total Penetration...............................................20

4.1.2 Error Bars of Non-Sealed Half Mask .......................................................................................... 21

4.1.3 Error Bars of Only Nose Sealed Half Mask ...........................................................................22

4.1.4 Error Bars of Nose and Chin Sealed Half Mask ....................................................................23

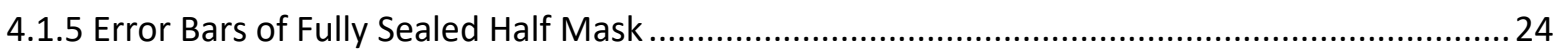

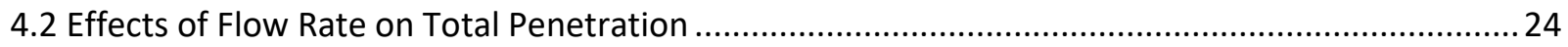

4.2.1 Effects of Flow Rates on Total Penetration for Non-Sealed Test Results ................................25

4.2.2 Effects of Flow Rates on Total Penetration for Only Nose Sealed Test Results.......................26

4.2.3 Effects of Flow Rates on Total Penetration for Nose and Chin Sealed Test Results .................26

4.2.4 Effects of Flow Rates on Total Penetration for Fully Sealed Test Results...............................27

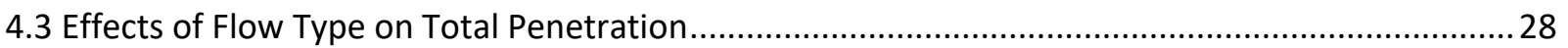

4.3.1 Effects of Flow Types on Total Penetration for Non-Sealed Test Results...............................29

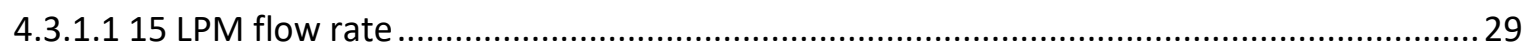

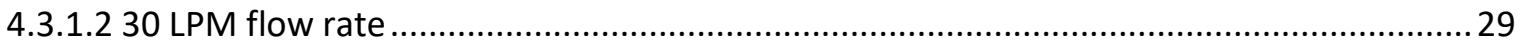

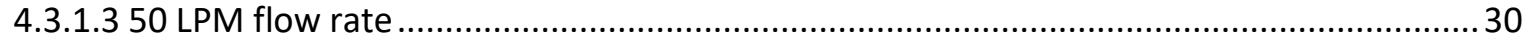

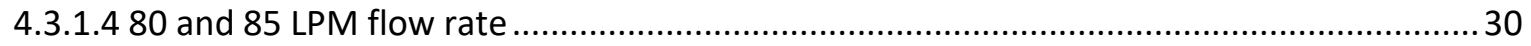

4.3.2 Effects of Flow Types on Total Penetration for Only Nose Sealed Test Results .......................31

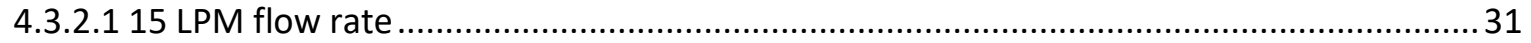

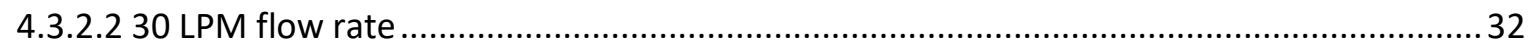

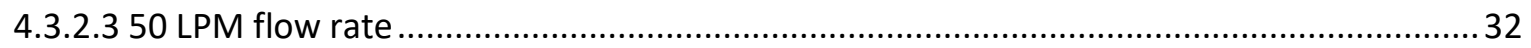

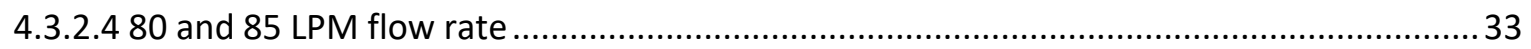

4.3.3 Effects of Flow Types on Total Penetration for Nose and Chin Sealed Test Results ................ 34

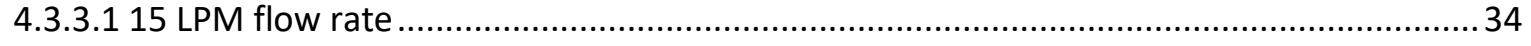

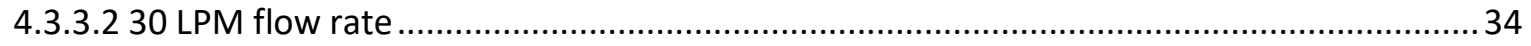

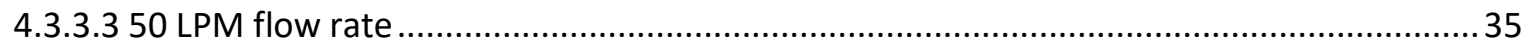

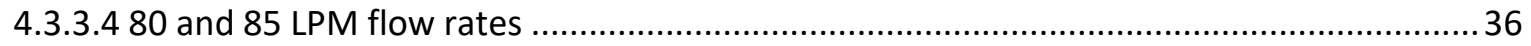

4.3.4 Effects of Flow Types on Total Penetration for Fully Sealed Test Results ..............................36

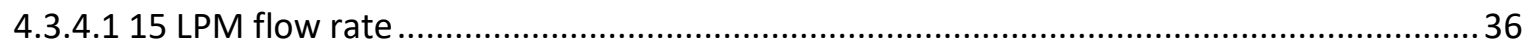

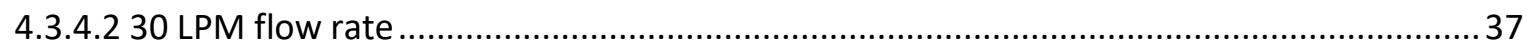

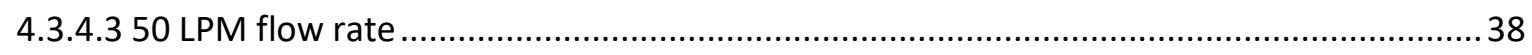

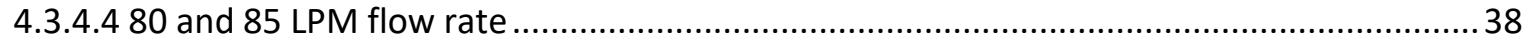




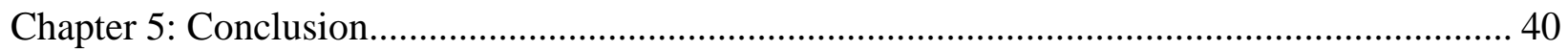

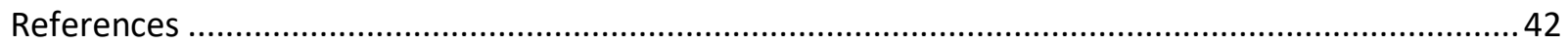

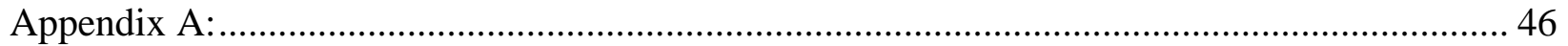




\section{List of Figures}

Figure 1: Example of an elastomeric half mask respirator (Source $3 \mathrm{M}$ ) ................................. 3

Figure 2: Example of a P-100 filter (Source:3M) .......................................................... 4

Figure 3: Experimental setup (Modified from He et all.,2013) ............................................ 10

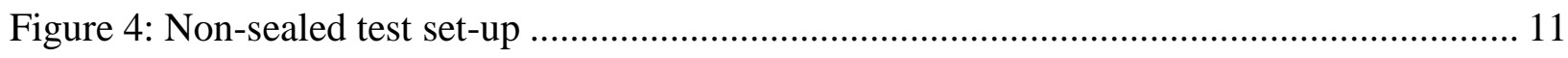

Figure 5: Only nose sealed test set up and sealing silicone ............................................... 12

Figure 6: Nose and chin areas sealed test set-up............................................................. 13

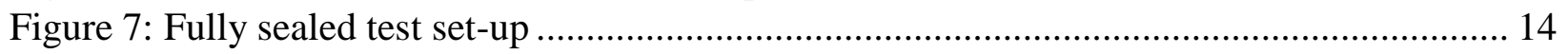

Figure 8: Combustion cigarette smoke generator ............................................................ 15

Figure 9: TSI P-Trak ultrafine particle counter 8525 (TSI Incorporated, 2013) ....................... 16

Figure 10: Error bars for non-sealed half mask test set-up ................................................. 22

Figure 11: Error bars for nose only sealed test set-up ........................................................ 23

Figure 12: Error bars for nose and chin sealed test set-up ................................................ 23

Figure 13: Error bars for fully sealed test set-up ................................................................ 24 


\section{List of Tables}

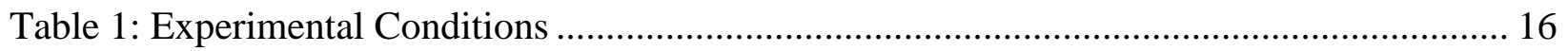

Table 2: Mean values of penetration percentages from 3 replicates.......................................... 20

Table 3: One-way ANOVA test result to the determine effects of sealing types ....................... 21

Table 4: Effects of flow rates on total penetration for non-sealed tests...................................... 25

Table 5: Effects of flow rates on total penetration for only nose sealed tests .......................... 26

Table 6: Effects of flow rates on total penetration for nose and chin sealed tests ..................... 27

Table 7: Effects of flow rates on total penetration for fully-sealed tests ................................ 28

Table 8: Flow types on total penetration for non-sealed respirator (15 LPM) ......................... 29

Table 9: Effects of flow types on total penetration for non-sealed respirator (30 LPM)............ 30

Table 10: Effects of flow types on total penetration for non-sealed respirator (50 LPM).......... 30

Table 11: Effects of flow types on total penetration for non-sealed respirator (80 and 85 LPM) 31

Table 12: Effects of flow types on total penetration for only nose sealed respirator (15 LPM) .. 31

Table 13: Effects of flow types on total penetration for only nose sealed respirator (30 LPM) .. 32

Table 14: Effects of flow types on total penetration for only nose sealed respirator (50 LPM) .. 33

Table 15: Effects of flow types on total penetration for only nose sealed respirator (80 and 85

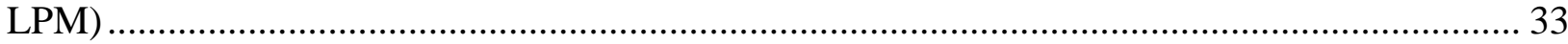

Table 16: Effects of flow types on total penetration for nose and chin sealed respirator (15 LPM)

Table 17: Effects of flow types on total penetration for nose and chin sealed respirator (30 LPM)

Table 18: Effects of flow types on total penetration for nose and chin sealed respirator (50 LPM)

Table 19: Effects of flow types on total penetration for nose and chin sealed respirator $(80$ and 85 LPM) 36

Table 20: Effects of flow types on total penetration for fully sealed respirator (15 LPM) ......... 37

Table 21: Effects of flow types on total penetration for fully sealed respirator (30 LPM) ......... 37

Table 22: Effects of flow types on total penetration for fully sealed respirator (50 LPM) ......... 38

Table 23: Effects of flow types on total penetration for fully sealed respirator (80 and 85 LPM)39 


\section{Chapter 1: Introduction}

Occupational Safety and Health Administration (OSHA) defines a respirator as a device that protects employees from inhalation of dangerous substances such as, chemicals and infectious particles (OSHA,1970). OSHA states that choosing an appropriate respirator is the most crucial issue. The selected respirator needs to be sure that it can be used safely for performing tasks in a hazardous environmental condition. Before choosing an appropriate respirator, it's essential to identify hazard type and airborne concentration in the working premises. Respirators to protect employees from airborne particle exposures operate in various ways such as, filtering particles from the air, purifying the air chemically, or providing clean air from an outside air supply.

According to National Institute for Occupational Safety and Health (NIOSH), P-100 filter has more than $99.97 \%$ filtering efficiency. Our study revealed that particle penetration efficiency depends on sealing conditions of respirator as well. Non-sealed or partially sealed respirator would increase leakage, leading to the increased particle penetration percentages. Half mask respirators are commonly used to protect employees from airborne contaminants causing several adverse health effects.

In this research, combustion of cigarette smoke aerosol was chosen to generate aerosolized ultrafine particles, because no similar research was conducted previously with cigarette smoke aerosol. Most of the similar researches were performed using other types of aerosolized particles, such as combustion of burning paper, wood and plastic, rather than those from cigarette smoke (He et. all, 2013).

Therefore, this study was performed to find out the effectiveness of half mask respirator with dual P-100 filters against ultrafine particles aerosolized from cigarette smoke. In this research, 
1 type of half mask respirator (3M 6200 Half Mask) and filter type (3M P-100) was put on a breathing manikin's face.

Three artificial leaks connected with tubes were used to utilize testing measurement terminals on the breathing manikin's head. One tube is specified as simulating human breathing, and the other two tubes are defined as inside and outside of the half mask to enable monitoring measurement spots.

A king size cigarette which was used as a smoke particle generator, was burned on cigarette holder in the testing chamber. The particle number concentration was measured with TSI P-Trak ultra-fine particle counter 8525 (TSI Incorporated, 2013) during the cigarette combustion. Once the particle concentration reached up to the device maximum measurement value of $500000 \mathrm{pt} / \mathrm{cc}$, sampling. Inside and outside of the mask was conducted every minute. When sampling finished, all sampled data were transferred from P-Trak's memory to the computer by a communication cable.

Four sealing conditions were applied on breathing manikin to find out leakage through the mask due to facial hair or different face configuration of the manikin. These 4 different sealing types were described as non-sealed, only nose sealed, nose and chin areas sealed, and fully sealed. Silicone material was applied between half mask and breathing manikin's face to establish different types of sealing conditions.

Four cyclic flows with mean inspiratory flow (MIF) rates of 15,30,50, and $85 \mathrm{~L} / \mathrm{min}$ were tested for each sealing conditions.

There are limited data available regarding particle penetration and faceseal leakage under cyclic breathing flow type. In addition, only a few information is available about filters and 
faceseal penetration under actual human breathing conditions. In this study, 4 cyclic breathing flows were tested with 4 sealing conditions.

Continuous flow does not represent an actual human breathing pattern; therefore, cyclic flow types were used to test closely actual human breathing features.

\subsection{M 6200 Half Mask Features}

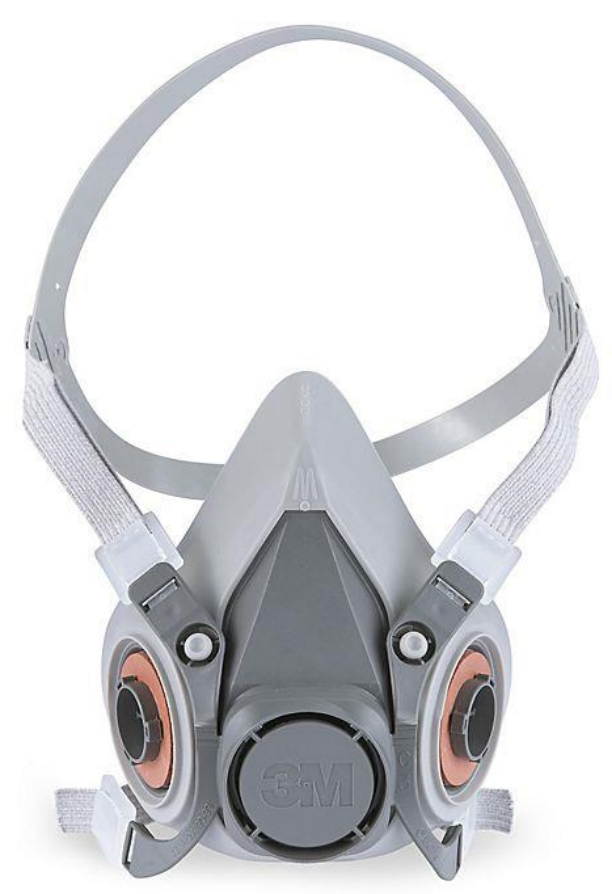

Figure 1: Example of an elastomeric half mask respirator (Source 3M)

Half mask elastomeric respirator is used commonly due to advantages of its comfort and convenience. The facepiece respirator is lightweight, very soft, comfortable, having easy adjustable head straps. This respirator can be disassembled, cleaned and reusable. Cartridges and filters could be replaced, if needed, therefore, these features utilize respirator cost effectiveness.

According to NIOSH approval, 3M 6200 respirator family enables to produce negative pressure on air purifying filter to preserve variety of gases, vapors, and particulate hazards. Dual airline system utilizes to connect double variety of cartridges and filters. In this course of tests 
medium size of half mask respirator was put on manikin's head with adjusted head straps. Tests were performed in an exposure chamber at various test conditions.

\subsection{P-100 Filter Performance}

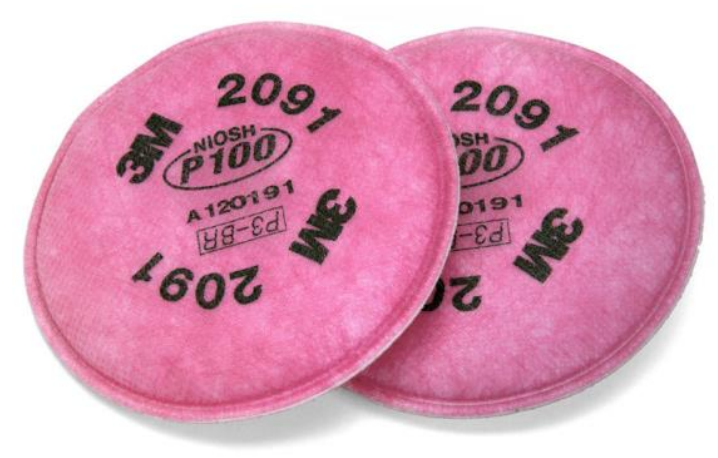

Figure 2: Example of a P-100 filter (Source:3M)

P-100 filter is classified as Advanced Electret Media (AEM) which is lightweight and has easy inhaling features. In addition, the 2091 filters are capable of filtering oil and non-oil based particulate contaminants. P-100 filter is one of the Air Purifying Filters (APR) which has either P, N, R product letters, corresponding to fine particles filtering efficiency of $100 \%, 99 \%$, and $95 \%$, respectively. According to the product manual, this filter is reusable and has an ability to filter fine particulates in the fire smoke. However, it cannot filter gases, for instance, carbon monoxide. In order to satisfy proper protection, users must wear facepiece respirators very tight to avoid faceseal leakage. 


\section{Chapter 2: Literature Review}

\subsection{Ultrafine Particles}

Particles that are less than $100 \mathrm{~nm}$ in diameter, commonly determined as ultrafine. Ultrafine particles are known as particulate matter of nanoscale size and they could be stationary or mobile. Ultrafine particles are universal matters and present almost everywhere. (Donaldson, Stone, Renwick, \& MacNee, 2001).

Ultrafine particles are commonly generated from combustion processes (Donaldson, Stone, Renwick, \& MacNee, 2001). In this study a cigarette was burnt to produce ultrafine cigarette smoke particles.

\subsection{Ultrafine Particles in Cigarette Smoke}

Studying the features of the particle size distribution of cigarette smoke can help us to provide some facts about smoke aerosol characteristics. Particle size distribution of mainstream cigarette smoke was generated by a smoking machine and was measured by an Electrical lowpressure impactor (ELPI). The results revealed the aerodynamic diameters of mainstream smoke particles vary from 0.021 to $1.956 \mu \mathrm{m}$. (li et al., 2014)

Cigarette smoke is a complex mixture of smoke components, generally described by diameter size-based distribution. Some studies concluded that cigarette smoke has potentially pathogenic ingredients, such as particulate matter, volatile substances, and gasses. Van et al. (2011) stated that fresh undiluted cigarette smoke contains numerous potentially toxic nanoparticles of which particle size is less than $50 \mathrm{~nm}$. 


\subsection{Environmental Tobacco Smoke}

Tobacco smoke is a mixture of chemicals and gaseous compounds containing about 4800 gaseous and identified particulate mixture. (Baker,1999; Perfetti and Rodgman, 2008). Various health problems could be related with airborne particulate matter (PM). Environmental tobacco smoke (ETS) is one of the most essential anthropogenic pollution in indoor surroundings. Besides, cigarette smoke is a compound of several well-known pollutant gaseous, for instance, carbon monoxide, sulphur dioxide, nitric oxide, nitrogen dioxide, methane, non-methane hydrocarbon, carbonyls, volatile organic compounds, and particulate matter (Diapouli et al., 2011;Wang et al., 2012).

There are two main routes of cigarette smoke generation. One is called mainstream of cigarette smoke (MCS), which is inhaled into the mouth passing through the filter of cigarette. The other one is called sidestream, which is releasing smoke into the air from the burning end. During the tests, sidestream of cigarette smoke was used to evaluate smoke penetration through the respirator.

\subsection{Health Effects of Ultrafine Smoke Particles}

Fine particulate matters in tobacco smoke and air pollution have significant effects on human mortality. Recent studies state that fine particulates have significant effects especially, on the brain and central nervous system. Fine particulate matters can cause cancer and minimize mortality ages easily. A large amount of studies demonstrated that on average, $60 \%$ to $80 \%$ of the mainstream cigarette smoke particulate matter is maintained in the lungs after inhalation. For instance, for nicotine, carbon monoxide, nitric oxide, and aldehydes the total smoke particulate matters retentions are of the order of 90\%-100\%, 55\%-65\%, 100\%, and approximately $90 \%$, respectively in the lungs after cigarette inhalation. (Baker, \& Dixon, 2005). 


\subsection{P-100 Filter Efficiency Against Nanoparticles}

According to the National Institute for Occupational Safety and Health (NIOSH) respirator certification test, a P-100 filter must provide not less than $99.97 \%$ efficiency challenged to polydisperse dioctyl phthalate (DOP) particles those having a count median diameter (CMD) of $185 \pm 20 \mathrm{~nm}$ (Shaffer and Rengasamy, 2009). However, nanoparticle (<100 nm size) exposure in this study is our main concern due to the potential danger on human health. NIOSH approved particulate respirators requirements and suggested to preserve employees against nanoparticles. (Rengasamy and Eimer ,2011).

\subsection{Filter Efficiency and Faceseal Leakage}

Some studies have been led to determine the filter efficiency of commercially available respirators. Nevertheless, the respirator performance is affected by the filter efficiency, as well as by the faceseal leakage. Additionally, some studies have shown that particle penetration through the faceseal leakage may be higher than through the filter medium (Coffey et al., 1998)

Oestentad and Perkins (1992) stated that respirator leakage was significantly caused by particle leaks at nose and chin areas. Furthermore, similar studies which are related with testing half mask respirator on breathing manikin, concluded that nose area was the primary leak site. (He et al., 2013)

\subsection{Flow Types and Rates}

It is more complex to quantify the particle penetration under actual breathing conditions, for instance, when the air flow through a respirator is not constant but has a cyclic nature. Early researches marked the effects of faceseal leakage on the particle penetration. (Hinds and Kraske, 1987; Chen et al., 1990; Chen and Willeke, 1992).

There is information deficiency about faceseal cigarette smoke aerosol penetration under the cyclic mean inflammatory flow types. Therefore, it would be crucial to investigate cigarette 
smoke aerosol penetration under cyclic flow types. Some studies pointed out that artificially fixed leaks and constant flow are not characteristic of actual environmental conditions. To overcome this limitation, not only testing constant, but also cyclic flow was performed under sealed and nonsealed conditions. In this study, sealing material was applied on breathing manikin due to hardships and inconvenience to test human subjects.

\subsection{Aerosol Type}

Most of the previous researches have used ambient aerosols or nebulizer-generated $\mathrm{NaCl}$ to investigate the performance of respirators. In addition, various challenge aerosols, for instance, biological and non-biological, have been used for different respiratory protection research including $\mathrm{NaCl}, \mathrm{Ag}, \mathrm{DOP}$, and viruses (all including significant number of ultrafine components). Some of the scientists used polystyrene latex spheres as an aerosol in their research (Myers et al.,1991; Quian et al., 1998). Others used fungal spores, bacteria, or viruses.

He et all. (2013) used combustion materials such as wood, paper, and plastic to determine effects of faceseal leakage of half or full elastomeric respirators. However, there is no specific study related with examining cigarette smoke aerosol penetration through half mask elastomeric respirator equipped with double P-100 filters. Since, there is no adequate literature on this subject, it was clear that a research gap is still present. 


\section{Chapter 3: Research Design and Methods}

\subsection{Objective of Study}

The purpose of this study is to investigate cigarette smoke penetration on half mask elastomeric respirators with double P-100 filters. To imitate real human breathing, constant and cyclic breathing patterns were used with different rates. Previous studies stated that faceseal leakage was a significant factor of concentration difference between inside and outside of the mask. In this research various sealing conditions were tested to find out leakage between manikin face and half mask elastomeric respirator.

One-way ANOVA compiled test results to find out which variable is more significant among others.

\subsection{Experimental Set-up}

Total airborne particle concentration was monitored inside $\left(\mathrm{C}_{\mathrm{in}}\right)$ and outside $\left(\mathrm{C}_{\text {out }}\right)$ of the respirator mask. Total penetration through mask was calculated by $\left(\mathrm{C}_{\mathrm{in}} / \mathrm{C}_{\mathrm{out}}\right)$. Experimental setup is plotted schematically in Figure 3.

An elastomeric half mask respirator with double P-100 filters was donned on manikin's head, and tygon plastic tubes were used to get samples from inside and outside of the mask.

Plastic tygon tubes were attached to the manikin's head to measure outside concentration. Another plastic tube was attached to manikin's neck, and there is connection through to its front face to ensure taking samples from inside of the respirators.

Manikin's head has 1.0-inch diameter copper tube that connects to the neck with breathing simulator. Constant flowing rates were produced by vacuum source of the laboratory and a vacuum pump. Cigarette smoke concentration was measured by TSI P-Trak ultrafine particle counter 8525 
(which can count particle size 10 to $1000 \mathrm{~nm}$ ) in 1-minute intervals with inside and outside of the respirator.

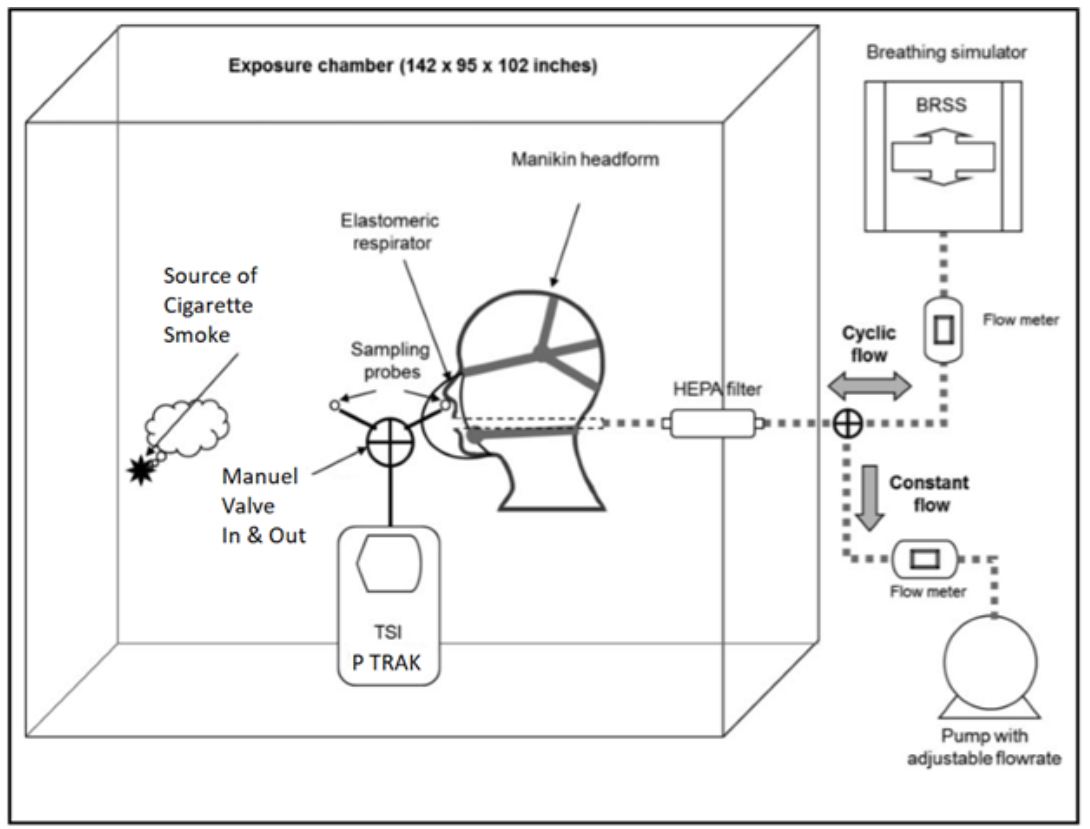

Figure 3: Experimental setup (Modified from He et all.,2013)

\subsection{Manikin Set-up}

In this study manikin head was donned with medium size 3M 6200 elastomeric half mask respirator with double P-100 filters. As shown in Figure 3, the manikin's head has two holes. One hole, 1-inch diameter, represents an artificial leak from either mouth or nose of the manikin. The other hole, 0.3-inch diameter, will be used to place a sampling probe to measure particle concentration inside of the mask. To mimic breathing condition, the breathing simulator is attached with HEPA filter. 


\subsubsection{Non-Sealed Test Set-up}

Non-sealed tests were conducted for 4 cyclic and 4 constant total 8 breathing types. Measurement of the sampling revealed that faceseal leakage was very significant for this type of test.

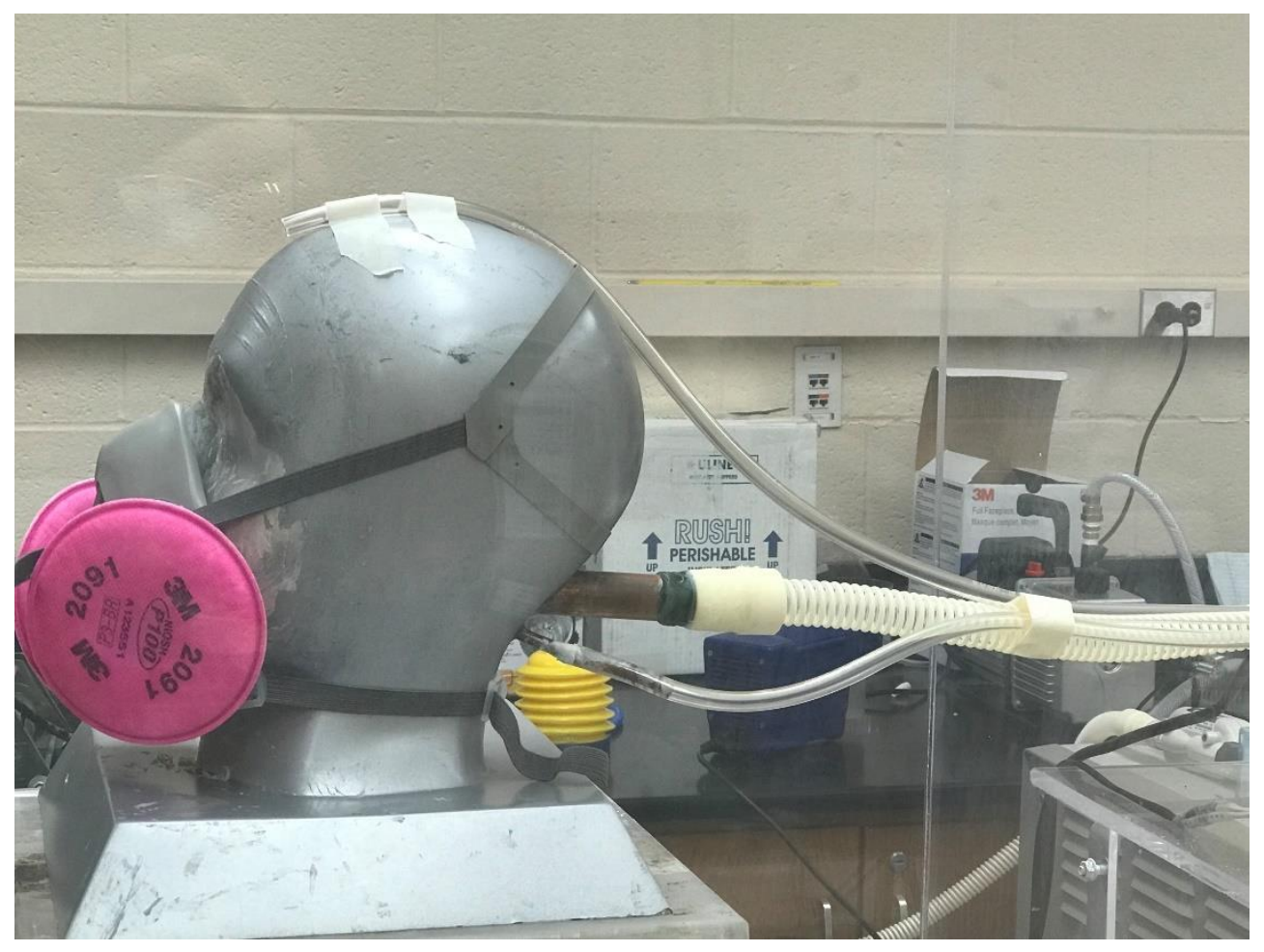

Figure 4: Non-sealed test set-up

As we can see in the figure 4, medium size 3M 6200 half mask respirator with double P 100 filters donned on breathing manikin. This non-sealed condition was tested for 4 cyclic and 4 constant total 8 flowing rates. Each test result was transferred to the spread sheets from particle counter device which is P-Trak.

\subsubsection{Only Nose Area Sealed Test Set-up}

Silicone sealing material was applied on the breathing manikin to utilize sealing condition tests. Nose area of the breathing manikin was covered with silicone material as seen in Figure 5. Only nose area sealed tests were performed both constant and cyclic types of breathing patterns. 
Total 8 different levels of inspiratory flow rates were applied for each breathing type. Sampling was conducted by P-Trak condensation particle counter device. Inside and outside of the respirator concentration was measured by sampling device every minute during the test.

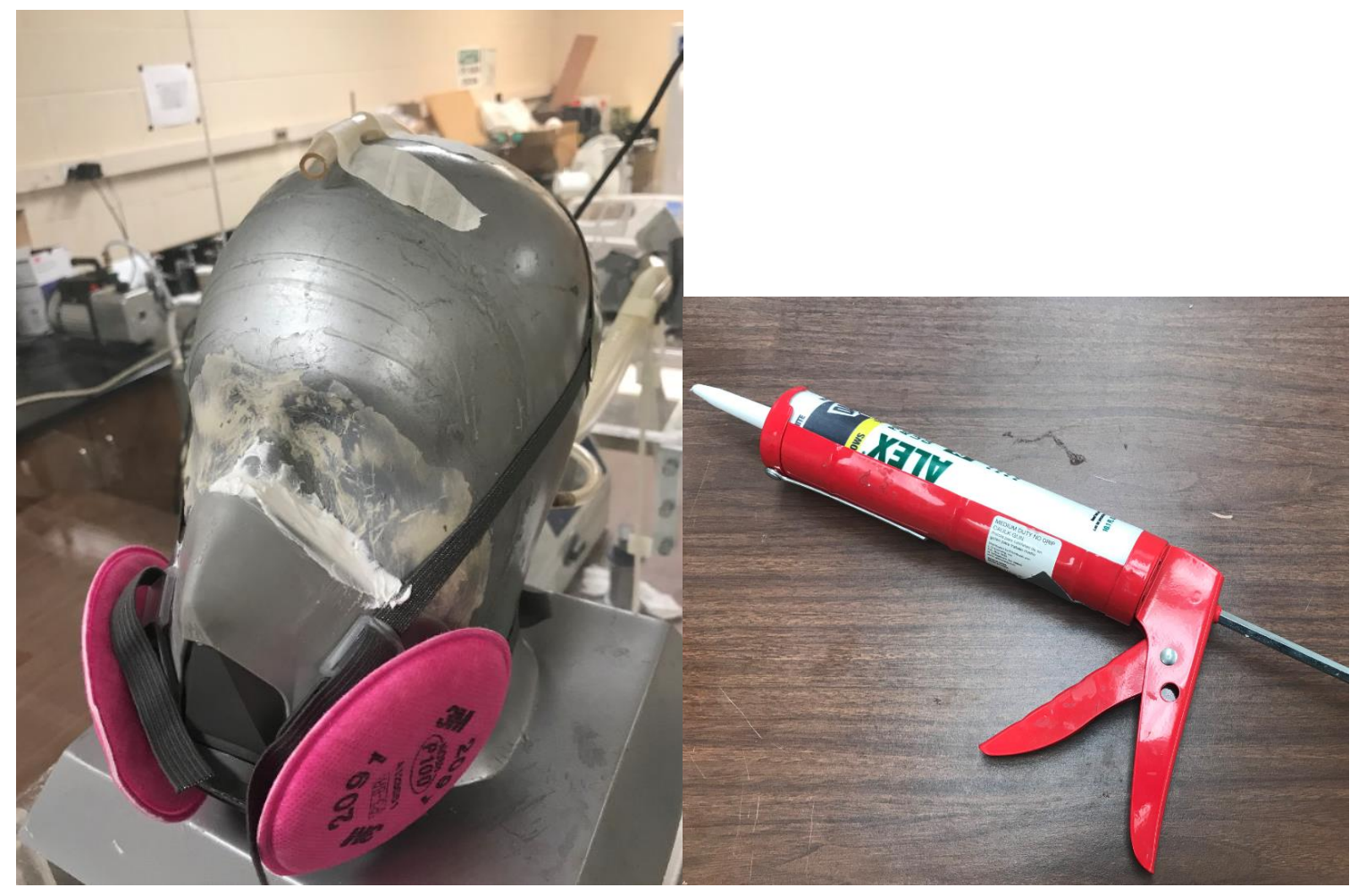

Figure 5: Only nose sealed test set up and sealing silicone

\subsubsection{Nose and Chin Areas Sealed Test Set-up}

Silicone sealing material was applied on breathing manikin's face to determine sealing condition of the test. Nose and chin areas of the breathing manikin were covered with silicone material as seen in Figure 6. Nose and chin areas sealed tests were performed both constant and cyclic types of breathing pattern. Total 4 different levels of inspiratory flow rates were applied for each breathing type. Sampling was measured from the inside and outside of the respirator's measurement terminals by P- Trak condensation particle counter device. Inside and outside of the respirator concentration was measured by sampling device each minute during the test. 


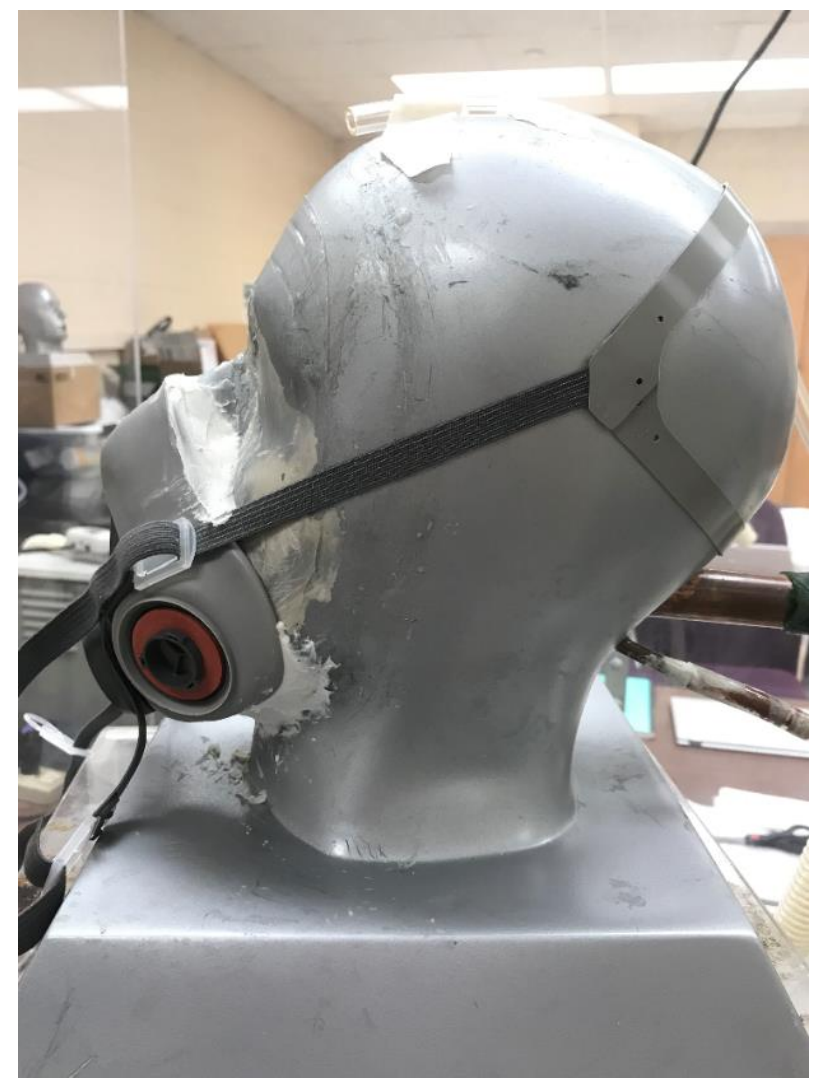

Figure 6: Nose and chin areas sealed test set-up

\subsubsection{Fully-Sealed Test Set-up}

Nose, chin and chick areas of the breathing manikin were covered with silicone material as seen in Figure 7. Fully-sealed tests were performed both constant and cyclic types of breathing patterns. Total 4 different levels of inspiratory flow rates were applied for each breathing type. Sampling was measured from inside and outside of the measurement terminals by P- Trak condensation particle counter device. Inside and outside of the respirator concentration were measured by sampling device each minute during the test. 


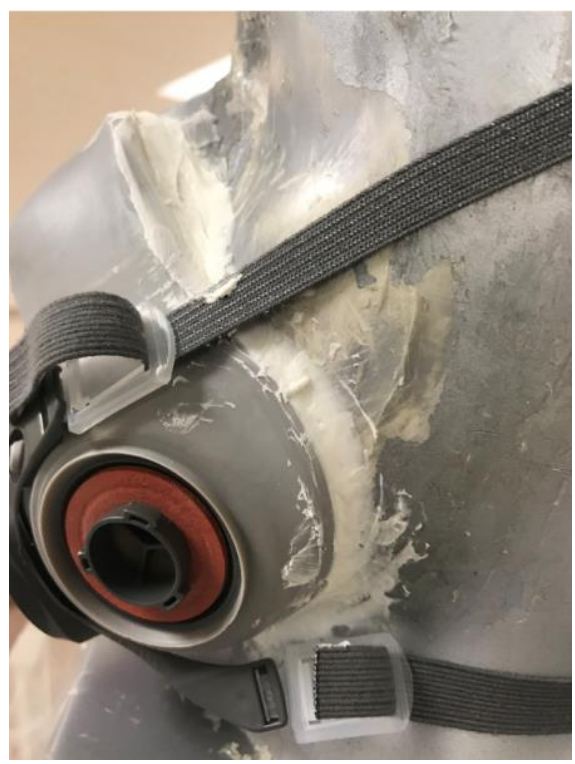

Figure 7: Fully sealed test set-up

\subsection{Smoke Generation}

Unfortunately, there was no smoke generation device to produce smoke aerosol with different concentration levels in the laboratory. Therefore, cigarette was used to generate combustion smoke source in the testing chamber. While generating combustion smoke, keeping constant concentration levels of smoke could not be satisfying, therefore, after burning a cigarette, sampling was started when the outside concentration levels reached up to maximum measurable value of the sampling device. Maximum sampling concentration is 500000 particle per cubic centimeter for the P-Trak. 


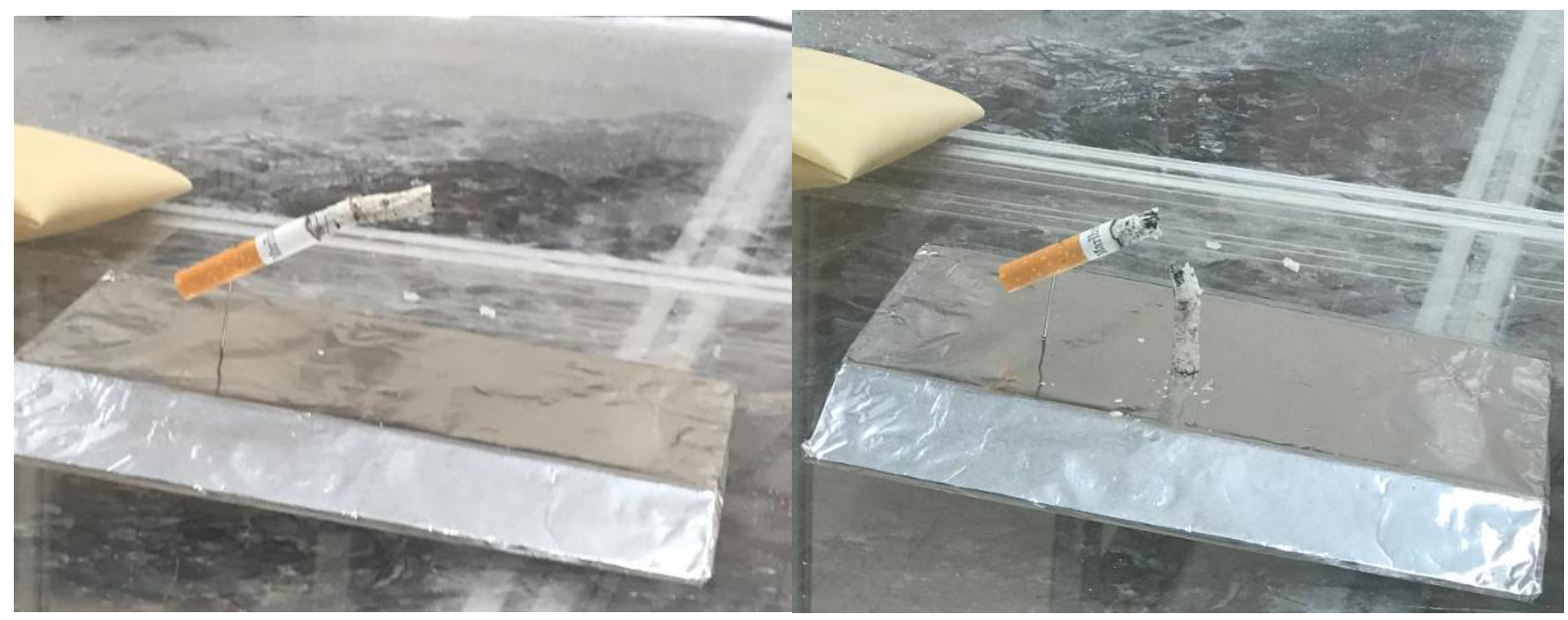

Figure 8: Combustion cigarette smoke generator

\subsection{Instrumentation}

In this study P-Trak ultrafine particle counter 8525 was used to measure particle concentration in the experimental chamber and inside of the elastomeric half mask respirator. PTrak ultrafine particle counter is commonly used to monitor ultrafine particles in helping elimination of indoor air quality problems. Considering the fact that it is difficult to adjust smoke aerosol concentration levels, the whole sampling process plotted decaying smoke concentration trends. The inside and outside concentration levels were sampled by P-Trak ultrafine particle counter device in every minute. Since, we have only one instrument, particle concentrations inside and outside the respirator cannot be measured simultaneously. Thus, a manual value was used to switch the measurement between inside and outside of the respirator. 


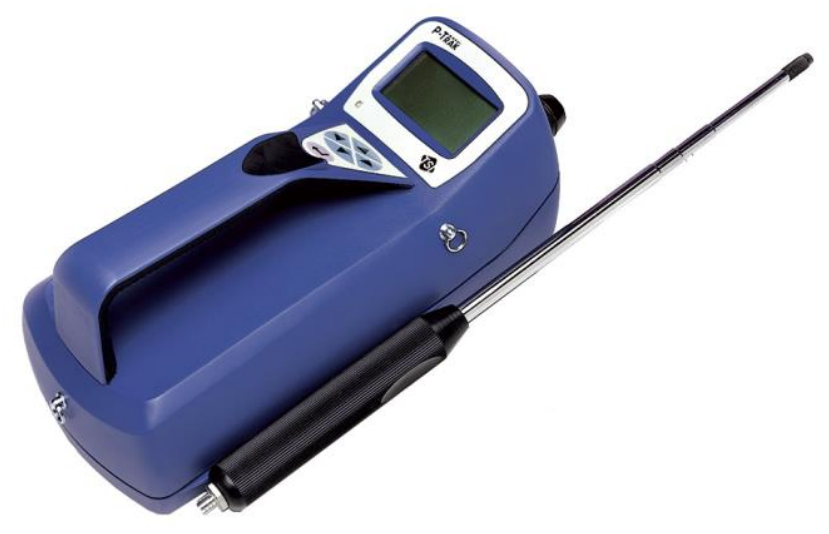

Figure 9: TSI P-Trak ultrafine particle counter 8525 (TSI Incorporated, 2013)

\subsection{Test Conditions}

In this experiment, a medium size 3M 6200 half mask respirator with double P-100 filters was tested. Constant and cyclic breathing patterns were used to simulate human breathing features closely. Manikin Breathing Rate was changed between cyclic and constant with the values of (15, 30, 50, and $85 \mathrm{~L} / \mathrm{min})$.

Similar studies pointed out that common leakage places are nose, chin, and cheek areas. In this study 4 sealing types such as, non-sealed, only nose sealed, nose and chin sealed, and fully sealed conditions were tested. Each sealing condition was established by applying a silicone material between the manikin's face and the respirator, every test was replicated 3 times.

\section{Table 1: Experimental Conditions}

\begin{tabular}{|l|l|}
\hline Variable & Levels \\
\hline Respirator type & $3 \mathrm{M} 6200$ Half mask \\
\hline Sealing condition & 4 (unsealed, only nose sealed, nose and chin \\
& sealed, fully sealed) \\
\hline
\end{tabular}




\begin{tabular}{|l|l|}
\hline Burning material & A cigarette \\
\hline Manikin breathing rate & 4 cyclic $(15,30,50,85 \mathrm{~L} / \mathrm{min})$ \\
& 4 constants $(15,30,50,80 \mathrm{~L} / \mathrm{min})$ \\
\hline Replicates & 3 \\
\hline Total runs & $1 \times 4 \times 8 \times 3=96$ \\
\hline
\end{tabular}

\subsection{Testing Procedure}

Each test condition was conducted as follows:

1. P-Trak was turned on;

2. P- Trak automatically counted down to 60 seconds in order to get ready for sampling;

3. Storage cap was removed and alcohol cartridge was inserted;

4. A zero-calibration filter was connected to the inlet screen assembly to utilize precalibration;

5. Zero calibration filter was removed;

6. Tygon plastic tubing was attached to inlet screen assembly to measure the outside concentration;

7. A cigarette was burnt with a lighter in the testing chamber;

8. P- Trak was set to operate in data logging mode;

9. P- Trak was set to sample 60 seconds intervals;

10. P-Trak's display was monitored until the maximum particle concentration on the screen reached to $500000 \mathrm{pt} / \mathrm{cc}$;

11. After reading the outside maximum concentration, sampling tubes were switched from inside to outside to measure inside and outside concentration every minute. 
Aerosol generation was not under control, especially concentration of smoke cannot be adjusted on certain points, therefore, decaying type of aerosol concentration was plotted in this study.

All sampled data were saved into P-Trak memory. Connection cable was used to connect PTrak to computer in order to transfer sampling data to the computer.

Alcohol wick was soaked into alcohol and allowed to insert P-Trak before starting every new sampling. Four small ventilation devices were used to maintain homogenous environment into the testing chamber.

\subsection{Data Collection}

Data collection was performed completely in randomized testing order. All tests were repeated 3 times. While collecting samples, P-Trak particle counter was running in a log mode and saved the number of sampled particle concentration in its memory. Sampler was set for one-minute data logging interval.

Combustion smoke aerosol generation was not under control; therefore, concentration of smoke could not be adjusted on certain levels. Thus, concentration levels could not be used as a variable to find out whether it was or was not significant feature of effecting penetration on the half mask. A cigarette was burnt in the testing chamber and sampling was not started until concentration level reached up to sampler device maximum measurement point which is 500000 $\mathrm{pt} / \mathrm{cc}$.

\subsection{Data Analysis}

For each combination of experimental conditions, the mean value of triplicated runs and the standard deviation were calculated. There were 4 types of sealing, 2 types of breathing flow, 4 types of flowing rates for each breathing type, and 3 replicates of testing produced total 96 tests. 
In this study, our null hypothesis claimed that flowing rates, breathing and sealing types have no significant effects on the total penetration of ultrafine cigarette smoke aerosol through $3 \mathrm{M}$ 6200 half mask respirator equipped with P-100 filters. In order to evaluate null hypothesis, oneway analysis of variance (ANOVA) was conducted to quantify the effects of sealing condition, flowing rates, and flowing types on the particle penetration separately. 


\section{Chapter 4: Results}

\subsection{Effects of Sealing on Total Penetration}

The null hypothesis states that sealing types have no significant effects on total cigarette smoke penetration through 3M-6200 half mask with P-100 filters. In contrast, the alternative hypothesis would be defined as sealing types have significant effects on penetration percentages through the half mask respirator with P-100 filters. In order to provide acceptable evidence to prove this alternative hypothesis statistically, ANOVA one-way analysis of variance was conducted to quantify the effects of sealing condition on the particle penetration through the half mask. Mean values of penetration percentages were measured from all 3 replicate tests. A summary of the test results is demonstrated in Table 2.

Table 2: Mean values of penetration percentages from 3 replicates

\begin{tabular}{|c|c|c|c|c|c|}
\hline & & \multicolumn{5}{|c|}{ Penetration, \% (Mean \pm STD) } \\
\hline \multirow{3}{*}{ Flow Type } & Flow Rate & Non sealed & Nose only sealed & nose and chin sealed & fully sealed \\
\hline \multirow{3}{*}{ CONSTANT } & CONSTANT 15LPM & $84.45 \pm 1.57$ & $11.17 \pm 2.01$ & $0.235 \pm 0.0044$ & $0.0040 \pm 0.00089$ \\
\cline { 2 - 6 } & CONSTANT 30LPM & $78.52 \pm 3.66$ & $3.33 \pm 0.63$ & $0.327 \pm 0.0032$ & $0.0011 \pm 0.00026$ \\
\cline { 2 - 6 } & CONSTANT 50LPM & $70.86 \pm 2.49$ & $6.42 \pm 1.61$ & $0.357 \pm 0.0023$ & $0.0039 \pm 0.00063$ \\
\cline { 2 - 6 } & CONSTANT 80LPM & $72.88 \pm 3.00$ & $8.72 \pm 2.06$ & $0.702 \pm 0.0607$ & $0.0030 \pm 0.00045$ \\
\hline \multirow{3}{*}{ CYCLIC } & CYCLIC 15LPM & $87.53 \pm 3.69$ & $18.40 \pm 2.02$ & $0.046 \pm 0.0033$ & $0.0286 \pm 0.00042$ \\
\cline { 2 - 6 } & CYCLIC 30LPM & $80.58 \pm 0.77$ & $5.81 \pm 1.38$ & $0.036 \pm 0.0007$ & $0.0321 \pm 0.00091$ \\
\cline { 2 - 6 } & CYCLIC 50LPM & $56.70 \pm 5.55$ & $9.58 \pm 2.15$ & $0.056 \pm 0.0134$ & $0.0299 \pm 0.00141$ \\
\cline { 2 - 6 } & CYCLIC 85LPM & $54.28 \pm 3.45$ & $4.17 \pm 0.94$ & $0.170 \pm 0.0542$ & $0.0231 \pm 0.00033$ \\
\hline
\end{tabular}

\subsubsection{Analyzing the Effects of Sealing Types on Total Penetration}

While analyzing the effects of different sealing types on total penetration, single factor ANOVA test was conducted statistically to calculate P- value. The null hypothesis states that sealing has no significant effects on ultrafine cigarette smoke penetration through half mask respirator with P-100 filters. Alpha value was assigned as $\alpha=0.05$ to detect statistically significant difference. 
If the analysis rendered $\mathrm{P}<\alpha$, then we would reject the null hypothesis. Table 3 describes the results of one-way ANOVA statistical analysis. The results show that $\mathrm{P}=7.58 \mathrm{E}-20<\alpha$, therefore, we could reject the null hypothesis. Hence, sealing types have significant effects on penetration percentages of the half mask respirator with P-100 filters.

Table 3: One-way ANOVA test result to the determine effects of sealing types

SUMMARY

\begin{tabular}{lrrrr}
\hline \multicolumn{1}{c}{ Groups } & Count & \multicolumn{1}{c}{ Sum } & Average & Variance \\
\hline Non sealed & 8 & 585.8086 & 73.22607 & 150.0662 \\
Nose only sealed & 8 & 67.60718 & 8.450897 & 23.32833 \\
nose and chin sealed & 8 & 1.927717 & 0.240965 & 0.050421 \\
fully sealed & 8 & 0.12578 & 0.015722 & 0.000193 \\
\hline
\end{tabular}

ANOVA

\begin{tabular}{|c|c|c|c|c|c|c|}
\hline Source of Variation & SS & $d f$ & $M S$ & $F$ & P-value & F crit \\
\hline Between Groups & 30042.02 & 3 & 10014.01 & 230.9435 & $7.58 \mathrm{E}-20$ & 2.946685 \\
\hline Within Groups & 1214.116 & 28 & 43.36129 & & & \\
\hline Total & 31256.14 & 31 & & & & \\
\hline
\end{tabular}

\subsubsection{Error Bars of Non-Sealed Half Mask}

For the constant flow type, the percent penetration ranged from $71 \%$ to $85 \%$ for all testing flow rates, while the cyclic flow type showed the percent penetration ranging from $55 \%$ to $88 \%$. Among all test conditions, the lowest penetration was observed when tested at a cyclic flow rate of $85 \mathrm{~L} / \mathrm{min}$, while the highest penetration happened at a cyclic flow rate of $15 \mathrm{~L} / \mathrm{min}$. Penetration percentages were recorded relatively high when compared to sealed condition test. 


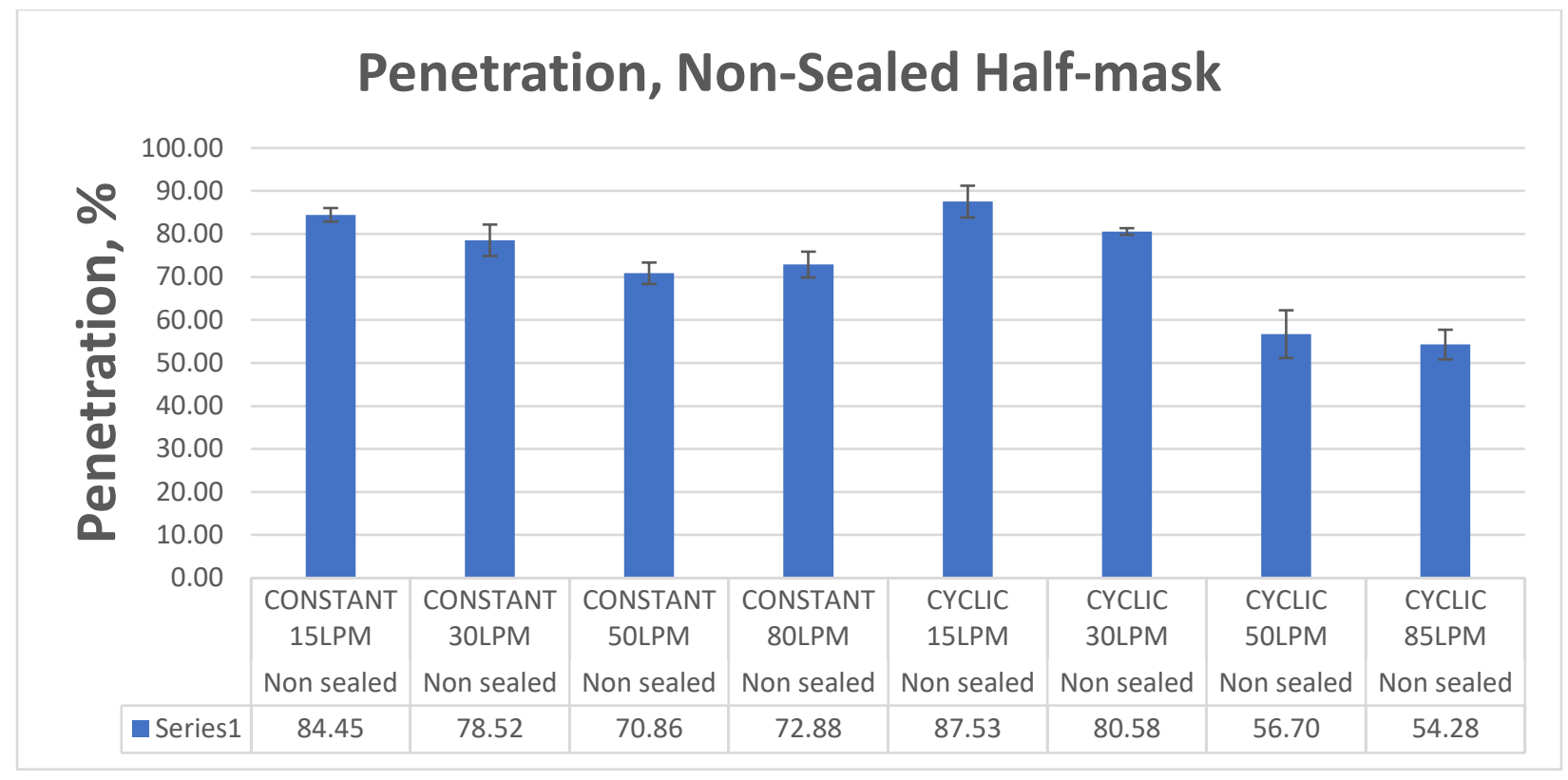

Figure 10: Error bars for non-sealed half mask test set-up

\subsubsection{Error Bars of Only Nose Sealed Half Mask}

As shown in Figure 11, penetration percentages were derived from the mean value of 3 test replicates of each testing combination. The measurement of maximum penetration percentage which was $18.40 \%$, was recorded at cyclic flow of $15 \mathrm{~L} / \mathrm{min}$ test. In addition, the minimum measurement of penetration percentage which was $3.34 \%$, was calculated at constant flow of 30 $\mathrm{L} / \mathrm{min}$ test. When the penetration percentages of only nose area sealed were compared with those of non-sealed tests, the penetration percentages for all flow rates were much smaller than those of the non-sealed condition test, clearly indicating that faceseal leakage was relatively high in nonsealed condition. 


\section{Penetration, Only Nose Sealed Half-mask}

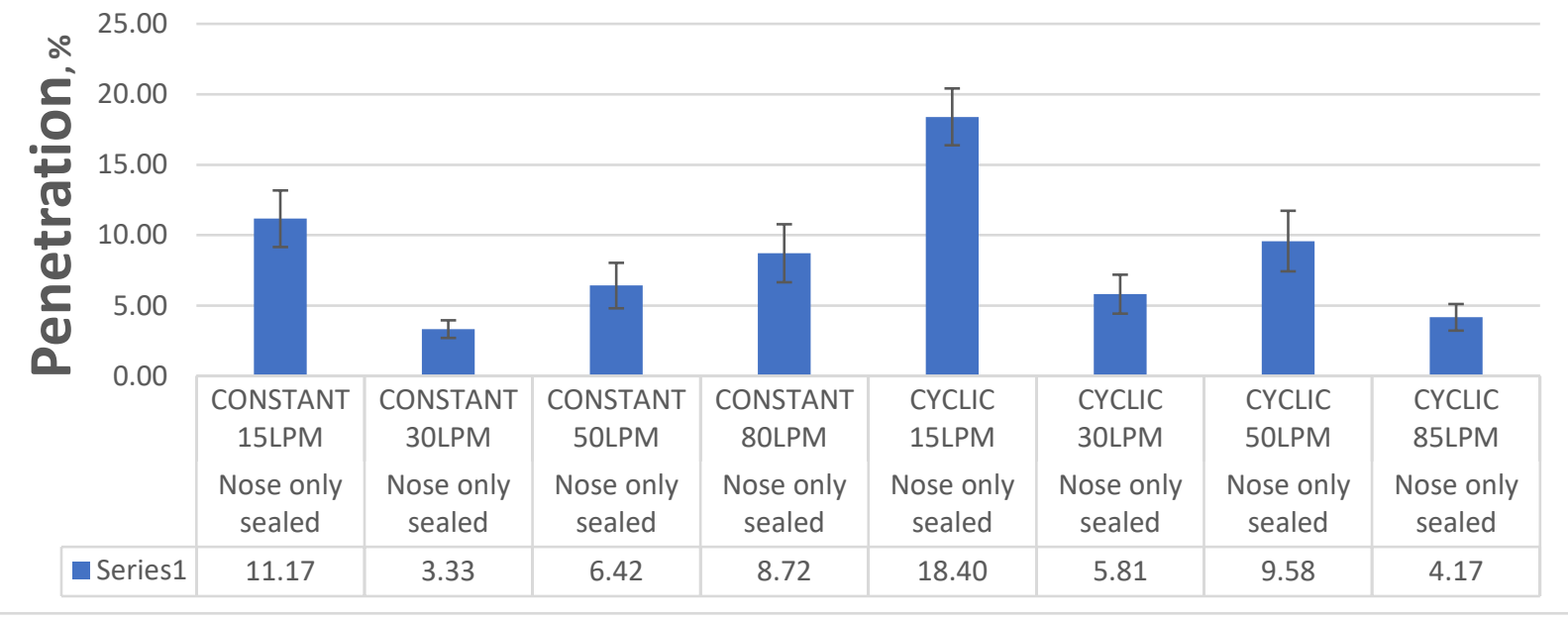

Figure 11: Error bars for nose only sealed test set-up

\subsubsection{Error Bars of Nose and Chin Sealed Half Mask}

As shown in Figure 12, penetration percentages were lower than non-sealed and only nose sealed test results. However, the mean value of penetration percentages was still higher than an acceptable filter performance percentage $0.03 \%$.

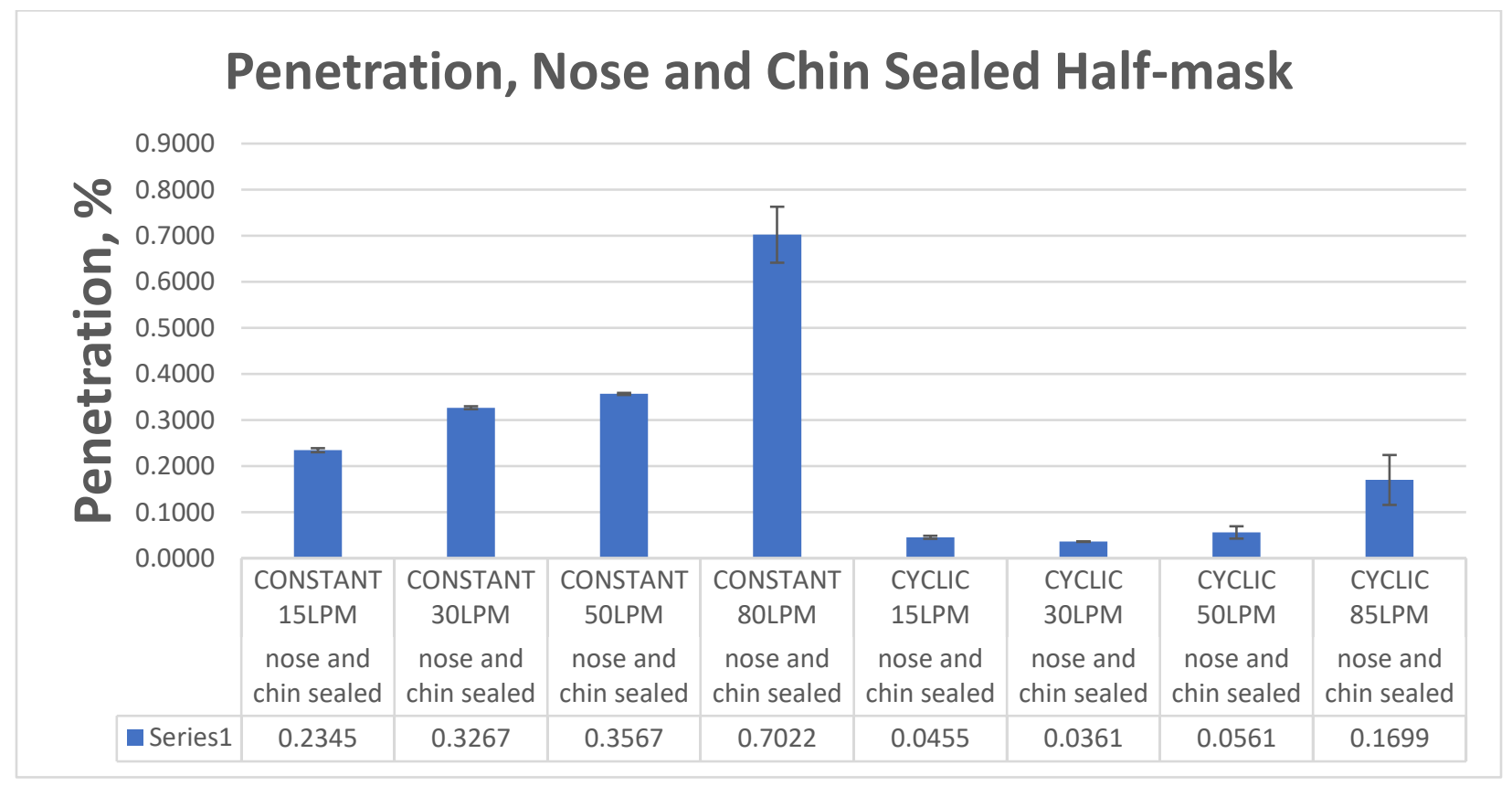

Figure 12: Error bars for nose and chin sealed test set-up 


\subsubsection{Error Bars of Fully Sealed Half Mask}

Fully sealed half mask test results showed that the constant flow types and rates were within the acceptable penetration percentage value $(0.03 \%)$. In contrast, the cyclic flow type had higher percentage values, especially a cyclic flow rate of $30 \mathrm{~L} / \mathrm{min}$ showed $0.032 \%$ penetration value and exceeded the acceptable value.

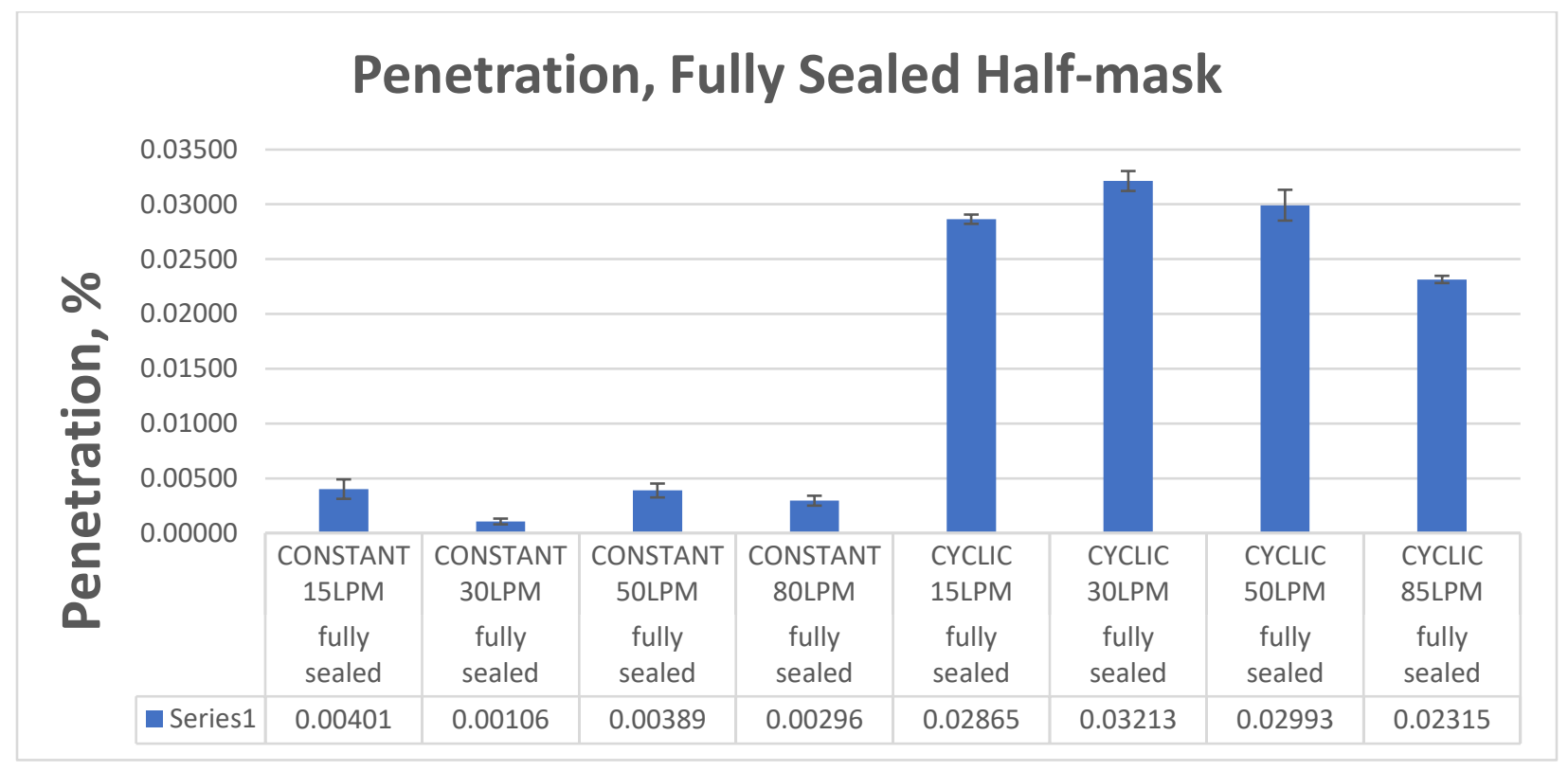

Figure 13: Error bars for fully sealed test set-up

\subsection{Effects of Flow Rate on Total Penetration}

In order to evaluate the effects of flow rates on total penetration, single factor ANOVA test was performed statistically to calculate $\mathrm{P}$ value. The null hypothesis states that flow rate has no significant effects on ultrafine cigarette smoke penetration through the half mask respirator with P-100 filters. Alpha value was assigned as $\alpha=0.05, \mathrm{P}$ value for flow rate was calculated by single way variance of ANOVA statistically. 
The effects of flow rate on total penetration was investigated for each sealing types separately. If we take into consideration of only one sealing type, we could measure the effects of different flow rates effects on cigarette smoke penetration through half mask for each sealing types.

\subsubsection{Effects of Flow Rates on Total Penetration for Non-Sealed Test Results}

The effects of flow rates on total cigarette smoke penetration were investigated for nonsealed test conditions. For the statistical analysis, sealing was considered as a fixed variable.

The null hypothesis claims that flow rate has no significant effects on ultrafine cigarette smoke penetration through the half mask respirator for non-sealed tests condition. Table 4 describes the results of single way variance of ANOVA statistical analysis. The results express that $\mathrm{P}=6.69511 \mathrm{E}-42<\alpha$, therefore, we would reject the null hypothesis. Hence, flow rate has significant effects on penetration percentages of the half mask respirator with P-100 filter for nonsealed condition.

\section{Table 4: Effects of flow rates on total penetration for non-sealed tests}

Anova: Single Factor

SUMMARY

\begin{tabular}{lrrrr}
\hline \multicolumn{1}{c}{ Groups } & \multicolumn{1}{c}{ Count } & \multicolumn{1}{c}{ Sum } & Average & Variance \\
\hline Non-Sealed Constant 15LPM & 17 & 1435.679 & 84.45172 & 26.81231 \\
Non-Sealed Constant 30LPM & 23 & 1805.991 & 78.52136 & 23.99074 \\
Non-Sealed Constant 50LPM & 16 & 1133.824 & 70.86399 & 93.68719 \\
Non-Sealed Constant 80LPM & 19 & 1384.7 & 72.87892 & 29.51294 \\
Non-Sealed Cyclic 15LPM & 23 & 2013.158 & 87.5286 & 22.03907 \\
Non-Sealed Cyclic 30LPM & 13 & 1047.576 & 80.58281 & 35.40228 \\
Non-Sealed Cyclic 50LPM & 23 & 1304.128 & 56.70122 & 29.74656 \\
Non-Sealed Cyclic 85LPM & 12 & 651.3599 & 54.28 & 85.0889 \\
\hline
\end{tabular}

ANOVA

\begin{tabular}{|c|c|c|c|c|c|c|}
\hline Source of Variation & SS & $d f$ & $M S$ & $F$ & P-value & F crit \\
\hline Between Groups & 18825.36 & 7 & 2689.337 & 68.81131 & $6.69511 E-42$ & 2.076559 \\
\hline Within Groups & 5393.423 & 138 & 39.08278 & & & \\
\hline Total & 24218.78 & 145 & & & & \\
\hline
\end{tabular}




\subsubsection{Effects of Flow Rates on Total Penetration for Only Nose Sealed Test Results}

For only nose sealed tests, we have the same null hypothesis. Table 5 shows the results of single way variance of ANOVA statistical analysis. The results demonstrate that $\mathrm{P}=6.0787 \mathrm{E}-$ $51<\alpha$, therefore, we would reject the null hypothesis. For this reason, flow rate has significant effects on penetration percentages of the half mask respirator with P-100 filter for only nose sealed condition.

Table 5: Effects of flow rates on total penetration for only nose sealed tests

Anova: Single Factor

SUMMARY

\begin{tabular}{lrrrl}
\hline \multicolumn{1}{c}{ Groups } & \multicolumn{1}{c}{ Count } & \multicolumn{1}{c}{ Sum } & Average & Variance \\
\hline Nose Sealed Constant 15LPM & 30 & 370.0767 & 12.33589 & 20.13738 \\
Nose Sealed Constant 30LPM & 25 & 83.31431 & 3.332572 & 5.831721 \\
Nose Sealed Constant 50LPM & 22 & 141.3255 & 6.423887 & 4.228294 \\
Nose Sealed Constant 8OLPM & 18 & 156.891 & 8.716169 & 4.800371 \\
Nose Sealed Cyclic 15LPM & 31 & 570.3756 & 18.39921 & 9.099042 \\
Nose Sealed Cyclic 30LPM & 29 & 168.6055 & 5.813983 & 12.51619 \\
Nose Sealed Cyclic 50LPM & 30 & 287.5121 & 9.583738 & 10.99058 \\
Nose Sealed Cyclic 85LPM & 25 & 104.2328 & 4.169312 & 6.894244 \\
\hline
\end{tabular}

ANOVA

\begin{tabular}{lcrcccc}
\hline \multicolumn{1}{c}{ Source of Variation } & SS & df & MS & $F$ & P-value & F crit \\
\hline Between Groups & 4910.692 & 7 & 701.5274 & 70.78493 & $6.07874 \mathrm{E}-51$ & 2.055134 \\
Within Groups & 2001.959 & 202 & 9.910689 & & & \\
& & & & & & \\
Total & 6912.651 & 209 & & & & \\
\hline
\end{tabular}

\subsubsection{Effects of Flow Rates on Total Penetration for Nose and Chin Sealed Test Results}

Table 6 indicates the results of single way variance of ANOVA statistical analysis for determining effects of flow rates on total penetration for nose and chin areas sealed tests. The results exhibit that $\mathrm{P}=1.62654 \mathrm{E}-37<\alpha$, therefore, we would reject the null hypothesis indicating that flow rate has significant effects on penetration percentages of the half mask respirator with P100 filter for only nose and chin sealed test. 
Table 6: Effects of flow rates on total penetration for nose and chin sealed tests

Anova: Single Factor

SUMMARY

\begin{tabular}{lrrrr}
\hline \multicolumn{1}{c}{ Groups } & Count & \multicolumn{1}{c}{ Sum } & \multicolumn{1}{c}{ Average } & Variance \\
\hline Nose \& Chin Sealed Constant 15LPM & 15 & 3.517796 & 0.23452 & 0.007307 \\
Nose \& Chin Sealed Constant 30LPM & 16 & 5.227252 & 0.326703 & 0.020731 \\
Nose \& Chin Sealed Constant 50LPM & 17 & 6.06427 & 0.356722 & 0.021718 \\
Nose \& Chin Sealed Constant 80LPM & 15 & 10.53305 & 0.702203 & 0.032281 \\
Nose \& Chin Sealed Cyclic 15LPM & 17 & 0.773729 & 0.045513 & 0.005661 \\
Nose \& Chin Sealed Cyclic 30LPM & 15 & 0.541504 & 0.0361 & 0.001459 \\
Nose \& Chin Sealed Cyclic 50LPM & 16 & 0.896846 & 0.056053 & 0.000416 \\
Nose \& Chin Sealed Cyclic 85LPM & 13 & 2.208736 & 0.169903 & 0.002669 \\
\hline
\end{tabular}

ANOVA

\begin{tabular}{|c|c|c|c|c|c|c|}
\hline Source of Variation & SS & $d f$ & $M S$ & $F$ & P-value & F crit \\
\hline Between Groups & 5.428726 & 7 & 0.775532 & 66.05335 & $1.62654 \mathrm{E}-37$ & 2.089477 \\
\hline Within Groups & 1.361956 & 116 & 0.011741 & & & \\
\hline Total & 6.790682 & 123 & & & & \\
\hline
\end{tabular}

\subsubsection{Effects of Flow Rates on Total Penetration for Fully Sealed Test Results}

Table 7 demonstrates the results of single way variance of ANOVA statistical analysis for investigating effects of flow rates on total penetration for fully sealed tests. The results establish that $\mathrm{P}=1.32642 \mathrm{E}-15<\alpha$, therefore, we would reject the null hypothesis. $\mathrm{P}$ value concludes that flow rate has significant effects on penetration percentages of the half mask respirator with P-100 filter for fully sealed test. 
Table 7: Effects of flow rates on total penetration for fully-sealed tests

Anova: Single Factor

SUMMARY

\begin{tabular}{lrrrr}
\hline \multicolumn{1}{c}{ Groups } & Count & \multicolumn{1}{c}{ Sum } & \multicolumn{1}{c}{ Average } & Variance \\
\hline Fully-Sealed Constant 15LPM & 18 & 0.072257 & 0.004014 & $1 \mathrm{E}-05$ \\
Fully-Sealed Constant 30LPM & 16 & 0.016973 & 0.001061 & $5.05 \mathrm{E}-07$ \\
Fully-Sealed Constant 50LPM & 14 & 0.054461 & 0.00389 & $5.69 \mathrm{E}-05$ \\
Fully-Sealed Constant 80LPM & 12 & 0.035493 & 0.002958 & $3.23 \mathrm{E}-06$ \\
Fully-Sealed Cyclic 15LPM & 27 & 0.773483 & 0.028648 & 0.000652 \\
Fully-Sealed Cyclic 30LPM & 24 & 0.771205 & 0.032134 & $8.56 \mathrm{E}-05$ \\
Fully-Sealed Cyclic 50LPM & 24 & 0.71823 & 0.029926 & $4.69 \mathrm{E}-05$ \\
Fully-Sealed Cyclic 85LPM & 20 & 0.462988 & 0.023149 & 0.000637 \\
\hline
\end{tabular}

ANOVA

\begin{tabular}{|c|c|c|c|c|c|c|}
\hline Source of Variation & SS & $d f$ & $M S$ & $F$ & $P$-value & Fcrit \\
\hline Between Groups & 0.025328 & 7 & 0.003618 & 16.09249 & $1.32642 \mathrm{E}-15$ & 2.072404 \\
\hline Within Groups & 0.033052 & 147 & 0.000225 & & & \\
\hline Total & 0.05838 & 154 & & & & \\
\hline
\end{tabular}

\subsection{Effects of Flow Type on Total Penetration}

The null hypothesis is that flow type has no significant effects on ultrafine cigarette smoke penetration through the half mask respirator.

Single way variance of ANOVA statistical analysis was performed for each sealing and flow rate conditions. We have 4 sealing types and 4 flow rates which produce total 16 combinations. Each sealing type and flow rate was tested in order to find out whether flow type has any significant effects on total penetration through the half mask respirator with P-100 filters or not. 


\subsubsection{Effects of Flow Types on Total Penetration for Non-Sealed Test Results}

\subsubsection{15 LPM flow rate}

Table 8 indicates that flow type does not have statistically significant effects on total penetration for non-sealed, 15 LPM (Liter per minute) test $(\mathrm{P}=0.05716>0.05)$. This means we would fail to reject the null hypotheses.

Table 8: Flow types on total penetration for non-sealed respirator (15 LPM)

Anova: Single Factor

SUMMARY

\begin{tabular}{lrrrr}
\hline \multicolumn{1}{c}{ Groups } & Count & Sum & Average & Variance \\
\hline Non-Sealed Constant 15LPM & 17 & 1435.679 & 84.45172 & 26.81231 \\
Non-Sealed Cyclic 15LPM & 23 & 2013.158 & 87.5286 & 22.03907 \\
\hline
\end{tabular}

ANOVA

\begin{tabular}{|c|c|c|c|c|c|c|}
\hline Source of Variation & SS & $d f$ & MS & $F$ & P-value & F crit \\
\hline Between Groups & 92.54178 & 1 & 92.54178 & 3.848074 & 0.057159455 & 4.098172 \\
\hline Within Groups & 913.8565 & 38 & 24.04886 & & & \\
\hline Total & 1006.398 & 39 & & & & \\
\hline
\end{tabular}

\subsubsection{30 LPM flow rate}

Table 9 expresses that flow types have no significant effects on the total penetration for non-sealed, 30 LPM (Liter per minute) test $(\mathrm{P}=0.2696>0.05)$. This means we would fail to reject the null hypotheses. 
Table 9: Effects of flow types on total penetration for non-sealed respirator (30 LPM)

SUMMARY

\begin{tabular}{lrccc}
\hline \multicolumn{1}{c}{ Groups } & Count & Sum & Average & Variance \\
\hline Non-Sealed Constant 30LPM & 23 & 1805.991 & 78.52136 & 23.99074 \\
Non-Sealed Cyclic 30LPM & 13 & 1047.576 & 80.58281 & 35.40228 \\
\hline
\end{tabular}

ANOVA

\begin{tabular}{lcrcccc}
\hline \multicolumn{1}{c}{ Source of Variation } & SS & $d f$ & MS & $F$ & P-value & F crit \\
\hline Between Groups & 35.29506 & 1 & 35.29506 & 1.259713 & 0.269569221 & 4.130018 \\
Within Groups & 952.6236 & 34 & 28.01834 & & & \\
& & & & & & \\
Total & 987.9187 & 35 & & & & \\
\hline
\end{tabular}

\subsubsection{50 LPM flow rate}

Table 10 demonstrates that the flow types which are constant and cyclic have significant effects on total penetration for non-sealed, 50 LPM (Liter per minute) test $(\mathrm{P}=1.064 \mathrm{E}-06<0.05)$. This means we would reject the null hypotheses. The constant flow rate showed higher average percent than cyclic flow rate ( $71 \%$ vs. $57 \%$ ) when the comparison was made at 50 LPM.

Table 10: Effects of flow types on total penetration for non-sealed respirator (50 LPM)

SUMMARY

\begin{tabular}{lrccc}
\hline \multicolumn{1}{c}{ Groups } & Count & Sum & Average & Variance \\
\hline Non-Sealed Constant 5OLPM & 16 & 1133.824 & 70.86399 & 93.68719 \\
Non-Sealed Cyclic 50LPM & 23 & 1304.128 & 56.70122 & 29.74656 \\
\hline
\end{tabular}

ANOVA

\begin{tabular}{|c|c|c|c|c|c|c|}
\hline Source of Variation & SS & $d f$ & $M S$ & $F$ & P-value & F crit \\
\hline Between Groups & 1892.691 & 1 & 1892.691 & 33.99935 & 1.06394E-06 & 4.105456 \\
\hline Within Groups & 2059.732 & 37 & 55.66844 & & & \\
\hline Total & 3952.423 & 38 & & & & \\
\hline
\end{tabular}

\subsubsection{80 and 85 LPM flow rate}

Table 11 exhibits that flow types which are constant and cyclic have significant effects on total penetration for non-sealed, constant 80 and cyclic 85 LPM (Liter per minute) tests ( $\mathrm{P}=8.404 \mathrm{E}-$ $08<0.05)$. Therefore, we would reject the null hypotheses. 
Table 11: Effects of flow types on total penetration for non-sealed respirator ( 80 and 85 LPM)

SUMMARY

\begin{tabular}{lrrrr}
\multicolumn{1}{c}{ Groups } & Count & \multicolumn{1}{c}{ Sum } & Average & Variance \\
\hline Non-Sealed Constant 80LPM & 19 & 1384.7 & 72.87892 & 29.51294 \\
Non-Sealed Cyclic 85LPM & 12 & 651.3599 & 54.28 & 85.0889 \\
\hline
\end{tabular}

ANOVA

\begin{tabular}{|c|c|c|c|c|c|c|}
\hline Source of Variation & SS & $d f$ & $M S$ & $F$ & P-value & F crit \\
\hline Between Groups & 2544.187 & 1 & 2544.187 & 50.28685 & 8.40368E-08 & 4.182964 \\
\hline Within Groups & 1467.211 & 29 & 50.59348 & & & \\
\hline Total & 4011.397 & 30 & & & & \\
\hline
\end{tabular}

\subsubsection{Effects of Flow Types on Total Penetration for Only Nose Sealed Test Results}

\subsubsection{15 LPM flow rate}

Table 12 shows that flow types which are constant and cyclic have significant effects on total penetration for only nose sealed, 15 LPM (Liter per minute) test $(\mathrm{P}=5.7358 \mathrm{E}-08<0.05)$. This means we would reject the null hypotheses.

Table 12: Effects of flow types on total penetration for only nose sealed respirator (15 LPM)

Anova: Single Factor

SUMMARY

\begin{tabular}{lrrrr}
\hline \multicolumn{1}{c}{ Groups } & Count & Sum & Average & Variance \\
\hline Nose Sealed Constant 15LPM & 30 & 370.0767 & 12.33589 & 20.13738 \\
Nose Sealed Cyclic 15LPM & 31 & 570.3756 & 18.39921 & 9.099042 \\
\hline
\end{tabular}

ANOVA

\begin{tabular}{|c|c|c|c|c|c|c|}
\hline Source of Variation & SS & $d f$ & $M S$ & $F$ & P-value & F crit \\
\hline Between Groups & 560.4991 & 1 & 560.4991 & 38.58946 & $5.73581 E-08$ & 4.003983 \\
\hline Within Groups & 856.9554 & 59 & 14.52467 & & & \\
\hline Total & 1417.454 & 60 & & & & \\
\hline
\end{tabular}




\subsubsection{30 LPM flow rate}

Table 13 indicates constant and cyclic flow types which have significant effects on total penetration for non-sealed, 30 LPM (Liter per minute) test $(\mathrm{P}=0.0046<0.05)$. This means we could reject the null hypotheses.

Table 13: Effects of flow types on total penetration for only nose sealed respirator (30 LPM)

Anova: Single Factor

SUMMARY

\begin{tabular}{lrrrr}
\hline \multicolumn{1}{c}{ Groups } & Count & Sum & Average & Variance \\
\hline Nose Sealed Constant 30LPM & 25 & 83.31431 & 3.332572 & 5.831721 \\
Nose Sealed Cyclic 30LPM & 29 & 168.6055 & 5.813983 & 12.51619 \\
\hline
\end{tabular}

ANOVA

\begin{tabular}{|c|c|c|c|c|c|c|}
\hline Source of Variation & SS & $d f$ & $M S$ & $F$ & P-value & F crit \\
\hline Between Groups & 82.66879 & 1 & 82.66879 & 8.765595 & 0.004615995 & 4.026631 \\
\hline Within Groups & 490.4147 & 52 & 9.431052 & & & \\
\hline Total & 573.0835 & 53 & & & & \\
\hline
\end{tabular}

\subsubsection{50 LPM flow rate}

The comparison of penetration between constant and cyclic flow rates showed a statistically significant difference $(\mathrm{P}=0.00025<0.05)$, showing higher percent penetration for the cyclic flow rate than for the constant flow rate. This means we could reject the null hypotheses. 
Table 14: Effects of flow types on total penetration for only nose sealed respirator (50 LPM)

Anova: Single Factor

SUMMARY

\begin{tabular}{lrccc}
\hline \multicolumn{1}{c}{ Groups } & Count & Sum & Average & Variance \\
\hline Nose Sealed Constant 50LPM & 22 & 141.3255 & 6.423887 & 4.228294 \\
Nose Sealed Cyclic 50LPM & 30 & 287.5121 & 9.583738 & 10.99058 \\
\hline
\end{tabular}

ANOVA

\begin{tabular}{|c|c|c|c|c|c|c|}
\hline Source of Variation & SS & $d f$ & $M S$ & $F$ & P-value & F crit \\
\hline Between Groups & 126.7284 & 1 & 126.7284 & 15.5487 & 0.000250705 & 4.03431 \\
\hline Within Groups & 407.5209 & 50 & 8.150418 & & & \\
\hline Total & 534.2492 & 51 & & & & \\
\hline
\end{tabular}

\subsubsection{80 and 85 LPM flow rate}

The comparison of penetration between constant and cyclic flow rates showed a statistically significant difference $(\mathrm{P}=4.4425 \mathrm{E}-07<0.05)$, showing higher percent penetration for the constant flow rate than for the cyclic flow rate. This means we could reject the null hypotheses.

Table 15: Effects of flow types on total penetration for only nose sealed respirator ( 80 and 85 LPM)

Anova: Single Factor

SUMMARY

\begin{tabular}{lrrrr}
\hline \multicolumn{1}{c}{ Groups } & Count & \multicolumn{1}{c}{ Sum } & Average & Variance \\
\hline Nose Sealed Constant 80LPM & 18 & 156.891 & 8.716169 & 4.800371 \\
Nose Sealed Cyclic 85LPM & 25 & 104.2328 & 4.169312 & 6.894244 \\
\hline
\end{tabular}

ANOVA

\begin{tabular}{lcrcccc}
\hline \multicolumn{1}{c}{ Source of Variation } & SS & $d f$ & MS & $F$ & P-value & F crit \\
\hline Between Groups & 216.3548 & 1 & 216.3548 & 35.90324 & $4.4425 \mathrm{E}-07$ & 4.078546 \\
Within Groups & 247.0682 & 41 & 6.026053 & & & \\
& & & & & & \\
Total & 463.423 & 42 & & & & \\
\hline
\end{tabular}




\subsubsection{Effects of Flow Types on Total Penetration for Nose and Chin Sealed Test Results}

\subsubsection{15 LPM flow rate}

Table 16 demonstrates that the flow types which are constant and cyclic have significant effects on total penetration for nose and chin sealed test $(\mathrm{P}=2.2749 \mathrm{E}-07<0.05)$. For that reason, we could reject the null hypotheses.

Table 16: Effects of flow types on total penetration for nose and chin sealed respirator (15 LPM)

Anova: Single Factor

SUMMARY

\begin{tabular}{lrcrc}
\hline \multicolumn{1}{c}{ Groups } & Count & Sum & Average & Variance \\
\hline Nose \& Chin Sealed Constant 15LPM & 15 & 3.517796 & 0.23452 & 0.007307 \\
Nose \& Chin Sealed Cyclic 15LPM & 17 & 0.773729 & 0.045513 & 0.005661 \\
\hline
\end{tabular}

ANOVA

\begin{tabular}{|c|c|c|c|c|c|c|}
\hline Source of Variation & SS & $d f$ & MS & $F$ & $P$-value & F crit \\
\hline Between Groups & 0.284671 & 1 & 0.284671 & 44.28105 & $2.27489 \mathrm{E}-07$ & 4.170877 \\
\hline Within Groups & 0.192862 & 30 & 0.006429 & & & \\
\hline Total & 0.477532 & 31 & & & & \\
\hline
\end{tabular}

\subsubsection{30 LPM flow rate}

As shown in Table 17, flow rates (constant and cyclic) have significant effects on total penetration for nose and chin sealed test $(\mathrm{P}=2.44 \mathrm{E}-08<0.05)$. When compared at $30 \mathrm{LPM}$, the constant flow rate showed higher average percent than the cyclic flow rate $(0.3 \%$ vs. $0.03 \%)$. This means we could reject the null hypotheses. 
Table 17: Effects of flow types on total penetration for nose and chin sealed respirator ( 30 LPM)

Anova: Single Factor

SUMMARY

\begin{tabular}{lrrrr}
\hline \multicolumn{1}{c}{ Groups } & Count & \multicolumn{1}{c}{ Sum } & Average & Variance \\
\hline Nose \& Chin Sealed Constant 30LPM & 16 & 5.227252 & 0.326703 & 0.020731 \\
Nose \& Chin Sealed Cyclic 30LPM & 15 & 0.541504 & 0.0361 & 0.001459 \\
\hline
\end{tabular}

ANOVA

\begin{tabular}{|c|c|c|c|c|c|c|}
\hline Source of Variation & SS & $d f$ & $M S$ & $F$ & P-value & F crit \\
\hline Between Groups & 0.653807 & 1 & 0.653807 & 57.2132 & $2.44421 \mathrm{E}-08$ & 4.182964 \\
\hline Within Groups & 0.331399 & 29 & 0.011428 & & & \\
\hline Total & 0.985206 & 30 & & & & \\
\hline
\end{tabular}

\subsubsection{50 LPM flow rate}

Table 18 shows that flow rates which are constant and cyclic, have significant effects on total penetration for nose and chin sealed test $(\mathrm{P}=3.99 \mathrm{E}-09<0.05)$, which means we could reject the null hypotheses for this type of test.

Table 18: Effects of flow types on total penetration for nose and chin sealed respirator (50 LPM)

Anova: Single Factor

SUMMARY

\begin{tabular}{lrrrr}
\hline \multicolumn{1}{c}{ Groups } & Count & \multicolumn{1}{c}{ Sum } & Average & Variance \\
\hline Nose \& Chin Sealed Constant 50LPM & 17 & 6.06427 & 0.356722 & 0.021718 \\
Nose \& Chin Sealed Cyclic 50LPM & 16 & 0.896846 & 0.056053 & 0.000416 \\
\hline
\end{tabular}

ANOVA

\begin{tabular}{|c|c|c|c|c|c|c|}
\hline Source of Variation & SS & $d f$ & $M S$ & $F$ & P-value & F crit \\
\hline Between Groups & 0.74513 & 1 & 0.74513 & 65.30096 & 3.98928E-09 & 4.159615 \\
\hline Within Groups & 0.353732 & 31 & 0.011411 & & & \\
\hline Total & 1.098862 & 32 & & & & \\
\hline
\end{tabular}




\subsubsection{80 and 85 LPM flow rates}

As seen in Table 19, constant and cyclic flow rates have significant effects on total penetration for nose and chin sealed test when compared at 80 and 85 LPM $(\mathrm{P}=1.15 \mathrm{E}-10<0.05)$. This means we could reject the null hypotheses.

Table 19: Effects of flow types on total penetration for nose and chin sealed respirator (80 and 85 LPM)

Anova: Single Factor

SUMMARY

\begin{tabular}{lrccc}
\hline \multicolumn{1}{c}{ Groups } & Count & Sum & Average & Variance \\
\hline Nose \& Chin Sealed Constant 80LPM & 15 & 10.53305 & 0.702203 & 0.032281 \\
Nose \& Chin Sealed Cyclic 85LPM & 13 & 2.208736 & 0.169903 & 0.002669 \\
\hline
\end{tabular}

ANOVA

\begin{tabular}{lcrcccc}
\hline \multicolumn{1}{c}{ Source of Variation } & SS & $d f$ & MS & $F$ & P-value & Fcrit \\
\hline Between Groups & 1.973286 & 1 & 1.973286 & 106.011 & $1.15053 \mathrm{E}-10$ & 4.225201 \\
Within Groups & 0.483963 & 26 & 0.018614 & & & \\
& & & & & & \\
Total & 2.457249 & 27 & & & & \\
\hline
\end{tabular}

\subsubsection{Effects of Flow Types on Total Penetration for Fully Sealed Test Results}

\subsubsection{15 LPM flow rate}

Table 20 demonstrates that $\mathrm{P}$ value is lower than alpha $(\mathrm{P}=0.00020<0.05)$ for fully sealed test. Cyclic flow rate shows a higher average percent than constant flow rate $(0.7 \%$ vs. $0.07 \%)$ when compared at 15 LPM. This means we could reject the null hypotheses. 
Table 20: Effects of flow types on total penetration for fully sealed respirator (15 LPM)

Anova: Single Factor

SUMMARY

\begin{tabular}{lrccr}
\hline \multicolumn{1}{c}{ Groups } & Count & Sum & Average & Variance \\
\hline Fully-Sealed Constant 15LPM & 18 & 0.072257 & 0.004014 & $1 \mathrm{E}-05$ \\
Fully-Sealed Cyclic 15LPM & 27 & 0.773483 & 0.028648 & 0.000652 \\
\hline
\end{tabular}

ANOVA

\begin{tabular}{|c|c|c|c|c|c|c|}
\hline Source of Variation & SS & $d f$ & $M S$ & $F$ & P-value & F crit \\
\hline Between Groups & 0.006553 & 1 & 0.006553 & 16.46124 & 0.000205445 & 4.067047 \\
\hline Within Groups & 0.017119 & 43 & 0.000398 & & & \\
\hline Total & 0.023672 & 44 & & & & \\
\hline
\end{tabular}

\subsubsection{30 LPM flow rate}

Table 21 shows that flow rates have significant effects on total penetration for fully sealed test $(\mathrm{P}=6.36 \mathrm{E}-16<0.05)$. The cyclic flow rate shows a higher average percent than the constant flow rate $(0.7 \%$ vs. $0.01 \%)$ when comparison was made at $30 \mathrm{LPM}$, which means we could reject the null hypotheses.

Table 21: Effects of flow types on total penetration for fully sealed respirator (30 LPM)

Anova: Single Factor

SUMMARY

\begin{tabular}{lrccc}
\hline \multicolumn{1}{c}{ Groups } & Count & Sum & Average & Variance \\
\hline Fully-Sealed Constant 30LPM & 16 & 0.016973 & 0.001061 & $5.05 \mathrm{E}-07$ \\
Fully-Sealed Cyclic 30LPM & 24 & 0.771205 & 0.032134 & $8.56 \mathrm{E}-05$ \\
\hline
\end{tabular}

ANOVA

\begin{tabular}{|c|c|c|c|c|c|c|}
\hline Source of Variation & SS & $d f$ & $M S$ & $F$ & P-value & F crit \\
\hline Between Groups & 0.009269 & 1 & 0.009269 & 178.1815 & $6.35651 \mathrm{E}-16$ & 4.098172 \\
\hline Within Groups & 0.001977 & 38 & $5.2 \mathrm{E}-05$ & & & \\
\hline Total & 0.011246 & 39 & & & & \\
\hline
\end{tabular}




\subsubsection{50 LPM flow rate}

Table 22 demonstrates that flow rates (constant and cyclic) have significant effects on total penetration for fully sealed test when compared at 50 LPM $(\mathrm{P}=6.035 \mathrm{E}-13<0.05)$. This means we could reject the null hypotheses.

Table 22: Effects of flow types on total penetration for fully sealed respirator (50 LPM)

Anova: Single Factor

SUMMARY

\begin{tabular}{lrrrr}
\hline \multicolumn{1}{c}{ Groups } & Count & \multicolumn{1}{c}{ Sum } & Average & Variance \\
\hline Fully-Sealed Constant 50LPM & 14 & 0.054461 & 0.00389 & $5.69 \mathrm{E}-05$ \\
Fully-Sealed Cyclic 50LPM & 24 & 0.71823 & 0.029926 & $4.69 \mathrm{E}-05$ \\
\hline
\end{tabular}

ANOVA

\begin{tabular}{lcrrrrr}
\hline \multicolumn{1}{c}{ Source of Variation } & SS & $d f$ & MS & $F$ & P-value & F crit \\
\hline Between Groups & 0.005994 & 1 & 0.005994 & 118.6377 & $6.03506 \mathrm{E}-13$ & 4.113165 \\
Within Groups & 0.001819 & 36 & $5.05 \mathrm{E}-05$ & & & \\
& & & & & & \\
Total & 0.007813 & 37 & & & \\
\hline
\end{tabular}

\subsubsection{80 and 85 LPM flow rate}

As seen in Table 23, flow rates (constant and cyclic) have significant effects on total penetration for fully sealed test when compared at 80 and $85 \mathrm{LPM}(\mathrm{P}=0.0100<0.05)$. The constant flow rate shows a higher average percent than the cyclic flow rate $(0.003 \%$ vs. $0.02 \%)$. That means we could reject the null hypotheses. 
Table 23: Effects of flow types on total penetration for fully sealed respirator ( 80 and 85 LPM)

Anova: Single Factor

SUMMARY

\begin{tabular}{lrccc}
\hline \multicolumn{1}{c}{ Groups } & Count & Sum & Average & Variance \\
\hline Fully-Sealed Constant 80LPM & 12 & 0.035493 & 0.002958 & $3.23 \mathrm{E}-06$ \\
Fully-Sealed Cyclic 85LPM & 20 & 0.462988 & 0.023149 & 0.000637 \\
\hline
\end{tabular}

ANOVA

\begin{tabular}{|c|c|c|c|c|c|c|}
\hline Source of Variation & SS & $d f$ & $M S$ & $F$ & P-value & F crit \\
\hline Between Groups & 0.003058 & & 10.003058 & 7.557851 & 0.010020427 & 4.170877 \\
\hline Within Groups & 0.012138 & & 300.000405 & & & \\
\hline Total & 0.015195 & & 31 & & & \\
\hline
\end{tabular}




\section{Chapter 5: Conclusion}

The purpose of this study was to evaluate ultrafine cigarette smoke penetration through a 3M 6200 elastomeric half mask respirators with P-100 filters. P-Trak particle counter was utilized to measure number of smoke particles from measurement terminals. In order to investigate our null hypothesis, several testing conditions were planned and applied on the breathing manikin. Statistical tests were performed using One-way ANOVA to determine the most significant variable that affects smoke particle penetration through the half mask respirator.

The statistical test results revealed that overall sealing conditions, flow types, and flow rates have significant effects on cigarette smoke penetration through the half mask respirator. When the penetration was compared between the constant and cyclic flow rates for the non-sealed respirator, no statistically significant differences were detected for 15 and 30 LPM, while other flow rates showed significant differences.

Cigarette smoke penetration through the elastomeric half mask respirator were measured unexpectedly higher percentages. Those exceeded penetration percentages might be observed due to loose fitting of half mask or breathing manikin's hard plastic materials itself. Breathing manikin's head was made of hard plastic which could not represent real human being skin features. Hard plastic production materials might utilize tiny gaps between half mask and plastic material. Therefore, penetration percentages could have been measured relatively higher even for fully sealed tests.

Regardless of these limitations, 3M 6200 half mask respirator with double P-100 filters should have a capability of capturing ultrafine cigarette smoke particles successfully to protect employees from adverse health consequences of ultrafine smoke particles. 
In conclusion, cigarette smoke particle penetration through 3M 6200 half mask respirator measured higher than the acceptable threshold value of $0.03 \%$. Especially, a fully sealed respirator testing at 30 LPM showed penetration of $0.032 \%>0.03 \%$ (acceptable penetration percent). However, based on our test results, smoke penetration percentages were measured higher than the threshold value even in the partially sealed and fully sealed testing conditions. 


\section{References}

Xinjian He, Michael Yermakov, Tiina Reponen, Roy T. McKay, Kelley James \& Sergey A. Grinshpun (2013) Laboratory Evaluation of the Particle Size Effect on the Performance of an Elastomeric Half-mask Respirator against Ultrafine Combustion Particles, Ann. Occup. Hyg., Vol. 57, No. 7, pp. 884-897, 2013 () The Author 2013. Published by Oxford University Press on behalf of the British Occupational Hygiene Society doi:10.1093/annhyg/met014

Xinjian He, Michael Yermakov, Tiina Reponen, Roy T. McKay, Kelley James \& Sergey A. Grinshpun (2013) Manikin-Based Performance Evaluation of Elastomeric Respirators Against Combustion Particles, Journal of Occupational and Environmental Hygiene, 10:4, 203-212, DOI: 10.1080/15459624.2012.760063

Perfetti T.A. and Rodgman A. (2008). The Chemical Components of Tobacco and Tobacco Smoke, CRC Press, USA.

Diapouli, E., Eleftheriadis, K., Angeliki, A.K., Vratolis, S., Hermansen, O., Colbeck, I. and Lazaridis, M. (2011). Indoor and Outdoor Particle Number and Mass Concentrations in Athens. Sources, Sinks and Variability of Aerosol Parameters Aerosol Air Qual. Res. 11: 632- 642. Retrieved from http://aerosol.ieexa.cas.cn/aaqrkw/kwlwqj/201207/W020120801400712711494.pdf 
Baker, R.R. (1999). Smoke Chemistry, In Tobacco Production, Chemistry and Technology, D. Layten Davis \& Mark T. Nielsen. (Eds.), Blackwell Science Ltd., Oxford, p. 398-439.

Baker, R.R. and Dixon, M. (2006). The Retention of Tobacco Smoke Constituents in the Human Respiratory Tract. Inhal. Toxicol. 18: 255-294. Retrieved from https://www.tandfonline.com/doi/full/10.1080/08958370500444163

Wang, B., Ho, S.S.H., Ho, K.F., Huang, Y., Chan, C.S., Feng, N.S.Y. and Ip, S.H.S. (2012). An Environmental Chamber Study of the Characteristics of Air Pollutants Released from Environmental Tobacco Smoke. Aerosol Air Qual. Res. 12: 1269-1281.

Retrieved from https://www.researchgate.net/publication/233965766_An_Environmental_Chamber_Stu dy_of_the_Characteristics_of_Air_Pollutants_Released_from_Environmental_Tobacco_ Smoke

Sahu, S.K., Tiwari, M., Bhangare, G.G., Pandit (2013). Particle Size Distribution of Mainstream and Exhaled Cigarette and Predictive Deposition in Human Respiratory Tract. Aerosol and Air Quality Research, 13: 324-332. Retrieved from http://www.aaqr.org/files/article/797/31_AAQR-12-02-OA-0041_324-332.pdf

Rengasamy S, Eimer BC. (2011) Total inward leakage of nanoparticles through filtering facepiece respirators. Ann Occup Hyg; 55: 253-63. 
Myers, W.R., H. Kim, and N. Kadrichu: Effect of particle size on assessment offaceseal leakage. J. Int. Soc. Resp. Prot. 9 (3):6-21(1991).

Qian, Y., K. Willeke, S.A. Grinshpun, J. Donnelly, and C.C. Coffey: PerformanceofN95respirators:Filtrationefficiencyforairborne microbial and inert particles. Am. Ind. Hyg. Assoc. J. 59 (2):128-132 (1998).

Van Dijk, W. D., Gopal, S., \& Scheepers, P. T. (2011). Nanoparticles in cigarette smoke; realtime undiluted measurements by a scanning mobility particle sizer. Analytical and bioanalytical chemistry, 399(10), 3573-3578. doi:10.1007/s00216-011-4701-4

Xiang Li, Haohui Kong, Xinying Zhang, Bin Peng, Cong Nie, Guanglin Shen, Huimin Liu, Characterization of particle size distribution of mainstream cigarette smoke generated by smoking machine with an electrical low pressure impactor, Journal of Environmental Sciences, Volume 26, Issue 4,2014,Pages 827-833, ISSN 1001-0742, https://doi.org/10.1016/S1001-0742(13)60472-6. (http://www.sciencedirect.com/science/article/pii/S1001074213604726)

TSI. (2012). P-Trak Ultrafine Particle Counter Theory of Operation. Retrieved from https://www.tsi.com/getmedia/86507a08-210f-4708-9991-b3c6cca9c2c1/ITI-071-AppNote-A4?ext=.pdf 
TSI Incorporated. (2013). P-Trak Ultrafine Particle Counter Model 8525 Operation and Service Manual. Retrieved from

https://www.tsi.com/getmedia/d1f26f38-5f1d-4851-80a2-b99d95c7c9c8/Model-8525-P-

$\underline{\text { Trak-Op_Svc_Mnl_1980380?ext=.pdf }}$ 


\section{Appendix A:}

\begin{tabular}{|c|c|c|c|c|c|c|c|c|c|}
\hline \multicolumn{4}{|c|}{ Non sealed-TEST1 } & \multicolumn{3}{|c|}{ Non sealed-TEST2 } & \multicolumn{3}{|c|}{ Non sealed-TEST3 } \\
\hline \multicolumn{4}{|c|}{ Constant flow rate $: 15 \mathrm{~L} / \mathrm{min}$} & \multicolumn{3}{|c|}{ Constant flow rate $: 15 \mathrm{~L} / \mathrm{min}$} & \multicolumn{3}{|c|}{ Constant flow rate $: 15 \mathrm{~L} / \mathrm{min}$} \\
\hline $\begin{array}{l}\text { Sam } \\
\text { ple }\end{array}$ & $\begin{array}{l}\text { Inside } \\
\text { (pt/cc) }\end{array}$ & $\begin{array}{l}\text { Outside } \\
\text { (pt/cc) }\end{array}$ & $\begin{array}{l}P(\text { Cin/C } \\
\text { out)\% }\end{array}$ & $\begin{array}{l}\text { Inside } \\
\text { (pt/cc) }\end{array}$ & $\begin{array}{l}\text { Outside } \\
\text { (pt/cc) }\end{array}$ & $\begin{array}{c}\mathrm{P}(\mathrm{Cin} / \mathrm{C} \\
\text { out }) \%\end{array}$ & $\begin{array}{l}\text { Inside } \\
\text { (pt/cc) }\end{array}$ & $\begin{array}{l}\text { Outside } \\
\text { (pt/cc) }\end{array}$ & $\begin{array}{c}P(\operatorname{Cin} / C \\
\text { out }) \%\end{array}$ \\
\hline 1 & 405995 & 450730 & 90.1 & 385408 & 446177 & 86.4 & 383826 & 468942 & 81.8 \\
\hline 2 & 434988 & 447975 & 97.1 & 374079 & 408356 & 91.6 & 392879 & 488253 & 80.5 \\
\hline 3 & 413660 & 472225 & 87.6 & 447284 & 476854 & 93.8 & 437456 & 439818 & 99.5 \\
\hline 4 & 346683 & 471876 & 73.5 & 394318 & 481039 & 82.0 & 381337 & 421483 & 90.5 \\
\hline 5 & 291159 & 360480 & 80.8 & 295875 & 386765 & 76.5 & 270369 & 379255 & 71.3 \\
\hline 6 & 219093 & 306037 & 71.6 & 224933 & 280295 & 80.2 & 239953 & 271716 & 88.3 \\
\hline 7 & 213578 & 232701 & 91.8 & 188906 & 225577 & 83.7 & 189325 & 254072 & 74.5 \\
\hline 8 & 160034 & 225791 & 70.9 & 195670 & 221609 & 88.3 & 179797 & 193835 & 92.8 \\
\hline 9 & 139878 & 218991 & 63.9 & 186367 & 217000 & 85.9 & 161258 & 182564 & 88.3 \\
\hline 10 & 151382 & 168862 & 89.6 & 175456 & 199401 & 88.0 & 143315 & 170659 & 84.0 \\
\hline 11 & 152621 & 172890 & 88.3 & 132903 & 152621 & 87.1 & 127404 & 197905 & 64.4 \\
\hline 12 & 141197 & 144357 & 97.8 & 147273 & 150190 & 98.1 & 136113 & 142900 & 95.3 \\
\hline 13 & 115462 & 147867 & 78.1 & 122786 & 146432 & 83.9 & 118476 & 136383 & 86.9 \\
\hline 14 & 96880 & 141240 & 68.6 & 118927 & 141240 & 84.2 & 113428 & 113520 & 99.9 \\
\hline 15 & 93536 & 117434 & 79.6 & 115801 & 136804 & 84.6 & 94118 & 108960 & 86.4 \\
\hline 16 & 106132 & 106418 & 99.7 & 84956 & 100876 & 84.2 & 84042 & 125264 & 67.1 \\
\hline 17 & 85010 & 105767 & 80.4 & 79059 & 93794 & 84.3 & 83461 & 99781 & 83.6 \\
\hline \multicolumn{4}{|c|}{ Non sealed-TEST1 } & \multicolumn{3}{|c|}{ Non sealed-TEST2 } & \multicolumn{3}{|c|}{ Non sealed-TEST3 } \\
\hline \multicolumn{4}{|c|}{ Constant flow rate: $30 \mathrm{~L} / \mathrm{min}$} & \multicolumn{3}{|c|}{ Constant flow rate: $30 \mathrm{~L} / \mathrm{min}$} & \multicolumn{3}{|c|}{ Constant flow rate: $30 \mathrm{~L} / \mathrm{min}$} \\
\hline $\begin{array}{l}\text { Sam } \\
\text { ple }\end{array}$ & $\begin{array}{l}\text { Inside } \\
\text { (pt/cc) }\end{array}$ & $\begin{array}{c}\text { Outside } \\
\text { (pt/cc) }\end{array}$ & $\begin{array}{c}\mathrm{P}(\mathrm{Cin} / \mathrm{C} \\
\text { out }) \%\end{array}$ & $\begin{array}{l}\text { Inside } \\
\text { (pt/cc) }\end{array}$ & $\begin{array}{l}\text { Outside } \\
\text { (pt/cc) }\end{array}$ & $\begin{array}{c}\mathrm{P}(\mathrm{Cin} / \mathrm{C} \\
\text { out }) \%\end{array}$ & $\begin{array}{l}\text { Inside } \\
\text { (pt/cc) }\end{array}$ & $\begin{array}{l}\text { Outside } \\
\text { (pt/cc) }\end{array}$ & $\begin{array}{c}P(\mathrm{Cin} / \mathrm{C} \\
\text { out }) \%\end{array}$ \\
\hline 1 & 431019 & 478989 & 90.0 & 425691 & 474151 & 89.8 & 441834 & 498343 & 88.7 \\
\hline 2 & 361885 & 466676 & 77.5 & 349884 & 452390 & 77.3 & 388391 & 509534 & 76.2 \\
\hline 3 & 275952 & 406164 & 67.9 & 285676 & 422092 & 67.7 & 242644 & 366344 & 66.2 \\
\hline 4 & 212495 & 281069 & 75.6 & 223728 & 297442 & 75.2 & 175414 & 240138 & 73.0 \\
\hline 5 & 173284 & 204895 & 84.6 & 198969 & 236910 & 84.0 & 161447 & 198493 & 81.3 \\
\hline 6 & 185127 & 205475 & 90.1 & 156818 & 174750 & 89.7 & 170094 & 195874 & 86.8 \\
\hline 7 & 159778 & 183341 & 87.1 & 166802 & 192695 & 86.6 & 154884 & 185213 & 83.6 \\
\hline 8 & 161416 & 194039 & 83.2 & 151587 & 183259 & 82.7 & 128431 & 161700 & 79.4 \\
\hline 9 & 149115 & 182914 & 81.5 & 144117 & 177926 & 81.0 & 106629 & 138018 & 77.3 \\
\hline 10 & 113255 & 141314 & 80.1 & 134642 & 169878 & 79.3 & 105578 & 139812 & 75.5 \\
\hline 11 & 101006 & 124822 & 80.9 & 100006 & 124822 & 80.1 & 123734 & 161859 & 76.4 \\
\hline 12 & 102102 & 124382 & 82.1 & 96072 & 118100 & 81.3 & 103652 & 134434 & 77.1 \\
\hline 13 & 91906 & 119702 & 76.8 & 91774 & 120864 & 75.9 & 76726 & 108081 & 71.0 \\
\hline 14 & 86245 & 108156 & 79.7 & 83680 & 106135 & 78.8 & 64875 & 88952 & 72.9 \\
\hline
\end{tabular}




\begin{tabular}{|c|c|c|c|c|c|c|c|c|c|}
\hline 15 & 69052 & 86526 & 79.8 & 71483 & 90987 & 78.6 & 65298 & 90096 & 72.5 \\
\hline 16 & 61570 & 77108 & 79.8 & 67339 & 85943 & 78.4 & 55687 & 77912 & 71.5 \\
\hline 17 & 62100 & 75591 & 82.2 & 59413 & 73452 & 80.9 & 47167 & 64895 & 72.7 \\
\hline 18 & 51530 & 65580 & 78.6 & 50039 & 64924 & 77.1 & 45521 & 66236 & 68.7 \\
\hline 19 & 46894 & 58298 & 80.4 & 48160 & 61272 & 78.6 & 40848 & 58894 & 69.4 \\
\hline 20 & 40731 & 50197 & 81.1 & 46380 & 58928 & 78.7 & 37556 & 54563 & 68.8 \\
\hline 21 & 41564 & 51508 & 80.7 & 45495 & 58009 & 78.4 & 26721 & 40507 & 66.0 \\
\hline 22 & 39040 & 47150 & 82.8 & 41172 & 51191 & 80.4 & 24188 & 36374 & 66.5 \\
\hline 23 & 34874 & 41810 & 83.4 & 30103 & 36939 & 81.5 & 29318 & 43029 & 68.1 \\
\hline \multicolumn{4}{|c|}{ Non Sealed-TEST1 } & \multicolumn{3}{|c|}{ Non Sealed-TEST2 } & \multicolumn{3}{|c|}{ Non Sealed-TEST3 } \\
\hline \multicolumn{4}{|c|}{ Constant flow rate:50L/min } & \multicolumn{3}{|c|}{ Constant flow rate:50L/min } & \multicolumn{3}{|c|}{ Constant flow rate:50L/min } \\
\hline $\begin{array}{l}\text { Sam } \\
\text { ple }\end{array}$ & $\begin{array}{l}\text { Inside } \\
\text { (pt/cc) }\end{array}$ & $\begin{array}{l}\text { Outside } \\
\text { (pt/cc) }\end{array}$ & $\begin{array}{l}\mathrm{P}(\mathrm{Cin} / \mathrm{C} \\
\text { out)\% }\end{array}$ & $\begin{array}{l}\text { Inside } \\
\text { (pt/cc) }\end{array}$ & $\begin{array}{l}\text { Outside } \\
\text { (pt/cc) }\end{array}$ & $\begin{array}{c}\mathrm{P}(\mathrm{Cin} / \mathrm{C} \\
\text { out }) \%\end{array}$ & $\begin{array}{l}\text { Inside } \\
\text { (pt/cc) }\end{array}$ & $\begin{array}{l}\text { Outside } \\
\text { (pt/cc) }\end{array}$ & $\begin{array}{c}P(\operatorname{Cin} / C \\
\text { out }) \%\end{array}$ \\
\hline 1 & 310523 & 400900 & 77.5 & 306412 & 396851 & 77.2 & 316470 & 417099 & 75.9 \\
\hline 2 & 306140 & 423262 & 72.3 & 295845 & 410305 & 72.1 & 327526 & 462133 & 70.9 \\
\hline 3 & 266559 & 428400 & 62.2 & 275914 & 445200 & 62.0 & 234172 & 386400 & 60.6 \\
\hline 4 & 211101 & 330182 & 63.9 & 222253 & 349416 & 63.6 & 174223 & 282099 & 61.8 \\
\hline 5 & 182886 & 234351 & 78.0 & 210072 & 270968 & 77.5 & 170750 & 227028 & 75.2 \\
\hline 6 & 181525 & 227142 & 79.9 & 153755 & 193177 & 79.6 & 166661 & 216529 & 77.0 \\
\hline 7 & 144484 & 191243 & 75.5 & 150728 & 201000 & 75.0 & 139434 & 193195 & 72.2 \\
\hline 8 & 137107 & 192715 & 71.1 & 128629 & 182008 & 70.7 & 108174 & 160596 & 67.4 \\
\hline 9 & 120218 & 176166 & 68.2 & 116008 & 171361 & 67.7 & 84825 & 132926 & 63.8 \\
\hline 10 & 91220 & 133449 & 68.4 & 108153 & 160423 & 67.4 & 83778 & 132031 & 63.5 \\
\hline 11 & 70644 & 111495 & 63.4 & 69644 & 111495 & 62.5 & 84364 & 144578 & 58.4 \\
\hline 12 & 67355 & 115285 & 58.4 & 63080 & 109463 & 57.6 & 66097 & 124602 & 53.0 \\
\hline 13 & 69976 & 102805 & 68.1 & 69631 & 103803 & 67.1 & 56926 & 92825 & 61.3 \\
\hline 14 & 62224 & 86671 & 71.8 & 60107 & 85051 & 70.7 & 45119 & 71281 & 63.3 \\
\hline 15 & 73434 & 73446 & 100.0 & 76172 & 77232 & 98.6 & 69941 & 76476 & 91.5 \\
\hline 16 & 50546 & 60559 & 83.5 & 55051 & 67498 & 81.6 & 44547 & 61191 & 72.8 \\
\hline \multicolumn{4}{|c|}{ Non Sealed-TEST1 } & \multicolumn{3}{|c|}{ Non Sealed-TEST2 } & \multicolumn{3}{|c|}{ Non Sealed-TEST3 } \\
\hline \multicolumn{4}{|c|}{ Constant flow rate: $80 \mathrm{~L} / \mathrm{min}$} & \multicolumn{3}{|c|}{ Constant flow rate: $80 \mathrm{~L} / \mathrm{min}$} & \multicolumn{3}{|c|}{ Constant flow rate: $80 \mathrm{~L} / \mathrm{min}$} \\
\hline $\begin{array}{l}\text { Sam } \\
\text { ple }\end{array}$ & $\begin{array}{l}\text { Inside } \\
\text { (pt/cc) }\end{array}$ & $\begin{array}{l}\text { Outside } \\
\text { (pt/cc) }\end{array}$ & $\begin{array}{c}\mathrm{P}(\text { Cin } / \mathrm{C} \\
\text { out }) \%\end{array}$ & $\begin{array}{l}\text { Inside } \\
\text { (pt/cc) }\end{array}$ & $\begin{array}{l}\text { Outside } \\
\text { (pt/cc) }\end{array}$ & $\begin{array}{c}\mathrm{P}(\mathrm{Cin} / \mathrm{C} \\
\text { out }) \%\end{array}$ & $\begin{array}{l}\text { Inside } \\
\text { (pt/cc) }\end{array}$ & $\begin{array}{l}\text { Outside } \\
\text { (pt/cc) }\end{array}$ & $\begin{array}{c}P(\operatorname{Cin} / C \\
\text { out }) \%\end{array}$ \\
\hline 1 & 315916 & 428042 & 73.8 & 311750 & 423718 & 73.6 & 322080 & 445337 & 72.3 \\
\hline 2 & 321599 & 411259 & 78.2 & 310831 & 398670 & 78.0 & 344405 & 449029 & 76.7 \\
\hline 3 & 312261 & 439398 & 71.1 & 323409 & 456629 & 70.8 & 275393 & 396321 & 69.5 \\
\hline 4 & 300979 & 437029 & 68.9 & 317366 & 462487 & 68.6 & 251012 & 373384 & 67.2 \\
\hline 5 & 314255 & 400320 & 78.5 & 361966 & 462870 & 78.2 & 298013 & 387810 & 76.8 \\
\hline 6 & 295230 & 402943 & 73.3 & 250457 & 342690 & 73.1 & 275052 & 384115 & 71.6 \\
\hline 7 & 201189 & 273680 & 73.5 & 210326 & 287643 & 73.1 & 196717 & 276474 & 71.2 \\
\hline 8 & 185617 & 221025 & 84.0 & 174444 & 208746 & 83.6 & 148598 & 184188 & 80.7 \\
\hline
\end{tabular}




\begin{tabular}{|c|c|c|c|c|c|c|c|c|c|}
\hline 9 & 166013 & 191962 & 86.5 & 160554 & 186726 & 86.0 & 119379 & 144845 & 82.4 \\
\hline 10 & 123343 & 153431 & 80.4 & 146769 & 184444 & 79.6 & 115559 & 151800 & 76.1 \\
\hline 11 & 101695 & 134876 & 75.4 & 100695 & 134876 & 74.7 & 124628 & 174895 & 71.3 \\
\hline 12 & 95686 & 125310 & 76.4 & 89980 & 118981 & 75.6 & 96717 & 135437 & 71.4 \\
\hline 13 & 79677 & 115702 & 68.9 & 79427 & 116826 & 68.0 & 65685 & 104470 & 62.9 \\
\hline 14 & 71176 & 101396 & 70.2 & 68893 & 99501 & 69.2 & 52482 & 83392 & 62.9 \\
\hline 15 & 55269 & 74607 & 74.1 & 56990 & 78453 & 72.6 & 50947 & 77685 & 65.6 \\
\hline 16 & 46581 & 62228 & 74.9 & 50632 & 69358 & 73.0 & 40541 & 62877 & 64.5 \\
\hline 17 & 42747 & 60679 & 70.4 & 40608 & 58962 & 68.9 & 30552 & 52093 & 58.6 \\
\hline 18 & 34430 & 47615 & 72.3 & 33110 & 47138 & 70.2 & 28250 & 48092 & 58.7 \\
\hline 19 & 30369 & 40523 & 74.9 & 30791 & 42590 & 72.3 & 24154 & 40937 & 59.0 \\
\hline \multicolumn{4}{|c|}{ Non sealed-TEST1 } & \multicolumn{3}{|c|}{ Non sealed-TEST2 } & \multicolumn{3}{|c|}{ Non sealed-TEST3 } \\
\hline \multicolumn{4}{|c|}{ Cyclic flow rate: $15 \mathrm{~L} / \mathrm{min}$} & \multicolumn{3}{|c|}{ Cyclic flow rate: $15 \mathrm{~L} / \mathrm{min}$} & \multicolumn{3}{|c|}{ Cyclic flow rate: $15 \mathrm{~L} / \mathrm{min}$} \\
\hline $\begin{array}{l}\text { Sam } \\
\text { ple }\end{array}$ & $\begin{array}{l}\text { Inside } \\
\text { (pt/cc) }\end{array}$ & $\begin{array}{l}\text { Outside } \\
\text { (pt/cc) }\end{array}$ & $\begin{array}{c}\mathrm{P}(\mathrm{Cin} / \mathrm{C} \\
\text { out }) \%\end{array}$ & $\begin{array}{l}\text { Inside } \\
\text { (pt/cc) }\end{array}$ & $\begin{array}{l}\text { Outside } \\
\text { (pt/cc) }\end{array}$ & $\begin{array}{c}\mathrm{P}(\mathrm{Cin} / \mathrm{C} \\
\text { out }) \%\end{array}$ & $\begin{array}{l}\text { Inside } \\
\text { (pt/cc) }\end{array}$ & $\begin{array}{l}\text { Outside } \\
\text { (pt/cc) }\end{array}$ & $\begin{array}{c}P(\operatorname{Cin} / C \\
\text { out }) \%\end{array}$ \\
\hline 1 & 328490 & 381858 & 86.0 & 360418 & 420430 & 85.7 & 298941 & 354859 & 84.2 \\
\hline 2 & 267801 & 291501 & 91.9 & 301994 & 330170 & 91.5 & 242352 & 270681 & 89.5 \\
\hline 3 & 257278 & 262571 & 98.0 & 228802 & 234254 & 97.7 & 263268 & 275443 & 95.6 \\
\hline 4 & 248876 & 251106 & 99.1 & 247876 & 251106 & 98.7 & 220848 & 229166 & 96.4 \\
\hline 5 & 212771 & 224871 & 94.6 & 224913 & 238925 & 94.1 & 219414 & 238926 & 91.8 \\
\hline 6 & 216196 & 232806 & 92.9 & 215196 & 232806 & 92.4 & 167756 & 187116 & 89.7 \\
\hline 7 & 177067 & 195118 & 90.7 & 202786 & 224983 & 90.1 & 154536 & 177199 & 87.2 \\
\hline 8 & 173202 & 194238 & 89.2 & 145332 & 163663 & 88.8 & 155639 & 181649 & 85.7 \\
\hline 9 & 150860 & 176921 & 85.3 & 128280 & 151187 & 84.8 & 125479 & 154405 & 81.3 \\
\hline 10 & 121265 & 138549 & 87.5 & 132899 & 153288 & 86.7 & 124873 & 150341 & 83.1 \\
\hline 11 & 108120 & 122704 & 88.1 & 123369 & 141582 & 87.1 & 116709 & 140234 & 83.2 \\
\hline 12 & 102822 & 116934 & 87.9 & 104862 & 120478 & 87.0 & 96323 & 116935 & 82.4 \\
\hline 13 & 97776 & 104560 & 93.5 & 100476 & 108621 & 92.5 & 79251 & 91364 & 86.7 \\
\hline 14 & 87737 & 103656 & 84.6 & 83550 & 99781 & 83.7 & 67695 & 87188 & 77.6 \\
\hline 15 & 74966 & 85777 & 87.4 & 75460 & 87545 & 86.2 & 73697 & 91968 & 80.1 \\
\hline 16 & 66384 & 76004 & 87.3 & 70042 & 81546 & 85.9 & 63212 & 79963 & 79.1 \\
\hline 17 & 67984 & 75716 & 89.8 & 68220 & 77145 & 88.4 & 49130 & 61431 & 80.0 \\
\hline 18 & 58283 & 67791 & 86.0 & 66208 & 78637 & 84.2 & 42858 & 56945 & 75.3 \\
\hline 19 & 51416 & 57370 & 89.6 & 58403 & 66736 & 87.5 & 39926 & 51517 & 77.5 \\
\hline 20 & 46081 & 50568 & 91.1 & 44607 & 50019 & 89.2 & 51425 & 64311 & 80.0 \\
\hline 21 & 46628 & 53292 & 87.5 & 43914 & 51222 & 85.7 & 37987 & 50706 & 74.9 \\
\hline 22 & 43699 & 50541 & 86.5 & 37991 & 44765 & 84.9 & 36023 & 49098 & 73.4 \\
\hline 23 & 38582 & 38906 & 99.2 & 37582 & 38906 & 96.6 & 28931 & 35507 & 81.5 \\
\hline \multicolumn{4}{|c|}{ Non sealed-TEST1 } & \multicolumn{3}{|c|}{ Non sealed-TEST2 } & \multicolumn{3}{|c|}{ Non sealed-TEST3 } \\
\hline \multicolumn{4}{|c|}{ Cyclic flow rate: $30 \mathrm{~L} / \mathrm{min}$} & \multicolumn{3}{|c|}{ Cyclic flow rate: $30 \mathrm{~L} / \mathrm{min}$} & \multicolumn{3}{|c|}{ Cyclic flow rate: $30 \mathrm{~L} / \mathrm{min}$} \\
\hline
\end{tabular}




\begin{tabular}{|c|c|c|c|c|c|c|c|c|c|}
\hline $\begin{array}{l}\text { Sam } \\
\text { ple }\end{array}$ & $\begin{array}{l}\text { Inside } \\
\text { (pt/cc) }\end{array}$ & $\begin{array}{l}\text { Outside } \\
\text { (pt/cc) }\end{array}$ & $\begin{array}{c}\mathrm{P}(\mathrm{Cin} / \mathrm{C} \\
\text { out)\% }\end{array}$ & $\begin{array}{l}\text { Inside } \\
\text { (pt/cc) }\end{array}$ & $\begin{array}{l}\text { Outside } \\
\text { (pt/cc) }\end{array}$ & $\begin{array}{c}\mathrm{P}(\mathrm{Cin} / \mathrm{C} \\
\text { out }) \%\end{array}$ & $\begin{array}{l}\text { Inside } \\
\text { (pt/cc) }\end{array}$ & $\begin{array}{l}\text { Outside } \\
\text { (pt/cc) }\end{array}$ & $\begin{array}{c}P(\operatorname{Cin} / C \\
\text { out }) \%\end{array}$ \\
\hline 1 & 287026 & 400383 & 71.7 & 291833 & 392533 & 74.3 & 292140 & 384683 & 75.9 \\
\hline 2 & 263860 & 324566 & 81.3 & 207200 & 257833 & 80.4 & 254940 & 327600 & 77.8 \\
\hline 3 & 243983 & 280635 & 86.9 & 170538 & 191229 & 89.2 & 244069 & 273185 & 89.3 \\
\hline 4 & 198756 & 210331 & 94.5 & 241600 & 265802 & 90.9 & 185993 & 217266 & 85.6 \\
\hline 5 & 164485 & 204465 & 80.4 & 206206 & 250143 & 82.4 & 163326 & 197940 & 82.5 \\
\hline 6 & 162073 & 211276 & 76.7 & 157849 & 197055 & 80.1 & 163633 & 201119 & 81.4 \\
\hline 7 & 148621 & 192814 & 77.1 & 132016 & 168942 & 78.1 & 144960 & 189142 & 76.6 \\
\hline 8 & 135891 & 169129 & 80.3 & 114945 & 150889 & 76.2 & 123159 & 177420 & 69.4 \\
\hline 9 & 115408 & 165920 & 69.6 & 113244 & 148863 & 76.1 & 120550 & 150415 & 80.1 \\
\hline 10 & 102681 & 141718 & 72.5 & 106899 & 138966 & 76.9 & 103487 & 132088 & 78.3 \\
\hline 11 & 100579 & 122715 & 82.0 & 89401 & 117757 & 75.9 & 87603 & 131393 & 66.7 \\
\hline 12 & 91203 & 105313 & 86.6 & 87541 & 99178 & 88.3 & 87365 & 102246 & 85.4 \\
\hline 13 & 69402 & 83638 & 83.0 & 65671 & 72796 & 90.2 & 69730 & 75895 & 91.9 \\
\hline \multicolumn{4}{|c|}{ Non sealed-TEST1 } & \multicolumn{3}{|c|}{ Non sealed-TEST2 } & \multicolumn{3}{|c|}{ Non sealed-TEST3 } \\
\hline \multicolumn{4}{|c|}{ Cyclic flow rate:50L/min } & \multicolumn{3}{|c|}{ Cyclic flow rate:50L/min } & \multicolumn{3}{|c|}{ Cyclic flow rate:50L/min } \\
\hline $\begin{array}{l}\text { Sam } \\
\text { ple }\end{array}$ & $\begin{array}{l}\text { Inside } \\
\text { (pt/cc) }\end{array}$ & $\begin{array}{l}\text { Outside } \\
\text { (pt/cc) }\end{array}$ & $\begin{array}{c}\mathrm{P}(\text { Cin/C } \\
\text { out)\% }\end{array}$ & $\begin{array}{l}\text { Inside } \\
\text { (pt/cc) }\end{array}$ & $\begin{array}{l}\text { Outside } \\
\text { (pt/cc) }\end{array}$ & $\begin{array}{c}\mathrm{P}(\mathrm{Cin} / \mathrm{C} \\
\text { out }) \%\end{array}$ & $\begin{array}{l}\text { Inside } \\
\text { (pt/cc) }\end{array}$ & $\begin{array}{l}\text { Outside } \\
\text { (pt/cc) }\end{array}$ & $\begin{array}{c}P(\operatorname{Cin} / C \\
\text { out }) \%\end{array}$ \\
\hline 1 & 297902 & 497580 & 59.9 & 309340 & 495591 & 62.4 & 325607 & 498078 & 65.4 \\
\hline 2 & 311703 & 485568 & 64.2 & 287366 & 482179 & 59.6 & 276033 & 484601 & 57.0 \\
\hline 3 & 266569 & 487595 & 54.7 & 248611 & 482253 & 51.6 & 211617 & 487110 & 43.4 \\
\hline 4 & 228440 & 438281 & 52.1 & 211156 & 339569 & 62.2 & 171053 & 406694 & 42.1 \\
\hline 5 & 161800 & 283505 & 57.1 & 169552 & 352045 & 48.2 & 193813 & 299084 & 64.8 \\
\hline 6 & 166927 & 250167 & 66.7 & 172312 & 218592 & 78.8 & 139675 & 259883 & 53.7 \\
\hline 7 & 143601 & 220993 & 65.0 & 137068 & 216660 & 63.3 & 134335 & 212327 & 63.3 \\
\hline 8 & 136782 & 225305 & 60.7 & 137037 & 178981 & 76.6 & 102674 & 227412 & 45.1 \\
\hline 9 & 133413 & 224172 & 59.5 & 128938 & 152754 & 84.4 & 85207 & 218222 & 39.0 \\
\hline 10 & 90201 & 160055 & 56.4 & 92092 & 202267 & 45.5 & 106832 & 165332 & 64.6 \\
\hline 11 & 78445 & 154285 & 50.8 & 75021 & 188752 & 39.7 & 88912 & 149362 & 59.5 \\
\hline 12 & 78530 & 148099 & 53.0 & 73874 & 138130 & 53.5 & 66913 & 140979 & 47.5 \\
\hline 13 & 69084 & 132819 & 52.0 & 66816 & 116375 & 57.4 & 54341 & 130290 & 41.7 \\
\hline 14 & 62581 & 116785 & 53.6 & 64526 & 104191 & 61.9 & 49602 & 122511 & 40.5 \\
\hline 15 & 57138 & 114161 & 50.1 & 51032 & 102425 & 49.8 & 45022 & 103493 & 43.5 \\
\hline 16 & 51422 & 93184 & 55.2 & 47098 & 91374 & 51.5 & 43973 & 86852 & 50.6 \\
\hline 17 & 49486 & 81801 & 60.5 & 51808 & 78496 & 66.0 & 41088 & 87586 & 46.9 \\
\hline 18 & 44018 & 75384 & 58.4 & 41809 & 70993 & 58.9 & 35100 & 73189 & 48.0 \\
\hline 19 & 44317 & 62363 & 71.1 & 39445 & 54279 & 72.7 & 32397 & 56590 & 57.2 \\
\hline 20 & 44684 & 74565 & 59.9 & 34956 & 59138 & 59.1 & 29457 & 59139 & 49.8 \\
\hline 21 & 40614 & 66027 & 61.5 & 35937 & 48072 & 74.8 & 23751 & 59657 & 39.8 \\
\hline 22 & 28371 & 43309 & 65.5 & 31351 & 49496 & 63.3 & 25568 & 49973 & 51.2 \\
\hline
\end{tabular}




\begin{tabular}{|c|c|c|c|c|c|c|c|c|c|}
23 & 29658 & 48446 & 61.2 & 29755 & 47957 & 62.0 & 22885 & 50405 & 45.4 \\
\hline \multicolumn{3}{|c|}{ Non sealed-TEST1 } & \multicolumn{3}{c|}{ Non sealed-TEST2 } & \multicolumn{3}{c|}{ Non sealed-TEST3 } \\
\hline \multicolumn{3}{|c|}{ Cyclic flow rate:85L/min } & \multicolumn{3}{c|}{ Cyclic flow rate:85L/min } & \multicolumn{3}{c|}{ Cyclic flow rate:85L/min } \\
\hline $\begin{array}{c}\text { Sam } \\
\text { ple }\end{array}$ & $\begin{array}{c}\text { Inside } \\
\text { (pt/cc) }\end{array}$ & $\begin{array}{c}\text { Outside } \\
\text { (pt/cc) }\end{array}$ & $\begin{array}{c}\text { P(Cin/C } \\
\text { out)\% }\end{array}$ & $\begin{array}{c}\text { Inside } \\
\text { (pt/cc) }\end{array}$ & $\begin{array}{c}\text { Outside } \\
\text { (pt/cc) }\end{array}$ & $\begin{array}{c}\text { P(Cin/C } \\
\text { out)\% }\end{array}$ & $\begin{array}{c}\text { Inside } \\
\text { (pt/cc) }\end{array}$ & $\begin{array}{c}\text { Outside } \\
\text { (pt/cc) }\end{array}$ & $\begin{array}{c}\text { P(Cin/C } \\
\text { out)\% }\end{array}$ \\
\hline 1 & 222569 & 465959 & 47.8 & 213023 & 484785 & 43.9 & 205387 & 461253 & 44.5 \\
\hline 2 & 199867 & 438039 & 45.6 & 200821 & 433744 & 46.3 & 185551 & 416567 & 44.5 \\
\hline 3 & 175330 & 280370 & 62.5 & 156224 & 313179 & 49.9 & 162246 & 301249 & 53.9 \\
\hline 4 & 146257 & 212147 & 68.9 & 121530 & 254083 & 47.8 & 150923 & 273819 & 55.1 \\
\hline 5 & 119937 & 250671 & 47.8 & 139734 & 212959 & 65.6 & 107322 & 201869 & 53.2 \\
\hline 6 & 103919 & 172980 & 60.1 & 86806 & 205654 & 42.2 & 93629 & 197966 & 47.3 \\
\hline 7 & 82542 & 186293 & 44.3 & 83176 & 182567 & 45.6 & 79310 & 190019 & 41.7 \\
\hline 8 & 88727 & 115292 & 77.0 & 69364 & 146489 & 47.4 & 81429 & 145133 & 56.1 \\
\hline 9 & 74500 & 97930 & 76.1 & 51900 & 139901 & 37.1 & 69965 & 143717 & 48.7 \\
\hline 10 & 59894 & 130060 & 46.1 & 71716 & 106310 & 67.5 & 51563 & 102918 & 50.1 \\
\hline 11 & 52750 & 81012 & 65.1 & 64105 & 65009 & 98.6 & 47907 & 66220 & 72.3 \\
\hline 12 & 49958 & 91079 & 54.9 & 47999 & 92957 & 51.6 & 45856 & 97652 & 47.0 \\
\hline
\end{tabular}

\begin{tabular}{|c|c|c|c|c|c|c|c|c|c|}
\hline \multicolumn{3}{|c|}{ Nose only sealed-TEST1 } & \multicolumn{3}{c|}{ Nose only sealed-TEST2 } & \multicolumn{3}{c|}{ Nose only sealed-TEST3 } \\
\hline \multicolumn{3}{|c|}{ Constant flow rate:15L/min } & \multicolumn{2}{c|}{ Constant flow rate:15L/min } & \multicolumn{2}{c|}{ Constant flow rate:15L/min } \\
\hline $\begin{array}{c}\text { Sa } \\
\mathrm{mpl} \\
\mathrm{e}\end{array}$ & $\begin{array}{c}\text { Inside } \\
\text { (pt/cc) }\end{array}$ & $\begin{array}{c}\text { Outside } \\
\text { (pt/cc) }\end{array}$ & $\begin{array}{c}\mathrm{P} \text { (Cin/C } \\
\text { out) }\end{array}$ & $\begin{array}{c}\text { Inside } \\
\text { (pt/cc) }\end{array}$ & $\begin{array}{c}\text { Outside } \\
\text { (pt/cc) }\end{array}$ & $\begin{array}{c}\text { P(Cin/C } \\
\text { out) }\end{array}$ & $\begin{array}{c}\text { Inside } \\
\text { (pt/cc) }\end{array}$ & $\begin{array}{c}\text { Outside } \\
\text { (pt/cc) }\end{array}$ & $\begin{array}{c}\text { P(Cin/C } \\
\text { out) }\end{array}$ \\
\hline 1 & 88462 & 500000 & 17.7 & 96929 & 500000 & 19.4 & 68625 & 500000 & 19.4 \\
\hline 2 & 42228 & 495804 & 8.5 & 38171 & 433828 & 8.8 & 41319 & 500572 & 8.8 \\
\hline 3 & 55477 & 488215 & 11.4 & 49796 & 432946 & 11.5 & 49662 & 460581 & 11.5 \\
\hline 4 & 61635 & 461400 & 13.4 & 62222 & 465880 & 13.4 & 52024 & 416605 & 13.4 \\
\hline 5 & 59935 & 273824 & 21.9 & 65437 & 299495 & 21.8 & 58020 & 282382 & 21.8 \\
\hline 6 & 44993 & 313864 & 14.3 & 42949 & 299197 & 14.4 & 34703 & 266932 & 14.4 \\
\hline 7 & 31802 & 261182 & 12.2 & 34608 & 285168 & 12.1 & 27118 & 253188 & 12.1 \\
\hline 8 & 29278 & 251544 & 11.6 & 27980 & 239899 & 11.7 & 20598 & 207292 & 11.7 \\
\hline 9 & 21855 & 254637 & 8.6 & 19794 & 229174 & 8.6 & 14547 & 210655 & 8.6 \\
\hline 10 & 26520 & 209573 & 12.7 & 28939 & 229639 & 12.6 & 25190 & 229640 & 12.6 \\
\hline 11 & 22999 & 185528 & 12.4 & 27063 & 220188 & 12.3 & 21641 & 205917 & 12.3 \\
\hline 12 & 16606 & 195834 & 8.5 & 19243 & 229463 & 8.4 & 10686 & 168142 & 8.4 \\
\hline 13 & 28846 & 198940 & 14.5 & 31794 & 220186 & 14.4 & 19739 & 160312 & 14.4 \\
\hline 14 & 12486 & 186246 & 6.7 & 10805 & 158396 & 6.8 & 8212 & 177544 & 6.8 \\
\hline 15 & 9756 & 150405 & 6.5 & 9932 & 153506 & 6.5 & 6621 & 161260 & 6.5 \\
\hline 16 & 7274 & 144976 & 5.0 & 7085 & 140445 & 5.0 & 4466 & 167629 & 5.0 \\
\hline 17 & 11345 & 138846 & 8.2 & 11059 & 134916 & 8.2 & 6167 & 119199 & 8.2 \\
\hline 18 & 14739 & 122359 & 12.0 & 16222 & 135818 & 11.9 & 9506 & 108900 & 11.9 \\
\hline
\end{tabular}




\begin{tabular}{|c|c|c|c|c|c|c|c|c|c|}
\hline 19 & 18600 & 106103 & 17.5 & 17184 & 97442 & 17.6 & 17330 & 121262 & 17.6 \\
\hline 20 & 7777 & 96321 & 8.1 & 8628 & 108884 & 7.9 & 4879 & 108885 & 7.9 \\
\hline 21 & 14063 & 101084 & 13.9 & 14063 & 101084 & 13.9 & 9194 & 92252 & 13.9 \\
\hline 22 & 22723 & 91634 & 24.8 & 23746 & 95998 & 24.7 & 14884 & 74181 & 24.7 \\
\hline 23 & 7525 & 84052 & 9.0 & 7160 & 79155 & 9.0 & 3593 & 81604 & 9.0 \\
\hline 24 & 8660 & 70306 & 12.3 & 8131 & 65284 & 12.5 & 5894 & 79633 & 12.5 \\
\hline 25 & 7880 & 62210 & 12.7 & 7745 & 60940 & 12.7 & 4672 & 67289 & 12.7 \\
\hline 26 & 7070 & 58688 & 12.0 & 7370 & 61714 & 11.9 & 3560 & 61110 & 11.9 \\
\hline 27 & 9392 & 56710 & 16.6 & 10198 & 62325 & 16.4 & 4595 & 49412 & 16.4 \\
\hline 28 & 6018 & 56197 & 10.7 & 6104 & 57209 & 10.7 & 765 & 38478 & 10.7 \\
\hline 29 & 4014 & 43881 & 9.1 & 4291 & 48269 & 8.9 & 809 & 52513 & 8.9 \\
\hline 30 & 7232 & 44239 & 16.3 & 7081 & 43122 & 16.4 & 3111 & 41491 & 16.4 \\
\hline \multicolumn{4}{|c|}{ Nose only sealed-TEST1 } & \multicolumn{3}{|c|}{ Nose only sealed-TEST2 } & \multicolumn{3}{|c|}{ Nose only sealed-TEST3 } \\
\hline \multicolumn{4}{|c|}{ Constant flow rate: $30 \mathrm{~L} / \mathrm{min}$} & \multicolumn{3}{|c|}{ Constant flow rate: $30 \mathrm{~L} / \mathrm{min}$} & \multicolumn{3}{|c|}{ Constant flow rate:30L/min } \\
\hline $\begin{array}{c}\mathrm{Sa} \\
\mathrm{mpl} \\
\mathrm{e}\end{array}$ & $\begin{array}{l}\text { Inside } \\
\text { (pt/cc) }\end{array}$ & $\begin{array}{c}\text { Outside } \\
\text { (pt/cc) }\end{array}$ & $\begin{array}{c}\% \\
\mathrm{P}(\text { Cin } / \mathrm{C} \\
\text { out })\end{array}$ & $\begin{array}{l}\text { Inside } \\
\text { (pt/cc) }\end{array}$ & $\begin{array}{c}\text { Outside } \\
\text { (pt/cc) }\end{array}$ & $\begin{array}{c}\% \\
\mathrm{P}(\text { Cin } / \mathrm{C} \\
\text { out })\end{array}$ & $\begin{array}{l}\text { Inside } \\
\text { (pt/cc) }\end{array}$ & $\begin{array}{c}\text { Outside } \\
\text { (pt/cc) }\end{array}$ & $\begin{array}{c}\% \\
P(\text { Cin } / C \\
\text { out })\end{array}$ \\
\hline 1 & 51270 & 500000 & 10.3 & 52251 & 500000 & 10.5 & 43598 & 500000 & 8.7 \\
\hline 2 & 31526 & 493529 & 6.4 & 27741 & 431838 & 6.4 & 28068 & 498276 & 5.6 \\
\hline 3 & 14526 & 506067 & 2.9 & 13023 & 448776 & 2.9 & 10025 & 477422 & 2.1 \\
\hline 4 & 8966 & 506433 & 1.8 & 9041 & 511350 & 1.8 & 4468 & 457266 & 1.0 \\
\hline 5 & 6895 & 335222 & 2.1 & 7425 & 366649 & 2.0 & 3323 & 345699 & 1.0 \\
\hline 6 & 14140 & 327617 & 4.3 & 13537 & 312308 & 4.3 & 8463 & 278629 & 3.0 \\
\hline 7 & 15058 & 251928 & 6.0 & 16326 & 275064 & 5.9 & 10886 & 244217 & 4.5 \\
\hline 8 & 4385 & 246957 & 1.8 & 4240 & 235523 & 1.8 & 84 & 203511 & 0.0 \\
\hline 9 & 10622 & 241810 & 4.4 & 9684 & 217629 & 4.4 & 5254 & 200044 & 2.6 \\
\hline 10 & 12168 & 202673 & 6.0 & 13213 & 222078 & 5.9 & 9464 & 222079 & 4.3 \\
\hline 11 & 5365 & 174932 & 3.1 & 6133 & 207611 & 3.0 & 2068 & 194156 & 1.1 \\
\hline 12 & 2041 & 184221 & 1.1 & 2391 & 215855 & 1.1 & 1753 & 158170 & 1.1 \\
\hline 13 & 12589 & 176337 & 7.1 & 13800 & 195169 & 7.1 & 6638 & 142097 & 4.7 \\
\hline 14 & 9096 & 177352 & 5.1 & 7923 & 150832 & 5.3 & 4980 & 169065 & 2.9 \\
\hline 15 & 10207 & 144620 & 7.1 & 10392 & 147602 & 7.0 & 7105 & 155057 & 4.6 \\
\hline 16 & 10753 & 134511 & 8.0 & 10456 & 130307 & 8.0 & 8488 & 155529 & 5.5 \\
\hline 17 & 986 & 126750 & 0.8 & 958 & 123163 & 0.8 & 848 & 108815 & 0.8 \\
\hline 18 & 1958 & 117615 & 1.7 & 2173 & 130552 & 1.7 & 1743 & 104678 & 1.7 \\
\hline 19 & 736 & 87474 & 0.8 & 833 & 98884 & 0.8 & 4011 & 120960 & 3.3 \\
\hline 20 & 1425 & 89538 & 1.6 & 1425 & 89538 & 1.6 & 834 & 98885 & 0.8 \\
\hline 21 & 992 & 71791 & 1.4 & 935 & 67609 & 1.4 & 1301 & 81716 & 1.6 \\
\hline 22 & 762 & 66057 & 1.2 & 707 & 61339 & 1.2 & 492 & 67117 & 0.7 \\
\hline 23 & 686 & 59657 & 1.1 & 672 & 58440 & 1.1 & 964 & 69700 & 1.4 \\
\hline 24 & 2012 & 66057 & 3.0 & 1957 & 61339 & 3.2 & 864 & 74821 & 1.2 \\
\hline 25 & 1936 & 59657 & 3.2 & 1922 & 58440 & 3.3 & 742 & 64528 & 1.1 \\
\hline
\end{tabular}




\begin{tabular}{|c|c|c|c|c|c|c|c|c|c|}
\hline \multicolumn{4}{|c|}{ Nose only sealed-TEST1 } & \multicolumn{3}{|c|}{ Nose only sealed-TEST2 } & \multicolumn{3}{|c|}{$\begin{array}{c}\text { Nose only } \\
\text { sealed-TEST3 }\end{array}$} \\
\hline \multicolumn{4}{|c|}{ Constant flow rate:50L/min } & \multicolumn{3}{|c|}{ Constant flow rate:50L/min } & \multicolumn{3}{|c|}{ Constant flow rate:50L/min } \\
\hline $\begin{array}{c}\mathrm{Sa} \\
\mathrm{mpl} \\
\mathrm{e} \\
\end{array}$ & $\begin{array}{l}\text { Inside } \\
\text { (pt/cc) }\end{array}$ & $\begin{array}{c}\text { Outside } \\
\text { (pt/cc) }\end{array}$ & $\begin{array}{c}\% \\
\mathrm{P}(\text { Cin/C } \\
\text { out })\end{array}$ & $\begin{array}{l}\text { Inside } \\
\text { (pt/cc) }\end{array}$ & $\begin{array}{c}\text { Outside } \\
\text { (pt/cc) }\end{array}$ & $\begin{array}{c}\% \\
\mathrm{P}(\text { Cin/C } \\
\text { out })\end{array}$ & $\begin{array}{l}\text { Inside } \\
\text { (pt/cc) }\end{array}$ & $\begin{array}{c}\text { Outside } \\
\text { (pt/cc) }\end{array}$ & $\begin{array}{c}\% \\
\mathrm{P}(\mathrm{Cin} / \mathrm{C} \\
\text { out }) \\
\end{array}$ \\
\hline 1 & 50655 & 500000 & 10.1 & 51144 & 500000 & 10.2 & 44949 & 500000 & 9.0 \\
\hline 2 & 34466 & 458024 & 7.5 & 30314 & 462428 & 6.6 & 31036 & 400772 & 7.7 \\
\hline 3 & 24551 & 317215 & 7.7 & 21914 & 299260 & 7.3 & 19483 & 281305 & 6.9 \\
\hline 4 & 33018 & 267502 & 12.3 & 33326 & 241531 & 13.8 & 26184 & 270100 & 9.7 \\
\hline 5 & 15192 & 224201 & 6.8 & 16499 & 231207 & 7.1 & 11878 & 245221 & 4.8 \\
\hline 6 & 13018 & 244869 & 5.3 & 12468 & 208253 & 6.0 & 7510 & 233427 & 3.2 \\
\hline 7 & 14928 & 201988 & 7.4 & 16185 & 195805 & 8.3 & 10761 & 220539 & 4.9 \\
\hline 8 & 13171 & 196053 & 6.7 & 12619 & 161562 & 7.8 & 7324 & 186977 & 3.9 \\
\hline 9 & 19013 & 172312 & 11.0 & 17237 & 142549 & 12.1 & 12196 & 155082 & 7.9 \\
\hline 10 & 9186 & 129929 & 7.1 & 9946 & 142369 & 7.0 & 6197 & 142370 & 4.4 \\
\hline 11 & 7376 & 110569 & 6.7 & 8520 & 122720 & 6.9 & 4300 & 131226 & 3.3 \\
\hline 12 & 5789 & 106816 & 5.4 & 6568 & 91710 & 7.2 & 1398 & 125159 & 1.1 \\
\hline 13 & 5089 & 85548 & 5.9 & 5499 & 68937 & 8.0 & 595 & 94685 & 0.6 \\
\hline 14 & 5563 & 80849 & 6.9 & 4918 & 77071 & 6.4 & 1612 & 68760 & 2.3 \\
\hline 15 & 4488 & 64417 & 7.0 & 4555 & 69066 & 6.6 & 973 & 65746 & 1.5 \\
\hline 16 & 5998 & 58532 & 10.2 & 5849 & 67677 & 8.6 & 2991 & 56704 & 5.3 \\
\hline 17 & 5093 & 54788 & 9.3 & 4984 & 47035 & 10.6 & 800 & 53238 & 1.5 \\
\hline 18 & 2261 & 48076 & 4.7 & 2509 & 42787 & 5.9 & 2013 & 53365 & 3.8 \\
\hline 19 & 2064 & 42684 & 4.8 & 1896 & 48782 & 3.9 & 2360 & 39201 & 6.0 \\
\hline 20 & 1723 & 35213 & 4.9 & 1947 & 39807 & 4.9 & 1948 & 39808 & 4.9 \\
\hline 21 & 1923 & 35898 & 5.4 & 1923 & 32761 & 5.9 & 1755 & 35899 & 4.9 \\
\hline 22 & 1316 & 33372 & 3.9 & 1379 & 27015 & 5.1 & 1066 & 34962 & 3.0 \\
\hline \multicolumn{4}{|c|}{ Nose only sealed-TEST1 } & \multicolumn{3}{|c|}{ Nose only sealed-TEST2 } & \multicolumn{3}{|c|}{ Nose only sealed-TEST3 } \\
\hline \multicolumn{4}{|c|}{ Constant flow rate:80L/min } & \multicolumn{3}{|c|}{ Constant flow rate: $80 \mathrm{~L} / \mathrm{min}$} & \multicolumn{3}{|c|}{ Constant flow rate: $80 \mathrm{~L} / \mathrm{min}$} \\
\hline $\begin{array}{c}\mathrm{Sa} \\
\mathrm{mpl} \\
\mathrm{e}\end{array}$ & $\begin{array}{l}\text { Inside } \\
\text { (pt/cc) }\end{array}$ & $\begin{array}{l}\text { Outside } \\
\text { (pt/cc) }\end{array}$ & $\begin{array}{c}\% \\
\mathrm{P}(\text { Cin/C } \\
\text { out })\end{array}$ & $\begin{array}{l}\text { Inside } \\
\text { (pt/cc) }\end{array}$ & $\begin{array}{l}\text { Outside } \\
\text { (pt/cc) }\end{array}$ & $\begin{array}{c}\% \\
\mathrm{P}(\text { Cin/C } \\
\text { out })\end{array}$ & $\begin{array}{l}\text { Inside } \\
\text { (pt/cc) }\end{array}$ & $\begin{array}{l}\text { Outside } \\
\text { (pt/cc) }\end{array}$ & $\begin{array}{c}\% \\
\mathrm{P}(\mathrm{Cin} / \mathrm{C} \\
\text { out })\end{array}$ \\
\hline 1 & 47433 & 500000 & 9.5 & 40897 & 500000 & 8.2 & 42377 & 500000 & 8.5 \\
\hline 2 & 37128 & 382031 & 9.7 & 37473 & 385704 & 9.7 & 28895 & 334278 & 8.6 \\
\hline 3 & 27245 & 268032 & 10.2 & 25774 & 252861 & 10.2 & 20553 & 237690 & 8.6 \\
\hline 4 & 23347 & 214060 & 10.9 & 21202 & 193278 & 11.0 & 19813 & 216140 & 9.2 \\
\hline 5 & 17987 & 195646 & 9.2 & 18510 & 201760 & 9.2 & 15807 & 213988 & 7.4 \\
\hline 6 & 15260 & 206746 & 7.4 & 13165 & 175831 & 7.5 & 10856 & 197086 & 5.5 \\
\hline 7 & 13565 & 158176 & 8.6 & 13188 & 153334 & 8.6 & 10947 & 172704 & 6.3 \\
\hline 8 & 17738 & 147642 & 12.0 & 14837 & 121668 & 12.2 & 13226 & 140808 & 9.4 \\
\hline 9 & 13907 & 114395 & 12.2 & 11721 & 94636 & 12.4 & 8892 & 102957 & 8.6 \\
\hline 10 & 9531 & 85927 & 11.1 & 10324 & 94154 & 11.0 & 6575 & 94155 & 7.0 \\
\hline
\end{tabular}




\begin{tabular}{|c|c|c|c|c|c|c|c|c|c|}
\hline 11 & 8592 & 74691 & 11.5 & 9399 & 82899 & 11.3 & 6215 & 88646 & 7.0 \\
\hline 12 & 4364 & 66845 & 6.5 & 3924 & 57392 & 6.8 & 1150 & 78325 & 1.5 \\
\hline 13 & 4935 & 60221 & 8.2 & 4219 & 48527 & 8.7 & 1579 & 66653 & 2.4 \\
\hline 14 & 5528 & 54957 & 10.1 & 5328 & 52389 & 10.2 & 1140 & 46740 & 2.4 \\
\hline 15 & 7018 & 41087 & 17.1 & 7434 & 44052 & 16.9 & 3388 & 41935 & 8.1 \\
\hline 16 & 3908 & 34572 & 11.3 & 4323 & 39974 & 10.8 & 76 & 33493 & 0.2 \\
\hline 17 & 2173 & 33383 & 6.5 & 1865 & 28659 & 6.5 & 2112 & 32439 & 6.5 \\
\hline 18 & 1819 & 26726 & 6.8 & 1618 & 23786 & 6.8 & 2020 & 29666 & 6.8 \\
\hline \multicolumn{4}{|c|}{ Nose only sealed-TEST1 } & \multicolumn{3}{|c|}{ Nose only sealed-TEST2 } & \multicolumn{3}{|c|}{ Nose only sealed-TEST3 } \\
\hline \multicolumn{4}{|c|}{ Cyclic flow rate:15L/min } & \multicolumn{3}{|c|}{ Cyclic flow rate: $15 \mathrm{~L} / \mathrm{min}$} & \multicolumn{3}{|c|}{ Cyclic flow rate: $15 \mathrm{~L} / \mathrm{min}$} \\
\hline $\begin{array}{c}\mathrm{Sa} \\
\mathrm{mpl} \\
\mathrm{e} \\
\end{array}$ & $\begin{array}{l}\text { Inside } \\
\text { (pt/cc) }\end{array}$ & $\begin{array}{c}\text { Outside } \\
\text { (pt/cc) }\end{array}$ & $\begin{array}{c}\% \\
\mathrm{P}(\text { Cin } / \mathrm{C} \\
\text { out })\end{array}$ & $\begin{array}{l}\text { Inside } \\
\text { (pt/cc) }\end{array}$ & $\begin{array}{c}\text { Outside } \\
\text { (pt/cc) }\end{array}$ & $\begin{array}{c}\% \\
\mathrm{P}(\text { Cin } / \mathrm{C} \\
\text { out })\end{array}$ & $\begin{array}{l}\text { Inside } \\
\text { (pt/cc) }\end{array}$ & $\begin{array}{c}\text { Outside } \\
\text { (pt/cc) }\end{array}$ & $\begin{array}{c}\% \\
P(\text { Cin } / C \\
\text { out }) \\
\end{array}$ \\
\hline 1 & $\begin{array}{c}10539 \\
0 \\
\end{array}$ & 500000 & 21.1 & 98513 & 500000 & 19.7 & 90834 & 500000 & 18.2 \\
\hline 2 & 80186 & 366221 & 21.9 & 92330 & 422563 & 21.8 & 87713 & 418539 & 21.0 \\
\hline 3 & 80631 & 397193 & 20.3 & 85698 & 422546 & 20.3 & 87015 & 447899 & 19.4 \\
\hline 4 & 82634 & 442169 & 18.7 & 74026 & 395401 & 18.7 & 78102 & 437918 & 17.8 \\
\hline 5 & 73607 & 447562 & 16.4 & 69472 & 421987 & 16.5 & 63656 & 409200 & 15.6 \\
\hline 6 & 55891 & 331493 & 16.9 & 49998 & 295744 & 16.9 & 54820 & 347744 & 15.8 \\
\hline 7 & 50749 & 290098 & 17.5 & 45197 & 257564 & 17.5 & 42836 & 265698 & 16.1 \\
\hline 8 & 41910 & 249434 & 16.8 & 36383 & 215530 & 16.9 & 40135 & 261543 & 15.3 \\
\hline 9 & 45979 & 222451 & 20.7 & 42364 & 204475 & 20.7 & 47200 & 247168 & 19.1 \\
\hline 10 & 40111 & 237642 & 16.9 & 40111 & 237642 & 16.9 & 32967 & 216878 & 15.2 \\
\hline 11 & 41883 & 202900 & 20.6 & 39250 & 189749 & 20.7 & 31738 & 170963 & 18.6 \\
\hline 12 & 27198 & 170095 & 16.0 & 20263 & 124638 & 16.3 & 19646 & 145168 & 13.5 \\
\hline 13 & 24960 & 156542 & 15.9 & 18513 & 113973 & 16.2 & 18923 & 141438 & 13.4 \\
\hline 14 & 25577 & 117369 & 21.8 & 28518 & 131556 & 21.7 & 26106 & 138006 & 18.9 \\
\hline 15 & 18871 & 109784 & 17.2 & 19760 & 115328 & 17.1 & 14766 & 107567 & 13.7 \\
\hline 16 & 21238 & 148251 & 14.3 & 25107 & 176945 & 14.2 & 18134 & 153034 & 11.8 \\
\hline 17 & 19752 & 141965 & 13.9 & 17597 & 125426 & 14.0 & 16542 & 146101 & 11.3 \\
\hline 18 & 25778 & 140376 & 18.4 & 20917 & 112553 & 18.6 & 19598 & 126465 & 15.5 \\
\hline 19 & 22355 & 99090 & 22.6 & 27514 & 123313 & 22.3 & 20481 & 107899 & 19.0 \\
\hline 20 & 25638 & 107917 & 23.8 & 25638 & 107917 & 23.8 & 19074 & 95466 & 20.0 \\
\hline 21 & 17403 & 106880 & 16.3 & 15992 & 97540 & 16.4 & 13654 & 106881 & 12.8 \\
\hline 22 & 22019 & 98255 & 22.4 & 17298 & 75924 & 22.8 & 17326 & 93790 & 18.5 \\
\hline 23 & 16584 & 81013 & 20.5 & 17059 & 83519 & 20.4 & 13784 & 86025 & 16.0 \\
\hline 24 & 14627 & 66030 & 22.2 & 17567 & 80542 & 21.8 & 11906 & 71110 & 16.7 \\
\hline 25 & 16285 & 67512 & 24.1 & 17851 & 74544 & 23.9 & 12849 & 68919 & 18.6 \\
\hline 26 & 13466 & 65862 & 20.4 & 13346 & 65216 & 20.5 & 9118 & 62634 & 14.6 \\
\hline 27 & 16772 & 60157 & 27.9 & 13555 & 47692 & 28.4 & 11624 & 54738 & 21.2 \\
\hline 28 & 13351 & 62806 & 21.3 & 9388 & 42241 & 22.2 & 9387 & 61695 & 15.2 \\
\hline 29 & 11562 & 48911 & 23.6 & 12468 & 53211 & 23.4 & 6875 & 44466 & 15.5 \\
\hline
\end{tabular}




\begin{tabular}{|c|c|c|c|c|c|c|c|c|c|}
\hline 30 & 9405 & 48473 & 19.4 & 9096 & 46638 & 19.5 & 5867 & 49729 & 11.8 \\
\hline 31 & 7319 & 44486 & 16.5 & 7078 & 42724 & 16.6 & 3630 & 44927 & 8.1 \\
\hline \multicolumn{4}{|c|}{ Nose only sealed-TEST1 } & \multicolumn{3}{|c|}{ Nose only sealed-TEST2 } & \multicolumn{3}{|c|}{ Nose only sealed-TEST3 } \\
\hline \multicolumn{4}{|c|}{ Cyclic flow rate:30L/min } & \multicolumn{3}{|c|}{ Cyclic flow rate: $30 \mathrm{~L} / \mathrm{min}$} & \multicolumn{3}{|c|}{ Cyclic flow rate:30L/min } \\
\hline $\begin{array}{c}\text { Sa } \\
\mathrm{mpl} \\
\mathrm{e}\end{array}$ & $\begin{array}{l}\text { Inside } \\
\text { (pt/cc) }\end{array}$ & $\begin{array}{c}\text { Outside } \\
\text { (pt/cc) }\end{array}$ & $\begin{array}{c}\% \\
\mathrm{P}(\text { Cin } / \mathrm{C} \\
\text { out })\end{array}$ & $\begin{array}{l}\text { Inside } \\
\text { (pt/cc) }\end{array}$ & $\begin{array}{l}\text { Outside } \\
\text { (pt/cc) }\end{array}$ & $\begin{array}{c}\% \\
P(\text { Cin } / C \\
\text { out })\end{array}$ & $\begin{array}{l}\text { Inside } \\
\text { (pt/cc) }\end{array}$ & $\begin{array}{l}\text { Outside } \\
\text { (pt/cc) }\end{array}$ & $\begin{array}{c}\% \\
\mathrm{P}(\text { Cin } / \mathrm{C} \\
\text { out })\end{array}$ \\
\hline 1 & 58686 & 500000 & 11.7 & 58686 & 500000 & 11.7 & 54936 & 500000 & 11.0 \\
\hline 2 & 36101 & 406661 & 8.9 & 36436 & 335118 & 10.9 & 27996 & 387835 & 7.2 \\
\hline 3 & 46406 & 499249 & 9.3 & 43850 & 428600 & 10.2 & 37544 & 485120 & 7.7 \\
\hline 4 & 26121 & 334656 & 7.8 & 23706 & 400132 & 5.9 & 22613 & 356482 & 6.3 \\
\hline 5 & 26967 & 288596 & 9.3 & 27771 & 333224 & 8.3 & 25629 & 270746 & 9.5 \\
\hline 6 & 19932 & 280398 & 7.1 & 17138 & 241912 & 7.1 & 15310 & 302390 & 5.1 \\
\hline 7 & 17788 & 266329 & 6.7 & 17282 & 208540 & 8.3 & 15558 & 278892 & 5.6 \\
\hline 8 & 20009 & 229040 & 8.7 & 16709 & 243505 & 6.9 & 15392 & 250739 & 6.1 \\
\hline 9 & 15016 & 251645 & 6.0 & 12638 & 232100 & 5.4 & 9890 & 249203 & 4.0 \\
\hline 10 & 13252 & 247482 & 5.4 & 14402 & 204343 & 7.0 & 10653 & 229319 & 4.6 \\
\hline 11 & 9002 & 212622 & 4.2 & 9854 & 192373 & 5.1 & 6701 & 202498 & 3.3 \\
\hline 12 & 11067 & 160622 & 6.9 & 9679 & 183319 & 5.3 & 9004 & 179828 & 5.0 \\
\hline 13 & 9430 & 177117 & 5.3 & 7841 & 178854 & 4.4 & 6554 & 164963 & 4.0 \\
\hline 14 & 2793 & 154117 & 1.8 & 2663 & 154117 & 1.7 & 2377 & 149541 & 1.6 \\
\hline 15 & 13000 & 138027 & 9.4 & 13848 & 112228 & 12.3 & 9493 & 136738 & 6.9 \\
\hline 16 & 4811 & 124833 & 3.9 & 5368 & 111629 & 4.8 & 951 & 123633 & 0.8 \\
\hline 17 & 3861 & 124433 & 3.1 & 3492 & 95629 & 3.7 & 38 & 125586 & 0.0 \\
\hline 18 & 6136 & 115515 & 5.3 & 5598 & 104300 & 5.4 & 2924 & 116638 & 2.5 \\
\hline 19 & 6025 & 101825 & 5.9 & 6707 & 96834 & 6.9 & 1886 & 100828 & 1.9 \\
\hline 20 & 1189 & 95578 & 1.2 & 1344 & 80103 & 1.7 & 1345 & 97399 & 1.4 \\
\hline 21 & 5728 & 82179 & 7.0 & 5337 & 82179 & 6.5 & 1979 & 92453 & 2.1 \\
\hline 22 & 2082 & 74328 & 2.8 & 1685 & 77331 & 2.2 & 2182 & 73578 & 3.0 \\
\hline 23 & 5238 & 73664 & 7.1 & 5122 & 75108 & 6.8 & 1256 & 67887 & 1.9 \\
\hline 24 & 11607 & 66233 & 17.5 & 12981 & 56043 & 23.2 & 7118 & 68781 & 10.3 \\
\hline 25 & 6759 & 52170 & 13.0 & 7209 & 65806 & 11.0 & 2898 & 59878 & 4.8 \\
\hline 26 & 4192 & 49465 & 8.5 & 4314 & 55848 & 7.7 & 595 & 54253 & 1.1 \\
\hline 27 & 663 & 51310 & 1.3 & 578 & 39292 & 1.5 & 730 & 48076 & 1.5 \\
\hline 28 & 762 & 52517 & 1.5 & 522 & 41461 & 1.3 & 777 & 44226 & 1.8 \\
\hline 29 & 576 & 47053 & 1.2 & 690 & 30305 & 2.3 & 635 & 42269 & 1.5 \\
\hline \multicolumn{4}{|c|}{ Nose only sealed-TEST1 } & \multicolumn{3}{|c|}{ Nose only sealed-TEST2 } & \multicolumn{3}{|c|}{ Nose only sealed-TEST3 } \\
\hline \multicolumn{4}{|c|}{ Cyclic flow rate:50L/min } & \multicolumn{3}{|c|}{ Cyclic flow rate: $50 \mathrm{~L} / \mathrm{min}$} & \multicolumn{3}{|c|}{ Cyclic flow rate:50L/min } \\
\hline $\begin{array}{c}\mathrm{Sa} \\
\mathrm{mpl} \\
\mathrm{e}\end{array}$ & $\begin{array}{l}\text { Inside } \\
\text { (pt/cc) }\end{array}$ & $\begin{array}{c}\text { Outside } \\
\text { (pt/cc) }\end{array}$ & $\begin{array}{c}\% \\
\mathrm{P}(\text { Cin/C } \\
\text { out })\end{array}$ & $\begin{array}{l}\text { Inside } \\
\text { (pt/cc) }\end{array}$ & $\begin{array}{c}\text { Outside } \\
\text { (pt/cc) }\end{array}$ & $\begin{array}{c}\% \\
\mathrm{P}(\text { Cin/C } \\
\text { out })\end{array}$ & $\begin{array}{l}\text { Inside } \\
\text { (pt/cc) }\end{array}$ & $\begin{array}{l}\text { Outside } \\
\text { (pt/cc) }\end{array}$ & $\begin{array}{c}\% \\
\mathrm{P}(\text { Cin } / \mathrm{C} \\
\text { out })\end{array}$ \\
\hline 1 & 53151 & 500000 & 10.6 & 56464 & 500000 & 11.3 & 56027 & 500000 & 11.2 \\
\hline 2 & 59690 & 477765 & 12.5 & 68882 & 473215 & 14.6 & 68417 & 414064 & 16.5 \\
\hline
\end{tabular}




\begin{tabular}{|c|c|c|c|c|c|c|c|c|c|}
\hline 3 & 53502 & 455651 & 11.7 & 60392 & 482990 & 12.5 & 58366 & 428312 & 13.6 \\
\hline 4 & 64205 & 419711 & 15.3 & 57337 & 464842 & 12.3 & 50154 & 469356 & 10.7 \\
\hline 5 & 51020 & 428160 & 11.9 & 41688 & 415185 & 10.0 & 40605 & 454110 & 8.9 \\
\hline 6 & 31523 & 305343 & 10.3 & 39092 & 359029 & 10.9 & 32591 & 342253 & 9.5 \\
\hline 7 & 18536 & 270304 & 6.9 & 24367 & 278840 & 8.7 & 19577 & 304449 & 6.4 \\
\hline 8 & 17087 & 199460 & 8.6 & 17558 & 242042 & 7.3 & 12397 & 230837 & 5.4 \\
\hline 9 & 35778 & 180065 & 19.9 & 38322 & 217661 & 17.6 & 34937 & 195896 & 17.8 \\
\hline 10 & 32106 & 207538 & 15.5 & 35877 & 189404 & 18.9 & 34871 & 207539 & 16.8 \\
\hline 11 & 18616 & 200642 & 9.3 & 19531 & 180776 & 10.8 & 16696 & 214549 & 7.8 \\
\hline 12 & 16812 & 157193 & 10.7 & 16515 & 183084 & 9.0 & 11136 & 214524 & 5.2 \\
\hline 13 & 14523 & 143119 & 10.1 & 13492 & 177605 & 7.6 & 10645 & 196574 & 5.4 \\
\hline 14 & 14246 & 148106 & 9.6 & 13860 & 155366 & 8.9 & 10497 & 132134 & 7.9 \\
\hline 15 & 9857 & 134602 & 7.3 & 11737 & 125542 & 9.3 & 8087 & 128131 & 6.3 \\
\hline 16 & 3746 & 142155 & 2.6 & 4014 & 122945 & 3.3 & 292 & 119104 & 0.2 \\
\hline 17 & 7689 & 99884 & 7.7 & 9706 & 116348 & 8.3 & 5879 & 113056 & 5.2 \\
\hline 18 & 8311 & 93557 & 8.9 & 9146 & 105121 & 8.7 & 5321 & 116685 & 4.6 \\
\hline 19 & 8728 & 106545 & 8.2 & 9037 & 93227 & 9.7 & 5365 & 85617 & 6.3 \\
\hline 20 & 7632 & 87904 & 8.7 & 9010 & 77762 & 11.6 & 5116 & 87905 & 5.8 \\
\hline 21 & 7152 & 73554 & 9.7 & 7889 & 80596 & 9.8 & 3403 & 80597 & 4.2 \\
\hline 22 & 5440 & 58636 & 9.3 & 5236 & 72433 & 7.2 & 1528 & 75883 & 2.0 \\
\hline 23 & 9388 & 64958 & 14.5 & 8605 & 66906 & 12.9 & 5482 & 63010 & 8.7 \\
\hline 24 & 6728 & 61556 & 10.9 & 7974 & 54346 & 14.7 & 3976 & 50465 & 7.9 \\
\hline 25 & 7815 & 55453 & 14.1 & 7224 & 51268 & 14.1 & 2706 & 50223 & 5.4 \\
\hline 26 & 5357 & 50260 & 10.7 & 5240 & 48270 & 10.9 & 1139 & 50759 & 2.2 \\
\hline 27 & 3615 & 39507 & 9.2 & 4144 & 45343 & 9.1 & 590 & 49834 & 1.2 \\
\hline 28 & 3820 & 29614 & 12.9 & 3991 & 43253 & 9.2 & 756 & 44033 & 1.7 \\
\hline 29 & 3614 & 40002 & 9.0 & 4547 & 33427 & 13.6 & 1171 & 36770 & 3.2 \\
\hline 30 & 4923 & 32850 & 15.0 & 5239 & 35027 & 15.0 & 1687 & 34144 & 4.9 \\
\hline \multicolumn{4}{|c|}{ Nose only sealed-TEST1 } & \multicolumn{3}{|c|}{ Nose only sealed-TEST2 } & \multicolumn{3}{|c|}{ Nose only sealed-TEST3 } \\
\hline \multicolumn{4}{|c|}{ Cyclic flow rate: $85 \mathrm{~L} / \mathrm{min}$} & \multicolumn{3}{|c|}{ Cyclic flow rate: $85 \mathrm{~L} / \mathrm{min}$} & \multicolumn{3}{|c|}{ Cyclic flow rate: $85 \mathrm{~L} / \mathrm{min}$} \\
\hline $\begin{array}{l}\mathrm{Sa} \\
\mathrm{mpl} \\
\mathrm{e}\end{array}$ & $\begin{array}{l}\text { Inside } \\
\text { (pt/cc) }\end{array}$ & $\begin{array}{c}\text { Outside } \\
\text { (pt/cc) }\end{array}$ & $\begin{array}{c}\% \\
\mathrm{P}(\text { Cin } / \mathrm{C} \\
\text { out })\end{array}$ & $\begin{array}{l}\text { Inside } \\
\text { (pt/cc) }\end{array}$ & $\begin{array}{c}\text { Outside } \\
\text { (pt/cc) }\end{array}$ & $\begin{array}{c}\% \\
\mathrm{P}(\text { Cin/C } \\
\text { out })\end{array}$ & $\begin{array}{l}\text { Inside } \\
\text { (pt/cc) }\end{array}$ & $\begin{array}{l}\text { Outside } \\
\text { (pt/cc) }\end{array}$ & $\begin{array}{c}\% \\
\mathrm{P}(\text { Cin } / \mathrm{C} \\
\text { out })\end{array}$ \\
\hline 1 & 45782 & 500000 & 9.2 & 64709 & 500000 & 12.9 & 56506 & 500000 & 11.3 \\
\hline 2 & 25728 & 518874 & 5.0 & 29579 & 513932 & 5.8 & 27205 & 449692 & 6.0 \\
\hline 3 & 24007 & 363795 & 6.6 & 27008 & 385622 & 7.0 & 24009 & 341968 & 7.0 \\
\hline 4 & 10837 & 261390 & 4.1 & 9791 & 289496 & 3.4 & 5519 & 292308 & 1.9 \\
\hline 5 & 8646 & 227810 & 3.8 & 7259 & 220907 & 3.3 & 3906 & 241618 & 1.6 \\
\hline 6 & 4738 & 206843 & 2.3 & 5610 & 243211 & 2.3 & 1544 & 231846 & 0.7 \\
\hline 7 & 5517 & 208777 & 2.6 & 6957 & 215370 & 3.2 & 2951 & 235150 & 1.3 \\
\hline 8 & 10650 & 169888 & 6.3 & 10929 & 206156 & 5.3 & 6342 & 196613 & 3.2 \\
\hline 9 & 15751 & 174932 & 9.0 & 16820 & 211456 & 8.0 & 13223 & 190311 & 6.9 \\
\hline 10 & 7015 & 177587 & 4.0 & 7720 & 162070 & 4.8 & 4483 & 177588 & 2.5 \\
\hline
\end{tabular}




\begin{tabular}{|l|c|c|c|c|c|c|c|c|c|}
11 & 13177 & 159731 & 8.2 & 13805 & 143916 & 9.6 & 10683 & 170802 & 6.3 \\
\hline 12 & 6140 & 114028 & 5.4 & 6047 & 132809 & 4.6 & 1786 & 155616 & 1.1 \\
\hline 13 & 1332 & 104449 & 1.3 & 1229 & 129618 & 0.9 & 1320 & 143462 & 0.9 \\
\hline 14 & 1448 & 114380 & 1.3 & 1405 & 119987 & 1.2 & 1449 & 102046 & 1.4 \\
\hline 15 & 1242 & 101055 & 1.2 & 1513 & 94253 & 1.6 & 1528 & 96198 & 1.6 \\
\hline 16 & 5598 & 98887 & 5.7 & 6066 & 85524 & 7.1 & 2364 & 82852 & 2.9 \\
\hline 17 & 665 & 72013 & 0.9 & 874 & 83884 & 1.0 & 867 & 81511 & 1.1 \\
\hline 18 & 4017 & 63969 & 6.3 & 4345 & 71876 & 6.0 & 566 & 79783 & 0.7 \\
\hline 19 & 5554 & 74805 & 7.4 & 5732 & 65455 & 8.8 & 2027 & 60112 & 3.4 \\
\hline 20 & 698 & 62999 & 1.1 & 849 & 55729 & 1.5 & 834 & 63000 & 1.3 \\
\hline 21 & 2049 & 50988 & 4.0 & 2305 & 55870 & 4.1 & 2050 & 55871 & 3.7 \\
\hline 22 & 4035 & 42104 & 9.6 & 3899 & 52011 & 7.5 & 177 & 54489 & 0.3 \\
\hline 23 & 1305 & 40780 & 3.2 & 1179 & 42003 & 2.8 & 1281 & 39557 & 3.2 \\
\hline 24 & 415 & 43796 & 0.9 & 509 & 38666 & 1.3 & 491 & 35905 & 1.4 \\
\hline 25 & 2256 & 36691 & 6.1 & 2053 & 33922 & 6.1 & 1790 & 33231 & 5.4 \\
\hline
\end{tabular}

\begin{tabular}{|c|c|c|c|c|c|c|c|c|c|}
\hline \multicolumn{4}{|c|}{ Nose and chin sealed-TEST1 } & \multicolumn{3}{|c|}{ Nose and chin sealed-TEST2 } & \multicolumn{3}{|c|}{ Nose and chin sealed-TEST3 } \\
\hline \multicolumn{4}{|c|}{ Constant flow rate $: 15 \mathrm{~L} / \mathrm{min}$} & \multicolumn{3}{|c|}{ Constant flow rate $: 15 \mathrm{~L} / \mathrm{min}$} & \multicolumn{3}{|c|}{ Constant flow rate $: 15 \mathrm{~L} / \mathrm{min}$} \\
\hline $\begin{array}{l}\text { Sam } \\
\text { ple }\end{array}$ & $\begin{array}{l}\text { Inside } \\
\text { (pt/cc) }\end{array}$ & $\begin{array}{l}\text { Outside } \\
\text { (pt/cc) }\end{array}$ & $\begin{array}{c}\% \\
\mathrm{P}(\text { Cin } / \mathrm{C} \\
\text { out })\end{array}$ & $\begin{array}{l}\text { Inside } \\
\text { (pt/cc) }\end{array}$ & $\begin{array}{l}\text { Outside } \\
\text { (pt/cc) }\end{array}$ & $\begin{array}{c}\% \\
\mathrm{P}(\text { Cin/C } \\
\text { out })\end{array}$ & $\begin{array}{l}\text { Inside } \\
\text { (pt/cc) }\end{array}$ & $\begin{array}{l}\text { Outside } \\
\text { (pt/cc) }\end{array}$ & $\begin{array}{c}\% \\
\mathrm{P}(\text { Cin } / \mathrm{C} \\
\text { out })\end{array}$ \\
\hline 1 & 1689 & 401058 & 0.42 & 1185 & 358638 & 0.33 & 1571 & 397202 & 0.40 \\
\hline 2 & 1124 & 332549 & 0.34 & 971 & 255570 & 0.38 & 1180 & 335629 & 0.35 \\
\hline 3 & 764 & 223440 & 0.34 & 675 & 201747 & 0.33 & 787 & 225611 & 0.35 \\
\hline 4 & 781 & 210510 & 0.37 & 876 & 200191 & 0.44 & 734 & 208447 & 0.35 \\
\hline 5 & 432 & 217909 & 0.20 & 532 & 182629 & 0.29 & 461 & 222061 & 0.21 \\
\hline 6 & 397 & 179280 & 0.22 & 317 & 179280 & 0.18 & 369 & 201690 & 0.18 \\
\hline 7 & 273 & 154341 & 0.18 & 204 & 160577 & 0.13 & 261 & 152782 & 0.17 \\
\hline 8 & 235 & 134283 & 0.18 & 228 & 136916 & 0.17 & 215 & 123751 & 0.17 \\
\hline 9 & 169 & 94739 & 0.18 & 157 & 80164 & 0.20 & 171 & 98384 & 0.17 \\
\hline 10 & 190 & 80780 & 0.24 & 170 & 101893 & 0.17 & 207 & 92714 & 0.22 \\
\hline 11 & 134 & 74642 & 0.18 & 127 & 84274 & 0.15 & 141 & 81867 & 0.17 \\
\hline 12 & 145 & 76032 & 0.19 & 148 & 58223 & 0.25 & 130 & 71238 & 0.18 \\
\hline 13 & 103 & 66188 & 0.16 & 112 & 52254 & 0.21 & 112 & 55738 & 0.20 \\
\hline 14 & 74 & 57601 & 0.13 & 76 & 37099 & 0.20 & 77 & 51744 & 0.15 \\
\hline 15 & 77 & 44040 & 0.17 & 63 & 38639 & 0.16 & 79 & 41964 & 0.19 \\
\hline \multicolumn{4}{|c|}{ Nose and chin sealed-TEST1 } & \multicolumn{3}{|c|}{ Nose and chin sealed-TEST2 } & \multicolumn{3}{|c|}{ Nose and chin sealed-TEST3 } \\
\hline \multicolumn{4}{|c|}{ Constant flow rate: $30 \mathrm{~L} / \mathrm{min}$} & \multicolumn{3}{|c|}{ Constant flow rate:30L/min } & \multicolumn{3}{|c|}{ Constant flow rate:30L/min } \\
\hline $\begin{array}{l}\text { Sam } \\
\text { ple }\end{array}$ & $\begin{array}{l}\text { Inside } \\
\text { (pt/cc) }\end{array}$ & $\begin{array}{c}\text { Outside } \\
\text { (pt/cc) }\end{array}$ & $\begin{array}{c}\% \\
\mathrm{P}(\text { Cin } / \mathrm{C} \\
\text { out })\end{array}$ & $\begin{array}{l}\text { Inside } \\
\text { (pt/cc) }\end{array}$ & $\begin{array}{c}\text { Outside } \\
\text { (pt/cc) }\end{array}$ & $\begin{array}{c}\% \\
\mathrm{P}(\text { Cin } / \mathrm{C} \\
\text { out })\end{array}$ & $\begin{array}{l}\text { Inside } \\
\text { (pt/cc) }\end{array}$ & $\begin{array}{c}\text { Outside } \\
\text { (pt/cc) }\end{array}$ & $\begin{array}{c}\% \\
\mathrm{P}(\mathrm{Cin} / \mathrm{C} \\
\text { out }) \\
\end{array}$ \\
\hline 1 & 2010 & 432197 & 0.47 & 1517 & 332151 & 0.46 & 2163 & 436200 & 0.50 \\
\hline
\end{tabular}




\begin{tabular}{|c|c|c|c|c|c|c|c|c|c|}
\hline 2 & 2134 & 298545 & 0.71 & 1758 & 269560 & 0.65 & 2036 & 301444 & 0.68 \\
\hline 3 & 1681 & 294082 & 0.57 & 1443 & 279666 & 0.52 & 1634 & 291200 & 0.56 \\
\hline 4 & 966 & 220027 & 0.44 & 1156 & 184404 & 0.63 & 1030 & 224219 & 0.46 \\
\hline 5 & 712 & 206304 & 0.35 & 823 & 206304 & 0.40 & 669 & 232092 & 0.29 \\
\hline 6 & 595 & 203081 & 0.29 & 513 & 211286 & 0.24 & 643 & 201031 & 0.32 \\
\hline 7 & 499 & 183531 & 0.27 & 390 & 187130 & 0.21 & 523 & 169138 & 0.31 \\
\hline 8 & 376 & 157300 & 0.24 & 399 & 133100 & 0.30 & 412 & 163350 & 0.25 \\
\hline 9 & 317 & 110146 & 0.29 & 292 & 138934 & 0.21 & 315 & 126418 & 0.25 \\
\hline 10 & 269 & 100254 & 0.27 & 222 & 113190 & 0.20 & 250 & 109956 & 0.23 \\
\hline 11 & 222 & 101920 & 0.22 & 201 & 78047 & 0.26 & 212 & 95493 & 0.22 \\
\hline 12 & 167 & 89411 & 0.19 & 191 & 70587 & 0.27 & 188 & 75294 & 0.25 \\
\hline 13 & 151 & 77143 & 0.20 & 153 & 49685 & 0.31 & 142 & 69299 & 0.20 \\
\hline 14 & 125 & 57982 & 0.22 & 125 & 50871 & 0.25 & 122 & 55247 & 0.22 \\
\hline 15 & 104 & 45232 & 0.23 & 85 & 43441 & 0.20 & 104 & 45681 & 0.23 \\
\hline 16 & 59 & 22867 & 0.26 & 53 & 26347 & 0.20 & 59 & 25354 & 0.23 \\
\hline \multicolumn{4}{|c|}{ Nose and chin sealed-TEST1 } & \multicolumn{3}{|c|}{ Nose and chin sealed-TEST2 } & \multicolumn{3}{|c|}{ Nose and chin sealed-TEST3 } \\
\hline \multicolumn{4}{|c|}{ Constant flow rate:50L/min } & \multicolumn{3}{|c|}{ Constant flow rate:50L/min } & \multicolumn{3}{|c|}{ Constant flow rate:50L/min } \\
\hline $\begin{array}{c}\text { Sam } \\
\text { ple }\end{array}$ & $\begin{array}{l}\text { Inside } \\
\text { (pt/cc) }\end{array}$ & $\begin{array}{c}\text { Outside } \\
\text { (pt/cc) }\end{array}$ & $\begin{array}{c}\% \\
\mathrm{P}(\text { Cin } / \mathrm{C} \\
\text { out })\end{array}$ & $\begin{array}{l}\text { Inside } \\
\text { (pt/cc) }\end{array}$ & $\begin{array}{l}\text { Outside } \\
\text { (pt/cc) }\end{array}$ & $\begin{array}{c}\% \\
\mathrm{P}(\text { Cin/C } \\
\text { out })\end{array}$ & $\begin{array}{l}\text { Inside } \\
\text { (pt/cc) }\end{array}$ & $\begin{array}{l}\text { Outside } \\
\text { (pt/cc) }\end{array}$ & $\begin{array}{c}\% \\
\mathrm{P}(\mathrm{Cin} / \mathrm{C} \\
\text { out })\end{array}$ \\
\hline 1 & 2032 & 360045 & 0.56 & 1533 & 312039 & 0.49 & 2186 & 356616 & 0.61 \\
\hline 2 & 1145 & 311616 & 0.37 & 1307 & 334338 & 0.39 & 1283 & 327846 & 0.39 \\
\hline 3 & 1140 & 225933 & 0.50 & 1176 & 214523 & 0.55 & 1212 & 244192 & 0.50 \\
\hline 4 & 1178 & 205224 & 0.57 & 1155 & 181080 & 0.64 & 1132 & 217296 & 0.52 \\
\hline 5 & 1108 & 197916 & 0.56 & 1077 & 186497 & 0.58 & 952 & 186498 & 0.51 \\
\hline 6 & 923 & 160514 & 0.58 & 923 & 215235 & 0.43 & 1070 & 171459 & 0.62 \\
\hline 7 & 520 & 155124 & 0.34 & 434 & 165132 & 0.26 & 561 & 180144 & 0.31 \\
\hline 8 & 526 & 179705 & 0.29 & 420 & 142469 & 0.29 & 503 & 163516 & 0.31 \\
\hline 9 & 391 & 181591 & 0.22 & 346 & 133804 & 0.26 & 381 & 162477 & 0.23 \\
\hline 10 & 277 & 163904 & 0.17 & 323 & 108343 & 0.30 & 306 & 144459 & 0.21 \\
\hline 11 & 281 & 140060 & 0.20 & 270 & 129490 & 0.21 & 276 & 126848 & 0.22 \\
\hline 12 & 226 & 121609 & 0.19 & 215 & 111976 & 0.19 & 231 & 127630 & 0.18 \\
\hline 13 & 222 & 100616 & 0.22 & 203 & 117021 & 0.17 & 198 & 110460 & 0.18 \\
\hline 14 & 153 & 94803 & 0.16 & 145 & 74305 & 0.20 & 146 & 87118 & 0.17 \\
\hline 15 & 292 & 80721 & 0.36 & 233 & 60719 & 0.38 & 288 & 72864 & 0.40 \\
\hline 16 & 237 & 53938 & 0.44 & 217 & 47653 & 0.46 & 238 & 55510 & 0.43 \\
\hline 17 & 121 & 41335 & 0.29 & 105 & 36472 & 0.29 & 130 & 43767 & 0.30 \\
\hline \multicolumn{4}{|c|}{ Nose and chin sealed-TEST1 } & \multicolumn{3}{|c|}{ Nose and chin sealed-TEST2 } & \multicolumn{3}{|c|}{ Nose and chin sealed-TEST3 } \\
\hline \multicolumn{4}{|c|}{ Constant flow rate: $80 \mathrm{~L} / \mathrm{min}$} & \multicolumn{3}{|c|}{ Constant flow rate:80L/min } & \multicolumn{3}{|c|}{ Constant flow rate:80L/min } \\
\hline $\begin{array}{c}\text { Sam } \\
\text { ple }\end{array}$ & $\begin{array}{l}\text { Inside } \\
\text { (pt/cc) }\end{array}$ & $\begin{array}{c}\text { Outside } \\
\text { (pt/cc) }\end{array}$ & $\begin{array}{c}\% \\
\mathrm{P}(\text { Cin } / \mathrm{C} \\
\text { out })\end{array}$ & $\begin{array}{l}\text { Inside } \\
\text { (pt/cc) }\end{array}$ & $\begin{array}{l}\text { Outside } \\
\text { (pt/cc) }\end{array}$ & $\begin{array}{c}\% \\
\mathrm{P}(\text { Cin/C } \\
\text { out })\end{array}$ & $\begin{array}{l}\text { Inside } \\
\text { (pt/cc) }\end{array}$ & $\begin{array}{l}\text { Outside } \\
\text { (pt/cc) }\end{array}$ & $\begin{array}{c}\% \\
\mathrm{P}(\text { Cin/C } \\
\text { out })\end{array}$ \\
\hline 1 & 3299 & 340984 & 0.97 & 2490 & 377649 & 0.66 & 3549 & 381316 & 0.93 \\
\hline
\end{tabular}




\begin{tabular}{|c|c|c|c|c|c|c|c|c|c|}
\hline 2 & 2736 & 303614 & 0.90 & 2255 & 398722 & 0.57 & 2611 & 395064 & 0.66 \\
\hline 3 & 2495 & 321026 & 0.78 & 2142 & 358997 & 0.60 & 2425 & 355546 & 0.68 \\
\hline 4 & 1564 & 278983 & 0.56 & 1871 & 290488 & 0.64 & 1667 & 293365 & 0.57 \\
\hline 5 & 2423 & 221085 & 1.10 & 2797 & 268820 & 1.04 & 2274 & 263796 & 0.86 \\
\hline 6 & 2334 & 192528 & 1.21 & 2014 & 216594 & 0.93 & 2518 & 192528 & 1.31 \\
\hline 7 & 1428 & 196066 & 0.73 & 1118 & 186548 & 0.60 & 1497 & 188453 & 0.79 \\
\hline 8 & 1132 & 177840 & 0.64 & 1203 & 160740 & 0.75 & 1240 & 174420 & 0.71 \\
\hline 9 & 1255 & 144594 & 0.87 & 1158 & 177456 & 0.65 & 1244 & 170885 & 0.73 \\
\hline 10 & 890 & 141376 & 0.63 & 735 & 128639 & 0.57 & 826 & 112083 & 0.74 \\
\hline 11 & 646 & 117500 & 0.55 & 585 & 114143 & 0.51 & 616 & 104072 & 0.59 \\
\hline 12 & 511 & 79090 & 0.65 & 583 & 96769 & 0.60 & 573 & 103284 & 0.55 \\
\hline 13 & 383 & 62082 & 0.62 & 387 & 66221 & 0.58 & 358 & 78639 & 0.46 \\
\hline 14 & 261 & 40059 & 0.65 & 261 & 55872 & 0.47 & 254 & 62198 & 0.41 \\
\hline 15 & 215 & 35378 & 0.61 & 174 & 38421 & 0.45 & 214 & 40324 & 0.53 \\
\hline \multicolumn{4}{|c|}{ Nose and chin sealed-TEST1 } & \multicolumn{3}{|c|}{ Nose and chin sealed-TEST2 } & \multicolumn{3}{|c|}{ Nose and chin sealed-TEST3 } \\
\hline \multicolumn{4}{|c|}{ Cyclic flow rate:15L/min } & \multicolumn{3}{|c|}{ Cyclic flow rate: $15 \mathrm{~L} / \mathrm{min}$} & \multicolumn{3}{|c|}{ Cyclic flow rate:15L/min } \\
\hline $\begin{array}{c}\text { Sam } \\
\text { ple }\end{array}$ & $\begin{array}{l}\text { Inside } \\
\text { (pt/cc) }\end{array}$ & $\begin{array}{c}\text { Outside } \\
\text { (pt/cc) }\end{array}$ & $\begin{array}{c}\% \\
\mathrm{P}(\text { Cin/C } \\
\text { out })\end{array}$ & $\begin{array}{l}\text { Inside } \\
\text { (pt/cc) }\end{array}$ & $\begin{array}{c}\text { Outside } \\
\text { (pt/cc) }\end{array}$ & $\begin{array}{c}\% \\
\mathrm{P}(\mathrm{Cin} / \mathrm{C} \\
\text { out })\end{array}$ & $\begin{array}{l}\text { Inside } \\
\text { (pt/cc) }\end{array}$ & $\begin{array}{c}\text { Outside } \\
\text { (pt/cc) }\end{array}$ & $\begin{array}{c}\% \\
\mathrm{P}(\text { Cin } / \mathrm{C} \\
\text { out })\end{array}$ \\
\hline 1 & 177 & 497765 & 0.04 & 181 & 484020 & 0.04 & 208 & 490893 & 0.04 \\
\hline 2 & 209 & 498646 & 0.04 & 184 & 479281 & 0.04 & 210 & 474441 & 0.04 \\
\hline 3 & 362 & 522540 & 0.07 & 307 & 465536 & 0.07 & 366 & 437035 & 0.08 \\
\hline 4 & 114 & 388242 & 0.03 & 106 & 400250 & 0.03 & 116 & 412258 & 0.03 \\
\hline 5 & 104 & 263053 & 0.04 & 95 & 300632 & 0.03 & 95 & 303524 & 0.03 \\
\hline 6 & 67 & 252703 & 0.03 & 59 & 265865 & 0.02 & 71 & 271130 & 0.03 \\
\hline 7 & 54 & 259096 & 0.02 & 56 & 254016 & 0.02 & 54 & 248936 & 0.02 \\
\hline 8 & 31 & 242719 & 0.01 & 27 & 198986 & 0.01 & 34 & 214293 & 0.02 \\
\hline 9 & 70 & 202213 & 0.03 & 53 & 161055 & 0.03 & 72 & 173582 & 0.04 \\
\hline 10 & 35 & 153603 & 0.02 & 27 & 151762 & 0.02 & 30 & 154985 & 0.02 \\
\hline 11 & 21 & 129694 & 0.02 & 18 & 114451 & 0.02 & 18 & 143388 & 0.01 \\
\hline 12 & 20 & 105565 & 0.02 & 24 & 112881 & 0.02 & 22 & 95114 & 0.02 \\
\hline 13 & 13 & 88408 & 0.01 & 13 & 89310 & 0.01 & 15 & 92920 & 0.02 \\
\hline 14 & 227 & 82903 & 0.27 & 245 & 64978 & 0.38 & 263 & 76182 & 0.35 \\
\hline 15 & 13 & 68374 & 0.02 & 13 & 48406 & 0.03 & 13 & 64744 & 0.02 \\
\hline 16 & 9 & 43834 & 0.02 & 8 & 41281 & 0.02 & 9 & 42558 & 0.02 \\
\hline 17 & 5 & 37905 & 0.01 & 6 & 39763 & 0.02 & 7 & 33818 & 0.02 \\
\hline \multicolumn{4}{|c|}{ Nose and chin sealed-TEST1 } & \multicolumn{3}{|c|}{ Nose and chin sealed-TEST2 } & \multicolumn{3}{|c|}{ Nose and chin sealed-TEST3 } \\
\hline \multicolumn{4}{|c|}{ Cyclic flow rate:30L/min } & \multicolumn{3}{|c|}{ Cyclic flow rate:30L/min } & \multicolumn{3}{|c|}{ Cyclic flow rate: $30 \mathrm{~L} / \mathrm{min}$} \\
\hline $\begin{array}{c}\text { Sam } \\
\text { ple }\end{array}$ & $\begin{array}{l}\text { Inside } \\
\text { (pt/cc) }\end{array}$ & $\begin{array}{c}\text { Outside } \\
\text { (pt/cc) }\end{array}$ & $\begin{array}{c}\% \\
\mathrm{P}(\text { Cin/C } \\
\text { out })\end{array}$ & $\begin{array}{l}\text { Inside } \\
\text { (pt/cc) }\end{array}$ & $\begin{array}{c}\text { Outside } \\
\text { (pt/cc) }\end{array}$ & $\begin{array}{c}\% \\
\mathrm{P}(\mathrm{Cin} / \mathrm{C} \\
\text { out })\end{array}$ & $\begin{array}{l}\text { Inside } \\
\text { (pt/cc) }\end{array}$ & $\begin{array}{c}\text { Outside } \\
\text { (pt/cc) }\end{array}$ & $\begin{array}{c}\% \\
\mathrm{P}(\text { Cin } / \mathrm{C} \\
\text { out }) \\
\end{array}$ \\
\hline 1 & 428 & 500000 & 0.09 & 238 & 500000 & 0.05 & 48 & 500000 & 0.01 \\
\hline 2 & 349 & 431715 & 0.08 & 167 & 502877 & 0.03 & 35 & 488646 & 0.01 \\
\hline
\end{tabular}




\begin{tabular}{|c|c|c|c|c|c|c|c|c|c|}
\hline 3 & 169 & 295366 & 0.06 & 96 & 331872 & 0.03 & 43 & 368378 & 0.01 \\
\hline 4 & 102 & 279175 & 0.04 & 78 & 244278 & 0.03 & 45 & 224338 & 0.02 \\
\hline 5 & 67 & 233381 & 0.03 & 47 & 201417 & 0.02 & 21 & 221998 & 0.01 \\
\hline 6 & 24 & 179115 & 0.01 & 41 & 196264 & 0.02 & 57 & 196265 & 0.03 \\
\hline 7 & 5 & 130275 & 0.00 & 62 & 160928 & 0.04 & 107 & 168592 & 0.06 \\
\hline 8 & 16 & 129066 & 0.01 & 27 & 132937 & 0.02 & 37 & 125195 & 0.03 \\
\hline 9 & 84 & 115021 & 0.07 & 166 & 101550 & 0.16 & 254 & 94297 & 0.27 \\
\hline 10 & 21 & 98055 & 0.02 & 15 & 90654 & 0.02 & 9 & 88805 & 0.01 \\
\hline 11 & 16 & 73985 & 0.02 & 10 & 71055 & 0.01 & 4 & 74719 & 0.01 \\
\hline 12 & 15 & 53572 & 0.03 & 10 & 61486 & 0.02 & 1 & 67575 & 0.00 \\
\hline 13 & 7 & 37065 & 0.02 & 7 & 54134 & 0.01 & 6 & 55111 & 0.01 \\
\hline 14 & 18 & 45575 & 0.04 & 15 & 38084 & 0.04 & 18 & 41893 & 0.04 \\
\hline 15 & 8 & 33090 & 0.02 & 8 & 35282 & 0.02 & 10 & 34393 & 0.03 \\
\hline \multicolumn{4}{|c|}{ Nose and chin sealed-TEST1 } & \multicolumn{3}{|c|}{ Nose and chin sealed-TEST2 } & \multicolumn{3}{|c|}{ Nose and chin sealed-TEST3 } \\
\hline \multicolumn{4}{|c|}{ Cyclic flow rate:50L/min } & \multicolumn{3}{|c|}{ Cyclic flow rate:50L/min } & \multicolumn{3}{|c|}{ Cyclic flow rate:50L/min } \\
\hline $\begin{array}{c}\text { Sam } \\
\text { ple }\end{array}$ & $\begin{array}{l}\text { Inside } \\
\text { (pt/cc) }\end{array}$ & $\begin{array}{c}\text { Outside } \\
\text { (pt/cc) }\end{array}$ & $\begin{array}{c}\% \\
\mathrm{P}(\text { Cin/C } \\
\text { out })\end{array}$ & $\begin{array}{l}\text { Inside } \\
\text { (pt/cc) }\end{array}$ & $\begin{array}{c}\text { Outside } \\
\text { (pt/cc) }\end{array}$ & $\begin{array}{c}\% \\
\mathrm{P}(\text { Cin/C } \\
\text { out })\end{array}$ & $\begin{array}{l}\text { Inside } \\
\text { (pt/cc) }\end{array}$ & $\begin{array}{c}\text { Outside } \\
\text { (pt/cc) }\end{array}$ & $\begin{array}{c}\% \\
\mathrm{P}(\text { Cin/C } \\
\text { out })\end{array}$ \\
\hline 1 & 525 & 500000 & 0.11 & 300 & 500000 & 0.06 & 50 & 500000 & 0.01 \\
\hline 2 & 535 & 482782 & 0.11 & 256 & 463849 & 0.06 & 54 & 473316 & 0.01 \\
\hline 3 & 351 & 400979 & 0.09 & 200 & 498996 & 0.04 & 88 & 436623 & 0.02 \\
\hline 4 & 263 & 416128 & 0.06 & 199 & 437468 & 0.05 & 114 & 377553 & 0.03 \\
\hline 5 & 346 & 384911 & 0.09 & 242 & 351278 & 0.07 & 104 & 384911 & 0.03 \\
\hline 6 & 116 & 272085 & 0.04 & 197 & 210247 & 0.09 & 268 & 259718 & 0.10 \\
\hline 7 & 12 & 212457 & 0.01 & 128 & 219028 & 0.06 & 220 & 225599 & 0.10 \\
\hline 8 & 65 & 203126 & 0.03 & 110 & 247769 & 0.04 & 146 & 218752 & 0.07 \\
\hline 9 & 35 & 181743 & 0.02 & 70 & 200674 & 0.03 & 108 & 185530 & 0.06 \\
\hline 10 & 92 & 153951 & 0.06 & 67 & 152442 & 0.04 & 38 & 146406 & 0.03 \\
\hline 11 & 118 & 135215 & 0.09 & 79 & 107198 & 0.07 & 24 & 123035 & 0.02 \\
\hline 12 & 197 & 110599 & 0.18 & 131 & 74385 & 0.18 & 11 & 108643 & 0.01 \\
\hline 13 & 36 & 76677 & 0.05 & 39 & 83418 & 0.05 & 30 & 69707 & 0.04 \\
\hline 14 & 27 & 62249 & 0.04 & 23 & 59892 & 0.04 & 27 & 63862 & 0.04 \\
\hline 15 & 19 & 49799 & 0.04 & 19 & 47826 & 0.04 & 21 & 50293 & 0.04 \\
\hline 16 & 21 & 40161 & 0.05 & 21 & 38931 & 0.05 & 21 & 43850 & 0.05 \\
\hline \multicolumn{4}{|c|}{ Nose and chin sealed-TEST1 } & \multicolumn{3}{|c|}{ Nose and chin sealed-TEST2 } & \multicolumn{3}{|c|}{ Nose and chin sealed-TEST3 } \\
\hline \multicolumn{4}{|c|}{ Cyclic flow rate:85L/min } & \multicolumn{3}{|c|}{ Cyclic flow rate:85L/min } & \multicolumn{3}{|c|}{ Cyclic flow rate:85L/min } \\
\hline $\begin{array}{c}\text { Sam } \\
\text { ple }\end{array}$ & $\begin{array}{l}\text { Inside } \\
\text { (pt/cc) }\end{array}$ & $\begin{array}{l}\text { Outside } \\
\text { (pt/cc) }\end{array}$ & $\begin{array}{c}\% \\
\mathrm{P}(\mathrm{Cin} / \mathrm{C} \\
\text { out })\end{array}$ & $\begin{array}{l}\text { Inside } \\
\text { (pt/cc) }\end{array}$ & $\begin{array}{l}\text { Outside } \\
\text { (pt/cc) }\end{array}$ & $\begin{array}{c}\% \\
\mathrm{P}(\text { Cin/C } \\
\text { out })\end{array}$ & $\begin{array}{l}\text { Inside } \\
\text { (pt/cc) }\end{array}$ & $\begin{array}{l}\text { Outside } \\
\text { (pt/cc) }\end{array}$ & $\begin{array}{c}\% \\
\mathrm{P}(\text { Cin/C } \\
\text { out })\end{array}$ \\
\hline 1 & 2543 & 472191 & 0.54 & 1455 & 450126 & 0.32 & 241 & 401583 & 0.06 \\
\hline 2 & 1464 & 377054 & 0.39 & 701 & 404264 & 0.17 & 147 & 384829 & 0.04 \\
\hline 3 & 1278 & 346566 & 0.37 & 728 & 346566 & 0.21 & 318 & 346566 & 0.09 \\
\hline 4 & 631 & 229216 & 0.28 & 479 & 229216 & 0.21 & 272 & 229216 & 0.12 \\
\hline
\end{tabular}




\begin{tabular}{|c|c|c|c|c|c|c|c|c|c|}
5 & 457 & 197983 & 0.23 & 320 & 194023 & 0.16 & 138 & 201943 & 0.07 \\
\hline 6 & 131 & 155813 & 0.08 & 223 & 178072 & 0.13 & 303 & 143094 & 0.21 \\
\hline 7 & 16 & 118894 & 0.01 & 177 & 137762 & 0.13 & 304 & 131043 & 0.23 \\
\hline 8 & 78 & 104306 & 0.07 & 132 & 95191 & 0.14 & 176 & 104307 & 0.17 \\
\hline 9 & 75 & 94879 & 0.08 & 148 & 76806 & 0.19 & 227 & 99398 & 0.23 \\
\hline 10 & 161 & 82665 & 0.19 & 118 & 80258 & 0.15 & 66 & 77851 & 0.08 \\
\hline 11 & 142 & 61622 & 0.23 & 96 & 69796 & 0.14 & 29 & 57221 & 0.05 \\
\hline 12 & 127 & 48323 & 0.26 & 84 & 52268 & 0.16 & 7 & 47338 & 0.01 \\
\hline 13 & 54 & 37789 & 0.14 & 60 & 39347 & 0.15 & 44 & 39738 & 0.11 \\
\hline
\end{tabular}

\begin{tabular}{|c|c|c|c|c|c|c|c|c|c|}
\hline \multicolumn{4}{|c|}{ Fully sealed-TEST1 } & \multicolumn{3}{|c|}{ Fully sealed-TEST2 } & \multicolumn{3}{|c|}{ Fully sealedTEST3 } \\
\hline \multicolumn{4}{|c|}{ Constant flow rate $: 15 \mathrm{~L} / \mathrm{min}$} & \multicolumn{3}{|c|}{ Constant flow rate $: 15 \mathrm{~L} / \mathrm{min}$} & \multicolumn{3}{|c|}{ Constant flow rate $: 15 \mathrm{~L} / \mathrm{min}$} \\
\hline $\begin{array}{c}\mathrm{Sa} \\
\mathrm{mpl} \\
\mathrm{e}\end{array}$ & $\begin{array}{l}\text { Inside } \\
\text { (pt/cc) }\end{array}$ & $\begin{array}{l}\text { Outside } \\
\text { (pt/cc) }\end{array}$ & $\begin{array}{c}\% \\
\mathrm{P}(\text { Cin/ } \\
\text { Cout })\end{array}$ & $\begin{array}{l}\text { Inside } \\
\text { (pt/cc) }\end{array}$ & $\begin{array}{c}\text { Outside } \\
\text { (pt/cc) }\end{array}$ & $\begin{array}{c}\% \\
\mathrm{P}(\text { Cin/ } \\
\text { Cout })\end{array}$ & $\begin{array}{l}\text { Inside } \\
\text { (pt/cc) }\end{array}$ & $\begin{array}{c}\text { Outside } \\
\text { (pt/cc) }\end{array}$ & $\begin{array}{c}\% \\
\mathrm{P}(\text { Cin } / \\
\text { Cout })\end{array}$ \\
\hline 1 & 34 & 500000 & 0.007 & 9 & 500000 & 0.002 & 14 & 500000 & 0.003 \\
\hline 2 & 24 & 477130 & 0.005 & 3 & 486769 & 0.001 & 11 & 481950 & 0.002 \\
\hline 3 & 3 & 463354 & 0.001 & 1 & 477395 & 0.000 & 2 & 463355 & 0.000 \\
\hline 4 & 17 & 394795 & 0.004 & 9 & 394795 & 0.002 & 12 & 406759 & 0.003 \\
\hline 5 & 25 & 375554 & 0.007 & 8 & 357323 & 0.002 & 17 & 360970 & 0.005 \\
\hline 6 & 0 & 302345 & 0.000 & 1 & 348623 & 0.000 & 2 & 274580 & 0.001 \\
\hline 7 & 1 & 236621 & 0.000 & 21 & 241691 & 0.009 & 13 & 246038 & 0.005 \\
\hline 8 & 4 & 207125 & 0.002 & 8 & 214385 & 0.004 & 9 & 219083 & 0.004 \\
\hline 9 & 0 & 188174 & 0.000 & 1 & 188174 & 0.001 & 2 & 182585 & 0.001 \\
\hline 10 & 1 & 171995 & 0.001 & 0 & 151851 & 0.000 & 1 & 141006 & 0.001 \\
\hline 11 & 4 & 121416 & 0.003 & 1 & 148101 & 0.001 & 3 & 130757 & 0.002 \\
\hline 12 & 10 & 115116 & 0.009 & 1 & 126293 & 0.001 & 6 & 93882 & 0.006 \\
\hline 13 & 3 & 95716 & 0.003 & 2 & 96655 & 0.002 & 3 & 89148 & 0.003 \\
\hline 14 & 2 & 85793 & 0.002 & 1 & 81784 & 0.001 & 3 & 72965 & 0.004 \\
\hline 15 & 7 & 70488 & 0.010 & 9 & 71172 & 0.013 & 8 & 63645 & 0.013 \\
\hline 16 & 5 & 52506 & 0.010 & 4 & 58852 & 0.007 & 6 & 61738 & 0.010 \\
\hline 17 & 4 & 47778 & 0.008 & 3 & 54894 & 0.005 & 5 & 49812 & 0.010 \\
\hline 18 & 3 & 45461 & 0.007 & 2 & 48521 & 0.004 & 4 & 37157 & 0.011 \\
\hline \multicolumn{4}{|c|}{ Fully sealed-TEST1 } & \multicolumn{3}{|c|}{ Fully sealed-TEST2 } & \multicolumn{3}{|c|}{ Fully sealedTEST3 } \\
\hline \multicolumn{4}{|c|}{ Constant flow rate $: 30 \mathrm{~L} / \mathrm{min}$} & \multicolumn{3}{|c|}{ Constant flow rate $: 30 \mathrm{~L} / \mathrm{min}$} & \multicolumn{3}{|c|}{ Constant flow rate $: 30 \mathrm{~L} / \mathrm{min}$} \\
\hline $\begin{array}{c}\mathrm{Sa} \\
\mathrm{mpl} \\
\mathrm{e}\end{array}$ & $\begin{array}{l}\text { Inside } \\
\text { (pt/cc) }\end{array}$ & $\begin{array}{c}\text { Outside } \\
\text { (pt/cc) }\end{array}$ & $\begin{array}{c}\% \\
\text { P(Cin/ } \\
\text { Cout })\end{array}$ & $\begin{array}{l}\text { Inside } \\
\text { (pt/cc) }\end{array}$ & $\begin{array}{c}\text { Outside } \\
\text { (pt/cc) }\end{array}$ & $\begin{array}{c}\% \\
\text { P(Cin/ } \\
\text { Cout })\end{array}$ & $\begin{array}{l}\text { Inside } \\
\text { (pt/cc) }\end{array}$ & $\begin{array}{l}\text { Outside } \\
\text { (pt/cc) }\end{array}$ & $\begin{array}{c}\% \\
\mathrm{P}(\mathrm{Cin} / \\
\text { Cout })\end{array}$ \\
\hline 1 & 23 & 500000 & 0.005 & 13 & 500000 & 0.003 & 3 & 500000 & 0.001 \\
\hline 2 & 20 & 494866 & 0.004 & 10 & 484968 & 0.002 & 3 & 504764 & 0.001 \\
\hline 3 & 11 & 476236 & 0.002 & 6 & 523859 & 0.001 & 3 & 428613 & 0.001 \\
\hline 4 & 8 & 404101 & 0.002 & 6 & 406550 & 0.001 & 4 & 413898 & 0.001 \\
\hline
\end{tabular}




\begin{tabular}{|c|c|c|c|c|c|c|c|c|c|}
\hline 5 & 4 & 269790 & 0.001 & 2 & 267065 & 0.001 & 3 & 280692 & 0.001 \\
\hline 6 & 1 & 237055 & 0.000 & 1 & 217899 & 0.000 & 4 & 263395 & 0.002 \\
\hline 7 & 0 & 220059 & 0.000 & 1 & 207240 & 0.000 & 5 & 213650 & 0.002 \\
\hline 8 & 0 & 177510 & 0.000 & 0 & 182944 & 0.000 & 2 & 182945 & 0.001 \\
\hline 9 & 0 & 147209 & 0.000 & 0 & 150214 & 0.000 & 2 & 153219 & 0.001 \\
\hline 10 & 1 & 122705 & 0.001 & 1 & 131560 & 0.001 & 1 & 125235 & 0.001 \\
\hline 11 & 1 & 107110 & 0.001 & 1 & 107110 & 0.001 & 1 & 103929 & 0.001 \\
\hline 12 & 1 & 99583 & 0.001 & 1 & 68183 & 0.001 & 1 & 101378 & 0.001 \\
\hline 13 & 0 & 68827 & 0.000 & 0 & 82366 & 0.000 & 0 & 75711 & 0.000 \\
\hline 14 & 1 & 66114 & 0.002 & 0 & 62006 & 0.000 & 2 & 64446 & 0.003 \\
\hline 15 & 0 & 55360 & 0.000 & 0 & 52646 & 0.000 & 2 & 54818 & 0.004 \\
\hline 16 & 0 & 49295 & 0.000 & 0 & 43767 & 0.000 & 0 & 45150 & 0.000 \\
\hline \multicolumn{4}{|c|}{ Fully sealed-TEST1 } & \multicolumn{3}{|c|}{ Fully sealed-TEST2 } & \multicolumn{3}{|c|}{ Fully sealedTEST3 } \\
\hline \multicolumn{4}{|c|}{ Constant flow rate $: 50 \mathrm{~L} / \mathrm{min}$} & \multicolumn{3}{|c|}{ Constant flow rate $: 50 \mathrm{~L} / \mathrm{min}$} & \multicolumn{3}{|c|}{ Constant flow rate $: 50 \mathrm{~L} / \mathrm{min}$} \\
\hline $\begin{array}{c}\mathrm{Sa} \\
\mathrm{mpl} \\
\mathrm{e}\end{array}$ & $\begin{array}{l}\text { Inside } \\
\text { (pt/cc) }\end{array}$ & $\begin{array}{l}\text { Outside } \\
\text { (pt/cc) }\end{array}$ & $\begin{array}{c}\% \\
\text { P(Cin/ } \\
\text { Cout) }\end{array}$ & $\begin{array}{l}\text { Inside } \\
\text { (pt/cc) }\end{array}$ & $\begin{array}{l}\text { Outside } \\
\text { (pt/cc) }\end{array}$ & $\begin{array}{c}\% \\
\mathrm{P}(\text { Cin/ } \\
\text { Cout })\end{array}$ & $\begin{array}{l}\text { Inside } \\
\text { (pt/cc) }\end{array}$ & $\begin{array}{l}\text { Outside } \\
\text { (pt/cc) }\end{array}$ & $\begin{array}{c}\% \\
\mathrm{P}(\text { Cin/ } \\
\text { Cout })\end{array}$ \\
\hline 1 & 9 & 500000 & 0.002 & 5 & 500000 & 0.001 & 1 & 500000 & 0.000 \\
\hline 2 & 7 & 482483 & 0.001 & 3 & 477706 & 0.001 & 1 & 472929 & 0.000 \\
\hline 3 & 3 & 456964 & 0.001 & 1 & 443655 & 0.000 & 1 & 430346 & 0.000 \\
\hline 4 & 2 & 405408 & 0.000 & 2 & 397612 & 0.001 & 2 & 366428 & 0.001 \\
\hline 5 & 3 & 250105 & 0.001 & 1 & 220680 & 0.000 & 2 & 264818 & 0.001 \\
\hline 6 & 0 & 239884 & 0.000 & 0 & 231659 & 0.000 & 2 & 213840 & 0.001 \\
\hline 7 & 0 & 202949 & 0.000 & 0 & 193553 & 0.000 & 3 & 167246 & 0.002 \\
\hline 8 & 0 & 162301 & 0.000 & 0 & 163790 & 0.000 & 2 & 120609 & 0.002 \\
\hline 9 & 0 & 130425 & 0.000 & 0 & 117500 & 0.000 & 0 & 104575 & 0.000 \\
\hline 10 & 1 & 107123 & 0.001 & 1 & 96602 & 0.001 & 1 & 83213 & 0.001 \\
\hline 11 & 36 & 94163 & 0.038 & 24 & 82091 & 0.029 & 8 & 65191 & 0.012 \\
\hline 12 & 0 & 56253 & 0.000 & 0 & 62573 & 0.000 & 0 & 70791 & 0.000 \\
\hline 13 & 6 & 56521 & 0.011 & 6 & 49456 & 0.012 & 5 & 45420 & 0.011 \\
\hline 14 & 4 & 44564 & 0.009 & 3 & 45367 & 0.007 & 5 & 30513 & 0.016 \\
\hline \multicolumn{4}{|c|}{ Fully sealed-TEST1 } & \multicolumn{3}{|c|}{ Fully sealed-TEST2 } & \multicolumn{3}{|c|}{ Fully sealedTEST3 } \\
\hline \multicolumn{4}{|c|}{ Constant flow rate $: 80 \mathrm{~L} / \mathrm{min}$} & \multicolumn{3}{|c|}{ Constant flow rate $: 80 \mathrm{~L} / \mathrm{min}$} & \multicolumn{3}{|c|}{ Constant flow rate $: 80 \mathrm{~L} / \mathrm{min}$} \\
\hline $\begin{array}{c}\text { Sa } \\
\mathrm{mpl} \\
\mathrm{e}\end{array}$ & $\begin{array}{l}\text { Inside } \\
\text { (pt/cc) }\end{array}$ & $\begin{array}{c}\text { Outside } \\
\text { (pt/cc) }\end{array}$ & $\begin{array}{c}\% \\
\mathrm{P}(\text { Cin/ } \\
\text { Cout })\end{array}$ & $\begin{array}{l}\text { Inside } \\
\text { (pt/cc) }\end{array}$ & $\begin{array}{c}\text { Outside } \\
\text { (pt/cc) }\end{array}$ & $\begin{array}{c}\% \\
\mathrm{P}(\text { Cin/ } \\
\text { Cout })\end{array}$ & $\begin{array}{l}\text { Inside } \\
\text { (pt/cc) }\end{array}$ & $\begin{array}{c}\text { Outside } \\
\text { (pt/cc) }\end{array}$ & $\begin{array}{c}\% \\
\mathrm{P}(\text { Cin/ } \\
\text { Cout })\end{array}$ \\
\hline 1 & 37 & 500000 & 0.007 & 21 & 500000 & 0.004 & 4 & 500000 & 0.001 \\
\hline 2 & 20 & 477946 & 0.004 & 10 & 497454 & 0.002 & 3 & 487700 & 0.001 \\
\hline 3 & 28 & 388967 & 0.007 & 15 & 385227 & 0.004 & 7 & 347827 & 0.002 \\
\hline 4 & 4 & 332171 & 0.001 & 3 & 335460 & 0.001 & 2 & 319017 & 0.001 \\
\hline 5 & 4 & 245964 & 0.002 & 2 & 255516 & 0.001 & 3 & 214920 & 0.001 \\
\hline 6 & 1 & 214430 & 0.000 & 1 & 210306 & 0.000 & 4 & 193813 & 0.002 \\
\hline 7 & 0 & 156723 & 0.000 & 2 & 138285 & 0.001 & 10 & 165942 & 0.006 \\
\hline
\end{tabular}




\begin{tabular}{|c|c|c|c|c|c|c|c|c|c|}
\hline 8 & 1 & 123706 & 0.001 & 2 & 119465 & 0.002 & 5 & 110276 & 0.005 \\
\hline 9 & 1 & 90145 & 0.001 & 1 & 85972 & 0.001 & 4 & 74287 & 0.005 \\
\hline 10 & 5 & 66293 & 0.008 & 4 & 66902 & 0.006 & 3 & 49265 & 0.006 \\
\hline 11 & 1 & 53014 & 0.002 & 1 & 47761 & 0.002 & 1 & 42508 & 0.002 \\
\hline 12 & 3 & 39335 & 0.008 & 2 & 35472 & 0.006 & 1 & 30556 & 0.003 \\
\hline \multicolumn{4}{|c|}{ Fully sealed-TEST1 } & \multicolumn{3}{|c|}{ Fully sealed-TEST2 } & & \multicolumn{2}{|l|}{$\begin{array}{c}\text { Fully } \\
\text { sealedTEST3 }\end{array}$} \\
\hline \multicolumn{4}{|c|}{ Cyclic flow rate: $15 \mathrm{~L} / \mathrm{min}$} & \multicolumn{3}{|c|}{ Cyclic flow rate: $15 \mathrm{~L} / \mathrm{min}$} & \multicolumn{3}{|c|}{ Cyclic flow rate: $15 \mathrm{~L} / \mathrm{min}$} \\
\hline $\begin{array}{l}\text { Sa } \\
\mathrm{mpl} \\
\mathrm{e}\end{array}$ & $\begin{array}{l}\text { Inside } \\
\text { (pt/cc) }\end{array}$ & $\begin{array}{l}\text { Outside } \\
\text { (pt/cc) }\end{array}$ & $\begin{array}{c}\% \\
\mathrm{P}(\text { Cin/ } \\
\text { Cout })\end{array}$ & $\begin{array}{l}\text { Inside } \\
\text { (pt/cc) }\end{array}$ & $\begin{array}{l}\text { Outside } \\
\text { (pt/cc) }\end{array}$ & $\begin{array}{c}\% \\
\mathrm{P}(\text { Cin/ } \\
\text { Cout })\end{array}$ & $\begin{array}{l}\text { Inside } \\
\text { (pt/cc) }\end{array}$ & $\begin{array}{l}\text { Outside } \\
\text { (pt/cc) }\end{array}$ & $\begin{array}{c}\% \\
\mathrm{P}(\text { Cin/ } \\
\text { Cout })\end{array}$ \\
\hline 1 & 88 & 500000 & 0.018 & 50 & 500000 & 0.010 & 9 & 500000 & 0.002 \\
\hline 2 & 70 & 485694 & 0.014 & 33 & 495506 & 0.007 & 8 & 490600 & 0.002 \\
\hline 3 & 28 & 465553 & 0.006 & 15 & 412848 & 0.004 & 7 & 439201 & 0.002 \\
\hline 4 & 8 & 375656 & 0.002 & 6 & 379303 & 0.002 & 4 & 339185 & 0.001 \\
\hline 5 & 31 & 265584 & 0.012 & 14 & 193655 & 0.007 & 17 & 370713 & 0.005 \\
\hline 6 & 33 & 253405 & 0.013 & 44 & 189462 & 0.023 & 90 & 267616 & 0.034 \\
\hline 7 & 7 & 219755 & 0.003 & 44 & 134544 & 0.033 & 171 & 318421 & 0.054 \\
\hline 8 & 14 & 218864 & 0.006 & 20 & 178333 & 0.011 & 35 & 210759 & 0.017 \\
\hline 9 & 21 & 213811 & 0.010 & 42 & 192430 & 0.022 & 65 & 176881 & 0.037 \\
\hline 10 & 57 & 171662 & 0.033 & 42 & 188098 & 0.022 & 24 & 188099 & 0.013 \\
\hline 11 & 97 & 151840 & 0.064 & 65 & 180206 & 0.036 & 20 & 168527 & 0.012 \\
\hline 12 & 56 & 134271 & 0.042 & 37 & 157328 & 0.024 & 3 & 115284 & 0.003 \\
\hline 13 & 12 & 128983 & 0.009 & 12 & 125227 & 0.010 & 12 & 121471 & 0.010 \\
\hline 14 & 10 & 125560 & 0.008 & 11 & 119692 & 0.009 & 11 & 106785 & 0.010 \\
\hline 15 & 9 & 93784 & 0.010 & 9 & 99585 & 0.009 & 9 & 96685 & 0.009 \\
\hline 16 & 18 & 90777 & 0.020 & 18 & 96451 & 0.019 & 18 & 96452 & 0.019 \\
\hline 17 & 21 & 95532 & 0.022 & 22 & 96433 & 0.023 & 19 & 78409 & 0.024 \\
\hline 18 & 22 & 86724 & 0.025 & 22 & 85056 & 0.026 & 21 & 78386 & 0.027 \\
\hline 19 & 54 & 76104 & 0.071 & 47 & 67150 & 0.070 & 58 & 80581 & 0.072 \\
\hline 20 & 13 & 70949 & 0.018 & 13 & 68516 & 0.019 & 13 & 63247 & 0.021 \\
\hline 21 & 16 & 60519 & 0.026 & 15 & 57718 & 0.026 & 14 & 49873 & 0.028 \\
\hline 22 & 6 & 64366 & 0.009 & 6 & 64957 & 0.009 & 5 & 47833 & 0.010 \\
\hline 23 & 23 & 58171 & 0.040 & 21 & 52407 & 0.040 & 19 & 46643 & 0.041 \\
\hline 24 & 33 & 49654 & 0.066 & 30 & 44777 & 0.067 & 27 & 38571 & 0.070 \\
\hline 25 & 47 & 48168 & 0.098 & 41 & 41993 & 0.098 & 34 & 33348 & 0.102 \\
\hline 26 & 27 & 35223 & 0.077 & 30 & 39181 & 0.077 & 35 & 44327 & 0.079 \\
\hline 27 & 26 & 40458 & 0.064 & 23 & 35401 & 0.065 & 22 & 32512 & 0.068 \\
\hline \multicolumn{4}{|c|}{ Fully sealed-TEST1 } & \multicolumn{3}{|c|}{ Fully sealed-TEST2 } & \multicolumn{3}{|c|}{ Fully sealedTEST3 } \\
\hline \multicolumn{4}{|c|}{ Cyclic flow rate: $30 \mathrm{~L} / \mathrm{min}$} & $\begin{array}{c}\text { Cyclic flow } \\
\text { rate: } 30 \mathrm{~L} / \mathrm{m} \\
\mathrm{n}\end{array}$ & & & \multicolumn{3}{|c|}{$\begin{array}{c}\text { Cyclic flow } \\
\text { rate:30L/mi } \\
n\end{array}$} \\
\hline
\end{tabular}




\begin{tabular}{|c|c|c|c|c|c|c|c|c|c|}
\hline $\begin{array}{c}\text { Sa } \\
\mathrm{mpl} \\
\mathrm{e}\end{array}$ & $\begin{array}{l}\text { Inside } \\
\text { (pt/cc) }\end{array}$ & $\begin{array}{c}\text { Outside } \\
\text { (pt/cc) }\end{array}$ & $\begin{array}{c}\% \\
\mathrm{P}(\text { Cin/ } \\
\text { Cout })\end{array}$ & $\begin{array}{l}\text { Inside } \\
\text { (pt/cc) }\end{array}$ & $\begin{array}{c}\text { Outside } \\
\text { (pt/cc) }\end{array}$ & $\begin{array}{c}\% \\
\mathrm{P}(\text { Cin/ } \\
\text { Cout })\end{array}$ & $\begin{array}{l}\text { Inside } \\
\text { (pt/cc) }\end{array}$ & $\begin{array}{c}\text { Outside } \\
\text { (pt/cc) }\end{array}$ & $\begin{array}{c}\% \\
\mathrm{P}(\text { Cin/ } \\
\text { Cout })\end{array}$ \\
\hline 1 & 93 & 500000 & 0.019 & 96 & 500000 & 0.019 & 90 & 500000 & 0.018 \\
\hline 2 & 86 & 485660 & 0.018 & 87 & 490566 & 0.018 & 87 & 495472 & 0.018 \\
\hline 3 & 78 & 461452 & 0.017 & 69 & 400506 & 0.017 & 74 & 444040 & 0.017 \\
\hline 4 & 72 & 408986 & 0.018 & 72 & 408986 & 0.018 & 66 & 373250 & 0.018 \\
\hline 5 & 59 & 292028 & 0.020 & 43 & 319405 & 0.013 & 84 & 301155 & 0.028 \\
\hline 6 & 53 & 210126 & 0.025 & 40 & 202271 & 0.020 & 57 & 176742 & 0.032 \\
\hline 7 & 48 & 179568 & 0.027 & 29 & 179568 & 0.016 & 70 & 190563 & 0.037 \\
\hline 8 & 61 & 163531 & 0.037 & 50 & 148389 & 0.034 & 60 & 142333 & 0.042 \\
\hline 9 & 49 & 167473 & 0.029 & 44 & 147681 & 0.030 & 41 & 141592 & 0.029 \\
\hline 10 & 46 & 129128 & 0.036 & 50 & 138744 & 0.036 & 51 & 144240 & 0.035 \\
\hline 11 & 38 & 121672 & 0.031 & 45 & 148413 & 0.030 & 43 & 131032 & 0.033 \\
\hline 12 & 40 & 126617 & 0.032 & 47 & 116385 & 0.040 & 35 & 140686 & 0.025 \\
\hline 13 & 41 & 124725 & 0.033 & 40 & 124725 & 0.032 & 39 & 113828 & 0.034 \\
\hline 14 & 40 & 107864 & 0.037 & 38 & 102824 & 0.037 & 35 & 91736 & 0.038 \\
\hline 15 & 35 & 84660 & 0.041 & 38 & 93388 & 0.041 & 37 & 83788 & 0.044 \\
\hline 16 & 30 & 77425 & 0.039 & 32 & 80652 & 0.040 & 33 & 83879 & 0.039 \\
\hline 17 & 24 & 70801 & 0.034 & 24 & 60782 & 0.039 & 21 & 68798 & 0.031 \\
\hline 18 & 26 & 61953 & 0.042 & 25 & 55996 & 0.045 & 24 & 60763 & 0.039 \\
\hline 19 & 28 & 56122 & 0.050 & 25 & 49519 & 0.050 & 31 & 59424 & 0.052 \\
\hline 20 & 21 & 53607 & 0.039 & 20 & 51769 & 0.039 & 19 & 47788 & 0.040 \\
\hline 21 & 20 & 53342 & 0.037 & 19 & 50872 & 0.037 & 17 & 43958 & 0.039 \\
\hline 22 & 19 & 45770 & 0.042 & 19 & 46190 & 0.041 & 15 & 34013 & 0.044 \\
\hline 23 & 14 & 39490 & 0.035 & 13 & 35577 & 0.037 & 12 & 31664 & 0.038 \\
\hline 24 & 10 & 38986 & 0.026 & 9 & 35157 & 0.026 & 8 & 30284 & 0.026 \\
\hline \multicolumn{4}{|c|}{ Fully sealed-TEST1 } & \multicolumn{3}{|c|}{ Fully sealed-TEST2 } & \multicolumn{3}{|c|}{ Fully sealedTEST3 } \\
\hline \multicolumn{4}{|c|}{ Cyclic flow rate:50L/min } & \multicolumn{3}{|c|}{ Cyclic flow rate:50L/min } & \multicolumn{3}{|c|}{ Cyclic flow rate:50L/min } \\
\hline $\begin{array}{c}\mathrm{Sa} \\
\mathrm{mpl} \\
\mathrm{e}\end{array}$ & $\begin{array}{l}\text { Inside } \\
\text { (pt/cc) }\end{array}$ & $\begin{array}{c}\text { Outside } \\
\text { (pt/cc) }\end{array}$ & $\begin{array}{c}\% \\
\mathrm{P}(\text { Cin/ } \\
\text { Cout })\end{array}$ & $\begin{array}{l}\text { Inside } \\
\text { (pt/cc) }\end{array}$ & $\begin{array}{c}\text { Outside } \\
\text { (pt/cc) }\end{array}$ & $\begin{array}{c}\% \\
\mathrm{P}(\text { Cin/ } \\
\text { Cout })\end{array}$ & $\begin{array}{l}\text { Inside } \\
\text { (pt/cc) }\end{array}$ & $\begin{array}{c}\text { Outside } \\
\text { (pt/cc) }\end{array}$ & $\begin{array}{c}\% \\
\mathrm{P}(\mathrm{Cin} / \\
\text { Cout })\end{array}$ \\
\hline 1 & 136 & 497666 & 0.027 & 122 & 497666 & 0.025 & 132 & 497666 & 0.027 \\
\hline 2 & 99 & 497183 & 0.020 & 88 & 502154 & 0.018 & 92 & 492212 & 0.019 \\
\hline 3 & 95 & 429792 & 0.022 & 82 & 476509 & 0.017 & 92 & 495196 & 0.019 \\
\hline 4 & 84 & 397768 & 0.021 & 84 & 363012 & 0.023 & 78 & 397769 & 0.020 \\
\hline 5 & 78 & 377041 & 0.021 & 86 & 355496 & 0.024 & 82 & 344724 & 0.024 \\
\hline 6 & 90 & 331178 & 0.027 & 87 & 289379 & 0.030 & 77 & 344041 & 0.022 \\
\hline 7 & 80 & 272709 & 0.029 & 80 & 289406 & 0.028 & 86 & 272710 & 0.032 \\
\hline 8 & 85 & 233061 & 0.036 & 77 & 223548 & 0.034 & 75 & 256844 & 0.029 \\
\hline 9 & 67 & 208086 & 0.032 & 59 & 199505 & 0.030 & 57 & 235975 & 0.024 \\
\hline 10 & 58 & 215887 & 0.027 & 62 & 224437 & 0.028 & 66 & 200925 & 0.033 \\
\hline 11 & 53 & 210533 & 0.025 & 65 & 185876 & 0.035 & 58 & 172600 & 0.034 \\
\hline
\end{tabular}




\begin{tabular}{|c|c|c|c|c|c|c|c|c|c|}
\hline 12 & 43 & 154517 & 0.028 & 40 & 186778 & 0.021 & 49 & 168102 & 0.029 \\
\hline 13 & 41 & 112976 & 0.036 & 41 & 103104 & 0.040 & 38 & 112977 & 0.034 \\
\hline 14 & 37 & 104554 & 0.035 & 35 & 93278 & 0.038 & 32 & 109680 & 0.029 \\
\hline 15 & 29 & 108075 & 0.027 & 32 & 96964 & 0.033 & 29 & 97975 & 0.030 \\
\hline 16 & 24 & 96411 & 0.025 & 26 & 100267 & 0.026 & 28 & 92555 & 0.030 \\
\hline 17 & 20 & 83090 & 0.024 & 17 & 94047 & 0.018 & 20 & 96787 & 0.021 \\
\hline 18 & 32 & 73784 & 0.043 & 29 & 80063 & 0.036 & 32 & 81634 & 0.039 \\
\hline 19 & 21 & 68276 & 0.031 & 18 & 81932 & 0.022 & 23 & 77381 & 0.030 \\
\hline 20 & 26 & 68612 & 0.038 & 25 & 63334 & 0.039 & 24 & 71049 & 0.034 \\
\hline 21 & 20 & 58312 & 0.034 & 19 & 50386 & 0.038 & 17 & 61144 & 0.028 \\
\hline 22 & 19 & 46183 & 0.041 & 19 & 34007 & 0.056 & 15 & 45764 & 0.033 \\
\hline 23 & 17 & 38177 & 0.045 & 16 & 33977 & 0.047 & 15 & 42377 & 0.035 \\
\hline 24 & 15 & 42128 & 0.036 & 14 & 36288 & 0.039 & 13 & 46717 & 0.028 \\
\hline \multicolumn{4}{|c|}{ Fully sealed-TEST1 } & \multicolumn{3}{|c|}{ Fully sealed-TEST2 } & \multicolumn{3}{|c|}{ Fully sealedTEST3 } \\
\hline \multicolumn{4}{|c|}{ Cyclic flow rate: $85 \mathrm{~L} / \mathrm{min}$} & \multicolumn{3}{|c|}{ Cyclic flow rate: $85 \mathrm{~L} / \mathrm{min}$} & \multicolumn{3}{|c|}{ Cyclic flow rate: $85 \mathrm{~L} / \mathrm{min}$} \\
\hline $\begin{array}{c}\mathrm{Sa} \\
\mathrm{mpl} \\
\mathrm{e}\end{array}$ & $\begin{array}{l}\text { Inside } \\
\text { (pt/cc) }\end{array}$ & $\begin{array}{l}\text { Outside } \\
\text { (pt/cc) }\end{array}$ & $\begin{array}{c}\% \\
\mathrm{P}(\text { Cin/ } \\
\text { Cout })\end{array}$ & $\begin{array}{l}\text { Inside } \\
\text { (pt/cc) }\end{array}$ & $\begin{array}{l}\text { Outside } \\
\text { (pt/cc) }\end{array}$ & $\begin{array}{c}\% \\
\mathrm{P}(\text { Cin/ } \\
\text { Cout })\end{array}$ & $\begin{array}{l}\text { Inside } \\
\text { (pt/cc) }\end{array}$ & $\begin{array}{l}\text { Outside } \\
\text { (pt/cc) }\end{array}$ & $\begin{array}{c}\% \\
\mathrm{P}(\mathrm{Cin} / \\
\text { Cout })\end{array}$ \\
\hline 1 & 94 & 480338 & 0.020 & 84 & 470827 & 0.018 & 91 & 475583 & 0.019 \\
\hline 2 & 100 & 461835 & 0.022 & 89 & 457170 & 0.019 & 93 & 480495 & 0.019 \\
\hline 3 & 84 & 462229 & 0.018 & 73 & 435039 & 0.017 & 82 & 462230 & 0.018 \\
\hline 4 & 70 & 437544 & 0.016 & 70 & 433296 & 0.016 & 64 & 403560 & 0.016 \\
\hline 5 & 57 & 399183 & 0.014 & 63 & 428290 & 0.015 & 60 & 419975 & 0.014 \\
\hline 6 & 47 & 433561 & 0.011 & 45 & 417045 & 0.011 & 40 & 388142 & 0.010 \\
\hline 7 & 39 & 395549 & 0.010 & 39 & 383800 & 0.010 & 42 & 395550 & 0.011 \\
\hline 8 & 42 & 357481 & 0.012 & 38 & 330502 & 0.011 & 37 & 323758 & 0.011 \\
\hline 9 & 36 & 331763 & 0.011 & 32 & 312437 & 0.010 & 31 & 322100 & 0.010 \\
\hline 10 & 31 & 205597 & 0.015 & 33 & 220908 & 0.015 & 35 & 229658 & 0.015 \\
\hline 11 & 23 & 199957 & 0.012 & 28 & 235114 & 0.012 & 26 & 224128 & 0.012 \\
\hline 12 & 230 & 181870 & 0.126 & 212 & 167174 & 0.127 & 257 & 202079 & 0.127 \\
\hline 13 & 20 & 185657 & 0.011 & 20 & 185657 & 0.011 & 19 & 169435 & 0.011 \\
\hline 14 & 22 & 155131 & 0.014 & 21 & 147882 & 0.014 & 20 & 131935 & 0.015 \\
\hline 15 & 21 & 104204 & 0.020 & 23 & 114946 & 0.020 & 22 & 103130 & 0.021 \\
\hline 16 & 16 & 76649 & 0.021 & 17 & 79843 & 0.021 & 18 & 83037 & 0.022 \\
\hline 17 & 18 & 65513 & 0.027 & 15 & 56242 & 0.027 & 18 & 63660 & 0.028 \\
\hline 18 & 18 & 59634 & 0.030 & 16 & 53900 & 0.030 & 19 & 58488 & 0.032 \\
\hline 19 & 15 & 53517 & 0.028 & 13 & 47221 & 0.028 & 17 & 56666 & 0.030 \\
\hline 20 & 13 & 53098 & 0.024 & 13 & 51277 & 0.025 & 13 & 47334 & 0.027 \\
\hline
\end{tabular}

